\title{
Method for reducing excess heat supply experienced in typical Chinese district heating systems by achieving hydraulic balance and improving indoor air temperature control at the building level
}

Zhang, Lipeng; Gudmundsson, Oddgeir; Thorsen, Jan Eric; Li, Hongwei; Li, Xiaopeng; Svendsen, Svend

Published in:

Energy

Link to article, DOI:

10.1016/j.energy.2016.03.138

Publication date:

2016

Document Version

Peer reviewed version

Link back to DTU Orbit

Citation (APA):

Zhang, L., Gudmundsson, O., Thorsen, J. E., Li, H., Li, X., \& Svendsen, S. (2016). Method for reducing excess heat supply experienced in typical Chinese district heating systems by achieving hydraulic balance and improving indoor air temperature control at the building level. Energy, 107, 431-442.

https://doi.org/10.1016/j.energy.2016.03.138

\section{General rights}

Copyright and moral rights for the publications made accessible in the public portal are retained by the authors and/or other copyright owners and it is a condition of accessing publications that users recognise and abide by the legal requirements associated with these rights.

- Users may download and print one copy of any publication from the public portal for the purpose of private study or research.

- You may not further distribute the material or use it for any profit-making activity or commercial gain

- You may freely distribute the URL identifying the publication in the public portal 
Method for reducing excess heat supply experienced in typical Chinese district heating systems by achieving hydraulic balance and improving indoor air temperature control at the building level

\title{
Lipeng Zhang ${ }^{\mathrm{a}, \mathrm{b} 1}$, Oddgeir Gudmundsson ${ }^{\mathrm{b}}$, Jan Eric Thorsen ${ }^{\mathrm{b}}$, Hongwei $\mathrm{Li}^{\mathrm{a}}$, Xiaopeng $\mathrm{Li}^{\mathrm{c}}$, Svend Svendsen ${ }^{\mathrm{a}}$,
}

${ }^{a}$ Civil Engineering Department, Technical University of Denmark, Anker Engelunds Vej Building 118, 2800 Kgs. Lyngby, Denmark

${ }^{b}$ Danfoss A/S, Heating segment, Application Center. Nordborgvej 81,Nordborg,6430 Denmark

${ }^{c}$ Danfoss Automatic Controls Management (Shanghai) Co., Ltd. F2O, Building A, No.2A Gong Ti Bei Lu, Chaoyang District, Beijing,100027, China

\begin{abstract}
A common problem with Chinese district heating systems is that they supply more heat than the actual heat demand. The reason for this excess heat supply is the general failure to use control devices to adjust the indoor temperature and flow in the building heating systems in accordance with the actual heat demand. This results in $15-30 \%$ of the total supplied heat being lost. This paper proposes an integrated approach that aims to reduce the excess heat loss by introducing preset thermostatic radiator valves combined with automatic balancing valves. Those devices establish hydraulic balance, and stabilize indoor temperatures. The feasibility and the energy consumption reduction of this approach were verified by means of simulation and a field test. By moving the system from centrally planned heat delivery to demand-driven heat delivery, excess heat loss can be significantly reduced. Results show that once the hydraulic balance is achieved and indoor temperatures are controlled with this integrated approach, $17 \%$ heat savings and $42.8 \%$ pump electricity savings can be achieved. The energy savings will also have a positive environmental effect with seasonal reductions of $11 \mathrm{~kg} \mathrm{CO}_{2}, 0.1 \mathrm{~g} \mathrm{SO}_{2}$, and $0.03 \mathrm{~g} \mathrm{NO}_{\mathrm{x}}$ per heating square meter for a typical case in Harbin.
\end{abstract}

Key words: district heating, excess heat supply reduction, pre-set thermostatic radiator valves, automatic balancing valves, hydraulic balance, differential pressure control

\section{Introduction}

Research has shown that district heating (DH) is playing an important role in the societal goal of realizing an effective and sustainable energy system [1][2][3][4][5]. Along with the rapid growth of urbanization and industrialization, China has become one of the largest DH markets in the world in the last two decades. Statistics indicate that the total DH production in 2013 amounted to 3,197,032 TJ [6]. This number is still increasing steadily due to the process of rapid urbanization, expansion of the building area, enhancement of building services, and increases in comfort level. On the other hand, according to a World Bank report in 2012, the consumption of heating energy in China per square metre of floor area is almost twice that in developed countries at the same

${ }^{*}$ Corresponding author. Tel.: +86 1085352485 .

E-mail address: lipz@byg.dtu.dk; zhanglipeng@danfoss.com (L.Zhang) 
latitude. Nevertheless, the resulting room thermal comfort in China is still unsatisfactory [7]. Furthermore, the 2011 Annual Report on China Building Energy Efficiency [8] reports that 15\% $30 \%$ of the total heat is being lost due to excess heat supply in northern China's DH systems. These high losses are primarily due to a failure to use control devices to control the heating supply in accordance with the actual heating demand. There is an urgent need to apply appropriate technical approaches to improve the Chinese DH efficiency to create the maximum synergy between energy supply security and air pollution abatement, which are the two most important challenges for China today [9].

Chinese DH systems are very different from European DH systems. Structurally, a typical Chinese DH system is like this: pressurized hot water as the heat medium is produced in the central heat source and distributed to a few area substations (the primary side of the DH system). Each area substation then serves a number of multi-storey or high-rise buildings (the secondary side of the DH system). The heat entrance is the interface connecting the large-area substation to the building heating system (see Figure 1). It is usually equipped with shut-off valves, and measurement devices like thermometers, pressure gauges and heat meters, etc. [10].

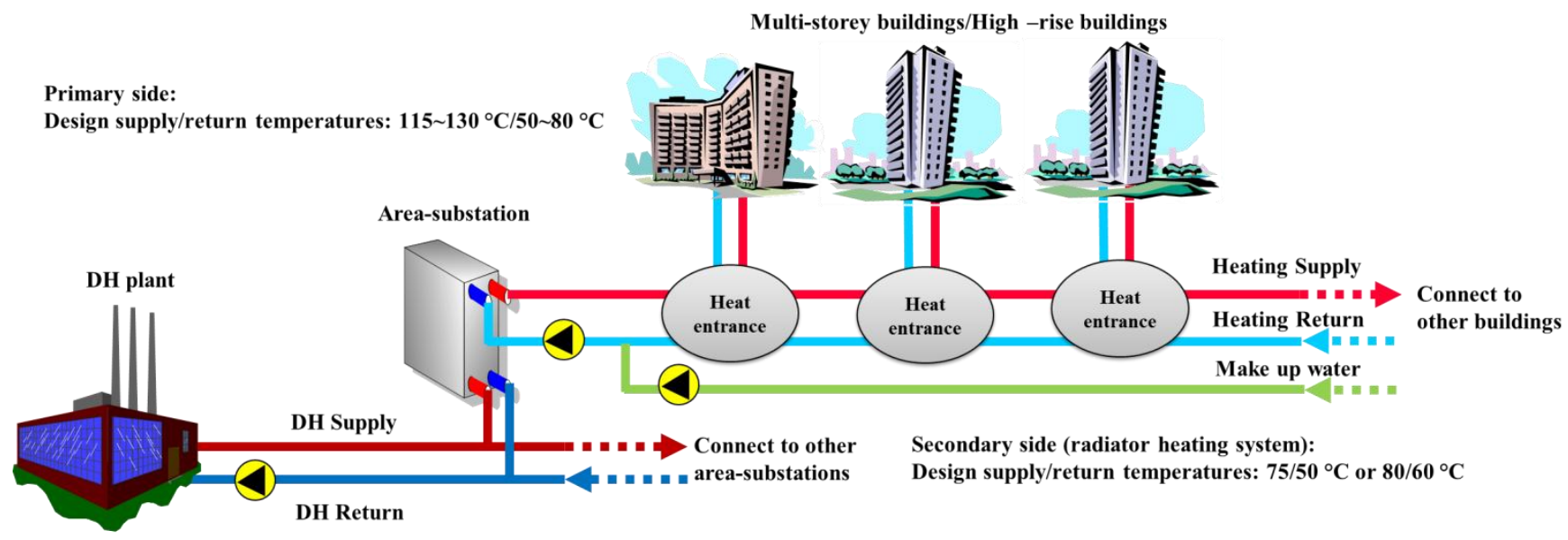

Figure 1. Typical district heating system used in China

In terms of temperatures, China's national design code [11] states that the DH primary side network should be designed with supply temperatures of $115^{\circ} \mathrm{C} \sim 130^{\circ} \mathrm{C}$ and return temperatures of $50 \sim 80^{\circ} \mathrm{C}$. The design code does not state any minimum design temperature difference. For the radiator space heating $(\mathrm{SH})$ systems, the design supply/return temperatures are recommended as $75 / 50{ }^{\circ} \mathrm{C}$ or $80 / 60{ }^{\circ} \mathrm{C}$ [12]. In practice, $\mathrm{DH}$ systems generally operate with different temperatures based on various conditions for the particular DH systems.

In terms of heat sources, the main heating production facilities are the coal-fired boilers and Combined Heat and Power (CHP) plants. For instance, in 2013, 48\% of DH came from coal-fired boilers, $42 \%$ CHP plants, $8 \%$ gas-fired boilers, and the remaining $2 \%$ came from scattered and individual heating facilities. Furthermore, coal is the dominant DH fuel in China [13]. Statistics show that $91 \%$ of the total energy supply to DH systems came from coal in 2008 [14].

Moreover, unlike European DH systems where DH supply covers both SH and Domestic Hot Water (DHW), approx. 90\% of Chinese DH systems supply SH without DHW [15]. 
These important characteristics make it possible to understand why excess heat supply occurs in typical Chinese DH systems.

From the perspective of temperature control, room temperature regulation and control functions are not available in approx. 84\% of the total heating area in China [16]. According to the national code [12], $18{ }^{\circ} \mathrm{C}$ is the standard room temperature for heat consumers in northern China to evaluate whether the heating effect is up to the required standard. The DH utility usually increases the secondary circulation flow rate until at least critical consumers attain this standard, which often result in the systems operating with large volume flow and small temperature differences between the supply and return streams. Moreover, once the heat demands of the critical consumers are fulfilled, the secondary flow rate often remains constant, with the varying SH demand being met by adjusting the secondary side supply temperature. Furthermore, there is a lack of automatic weather compensation control in some cases at substation level. Manual adjustment may be applied. e.g., tentatively adjusting the opening of the control valve installed on the primary side of the DH system, which is eventually reflected in changes in secondary supply temperatures. Such manual operation is based on the experience of past years and the level of complaints from critical users of the system, and the purpose of adjusting the supply temperature is to correlate the heat supply with the outdoor air temperature. Consequently, when the supply temperature to the SH system is higher than required, consumers will open windows to get comfortable indoor temperatures. In some cases, TRVs are installed in the DH systems. However, they are typically left fully open. Due to the fixed heating charges based on heating area, not actual heat consumption, there is no incentive for consumers to consciously reduce the TRV settings in an oversupply situation. They would generally regulate the indoor temperature by opening the windows. All these factors mean that consumers are either unable to control their room heating supply or lack motivation for energy conservation, which means excess heat supplied is wasted.

From the perspective of flow control in the secondary DH network and at building level, there are no automatic flow control devices, which results in an uneven flow distribution in the secondaryside DH network. Buildings close to the substation receive more flow than needed and become overheated, whereas buildings located in distal parts of the network receive less flow than required and are unable to fulfil their heating requirements. There is a lack of hydraulic balance inside the buildings. Specifically, the secondary side of Chinese DH systems generally operates on a constant flow and pressure basis. The pressure head at the pump is controlled to maintain constant differential pressure at area-substations. In addition, the constant flow operation principle makes the pumps run at constant speed. Although there are some variable-speed pumps, they are mainly used to correct the deviation between the design and operation conditions in terms of the pressure head and flow rate. Large volume flow leads therefore to higher than necessary electricity consumption in circulation pumps, small temperature differences, high return temperatures, and network heat losses.

In summary, it can be said that the general failure to use temperature and flow control devices in Chinese DH systems is the direct cause of excess heat loss, which subsequently compromises the efficiency of Chinese DH systems. 
Studies have investigated how to improve the efficiency of Chinese DH systems by focusing on various DH elements [17][18][19][20][21][22][23][24][25][26][27][28]. With the heat reform in 2006 in China, 16\% of the total heating area in China was given a heat metering retrofit [16] to install Thermostatic Radiator Valves (TRVs) by the year 2012. A lot of research has been carried out on TRV application in Chinese heating systems [29][30][31][32][33][34][35]. For instance, $\mathrm{Xu}$ et al. [33] investigated how hydraulic performance and energy consumption in individual apartments and the whole system were influenced when TRVs were regulated and when windows were opened. Xu et al. [34] developed a dynamic model and simulated the thermal and hydraulic behaviour of SH systems employing TRV-controlled radiators in multi-family buildings. Liu et al. [35] analysed the heat metering methods currently available in China and proposed a new method for metering the heat consumption of individual households in accordance with the accumulated on-time as well as the floor space of each household.

However, when we examine the previous research mentioned above, there is still a lack of expertise or knowledge on optimizing building heating systems by correctly using the flow control and temperature control functions of TRVs, including their inherent relationship with energy consumption reduction and indoor temperature improvement.

In this paper, an integrated approach has been developed and applied to a real project in northern China. The technical feasibility is shown and the advantages are quantified. This could give enhanced understanding and guidance for renovating future Chinese DH systems.

\section{Methodology}

The research objects in this study were the building heating systems. The central hypothesis of this study rests on the idea that the flow and temperature control functions of TRVs combined with differential pressure management can reduce the excess heat supply experienced in current Chinese DH systems while reducing their energy consumption. This idea is reflected in the research question: how large is the potential for reducing excess heat consumption by using temperature and flow control in the heating system of buildings?

Chinese energy statistics usually use the unit "metric tons of standard coal equivalent" (tce) because the primary energy source for DH systems in China is coal, and one tce equals 29.31 GJ. Burning 1 ton Chinese standard coal (29.3GJ/tce) releases about $2600 \mathrm{~kg} \mathrm{CO}_{2}, 24 \mathrm{~kg} \mathrm{SO}_{2}$, and $7 \mathrm{~kg} \mathrm{NO}_{\mathrm{x}}$ [36]. If the proposed controls were applied in Chinese DH systems, energy consumption reduction would be achieved which would have considerable positive environmental impacts due to the heavy reliance on coal as DH fuel in China.

To show the inter-relationship between excess heat supply, overheating of rooms, and the hydraulic imbalance, we analysed the data from two real cases, Case-Beijing-A and Case-Harbin, and proposed a technical approach to solve the excess heat supply.

We performed a two-step analysis. Firstly, a field test was made to demonstrate the technical feasibility of the approach. The field test was carried out in a high-rise building in Beijing (CaseBeijing-B), which is structurally similar to Case-Beijing-A. Secondly, simulations for scenarios analysis were carried out using building simulation software: IDA Indoor Climate and Energy [37]. The prototype of the building model is one of the multi-storey residential buildings in Case- 
Harbin. The linear fit-to-metered secondary supply temperatures from Case-Harbin were used as input for the model to run the simulation. The flowchart shown in Figure 2 illustrates the integrated design approach in this paper.

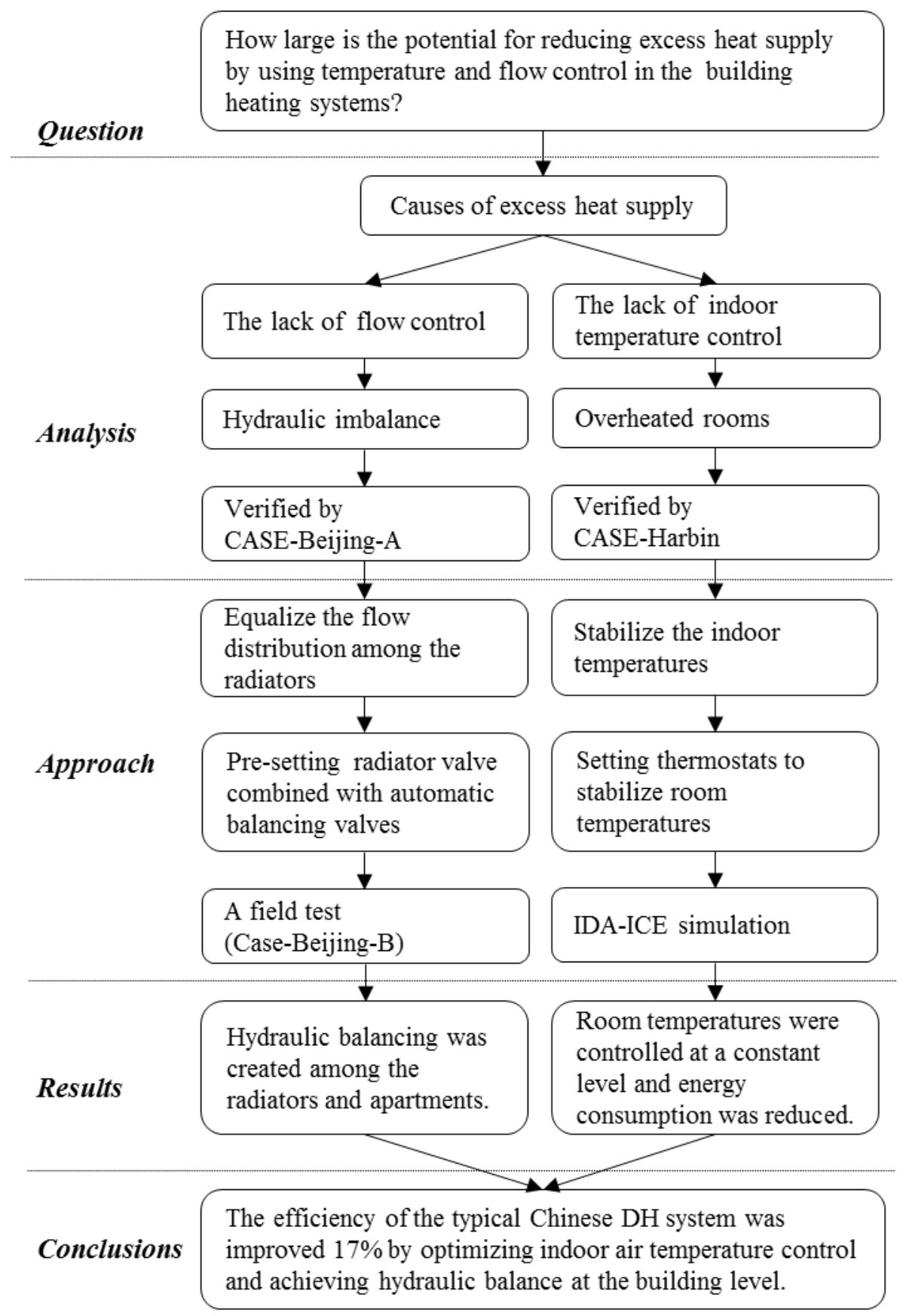

Figure 2. Flowchart of methods used in the study 


\subsection{Current situation from real cases}

First, the data from two real cases were analysed to present the excess heat supply experienced in Chinese DH systems.

Case-Beijing-A refers to a $\mathrm{DH}$ system in Beijing. The data from a residential high-rise building heating system were used to indicate the link between hydraulic imbalance and excess heat supply. Case-Harbin refers to a DH system in Harbin. The data from the secondary side of one substation were obtained to verify the causal link between overheated rooms and excess heat loss.

\subsubsection{Case-Beijing-A: Hydraulic imbalance and excess heat loss}

To understand the hydraulic situation in high-rise building heating systems, the volume flow data from a 21-floor residential building in Case-Beijing-A were obtained. The DH water from an area substation flows into the building via the heat entrance, where manual balancing valves are used as the only flow control device to manage the flow distribution among the connected buildings. DH utilities usually use a flow index to determine the required volume flow of each building in accordance with the heating area served. The manual balancing valves are set at the beginning of the heating season according to the estimated flow and differential pressure across the controlled loop. After initial commissioning is finalized, the setting values of these manual balancing valves are kept for the whole heating season, except for minor adjustments.

In this high-rise building, each floor had the same heating area. The instantaneous volume flows per square metre along one of vertical supply risers were measured by using a hand-held ultrasonic flow meter. The volume flows along the risers were measured on the 1st, 6th, and 13th floors and on the 14th, 18th, and 20th floors, as shown in Figure 3. The results show how the volume flow per square metre decreased along the supply water direction.
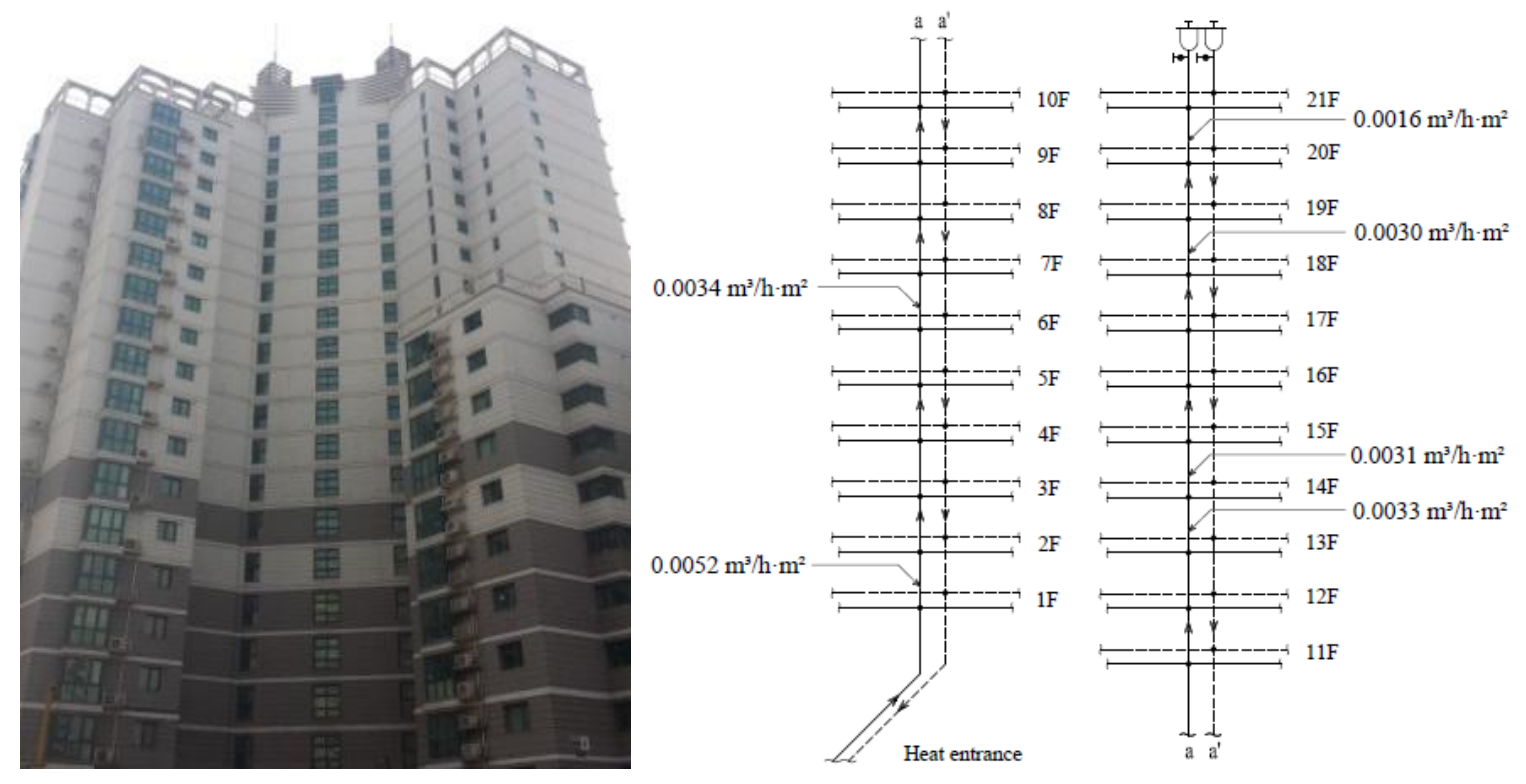

Figure 3. Flow measurement of a high-rise building in Beijing 
The top floor should have a higher heat demand because of its larger exterior surface, but in reality, it was supplied with the least volume flow. Even though the volume flow per square metre on the top floor was less than $1 / 3^{\text {rd }}$ that of the first floor, few thermal comfort complaints were reported. As a complaint over the phone is the most common way for Chinese heat consumers to inform the DH utilities about the heat effects, it can therefore be assumed that the floors below the top floor were receiving a higher volume flow than they actually required. These floors would be overheated. This case illustrates the excess heat supply caused by hydraulic imbalance in a building heating network where no flow control devices were used.

\subsubsection{Case-Harbin: Overheated rooms and excess heat supply}

To understand the relation between the overheated rooms and excess heat supply, the data from one of the area-substations of Case-Harbin were obtained. The data included the supply and return temperatures of the area substation and the corresponding outdoor temperatures. The data covered the entire heating period from 20 October 2013 to 20 April 2014. This area substation supplied heat to 14 multi-storey buildings with a heating area of $124,150 \mathrm{~m}^{2}$.

The control situation in this case was that no indoor temperature control devices were applied in the SH system. In addition, automatic weather compensation control was not available at the substation, and the system was operating under constant flow rate. The secondary supply temperature was manually adjusted based on the average daily outdoor temperatures from metrological data and past years' experience in relation to the level of complaints from heat consumers.

The data presented in Figure 4 reveals the relationship between the supply temperature and outdoor air temperature being scattered when the manual control was applied. For the same outdoor temperature, the temperature differences between supply and return varied a lot.

According to the records of the DH utility, very few complaints were received from the occupants during the heating period, and this implies that most consumers had room temperatures above $18{ }^{\circ} \mathrm{C}$. This also implies that, for a given outdoor temperature, the lowest temperature difference has met the heat demand. All other temperature differences higher than the lowest values imply the buildings were overheated, since the constant flow principle was being applied in the secondary DH network. All heat supplied in excess of the lowest value can be regarded as heat loss due to excess heat supply. Due to the lack of the individual control for the indoor terminal heat units, overheated rooms inevitably leads to window opening, which also explains why several different temperature differences exist under the same outdoor temperature. 


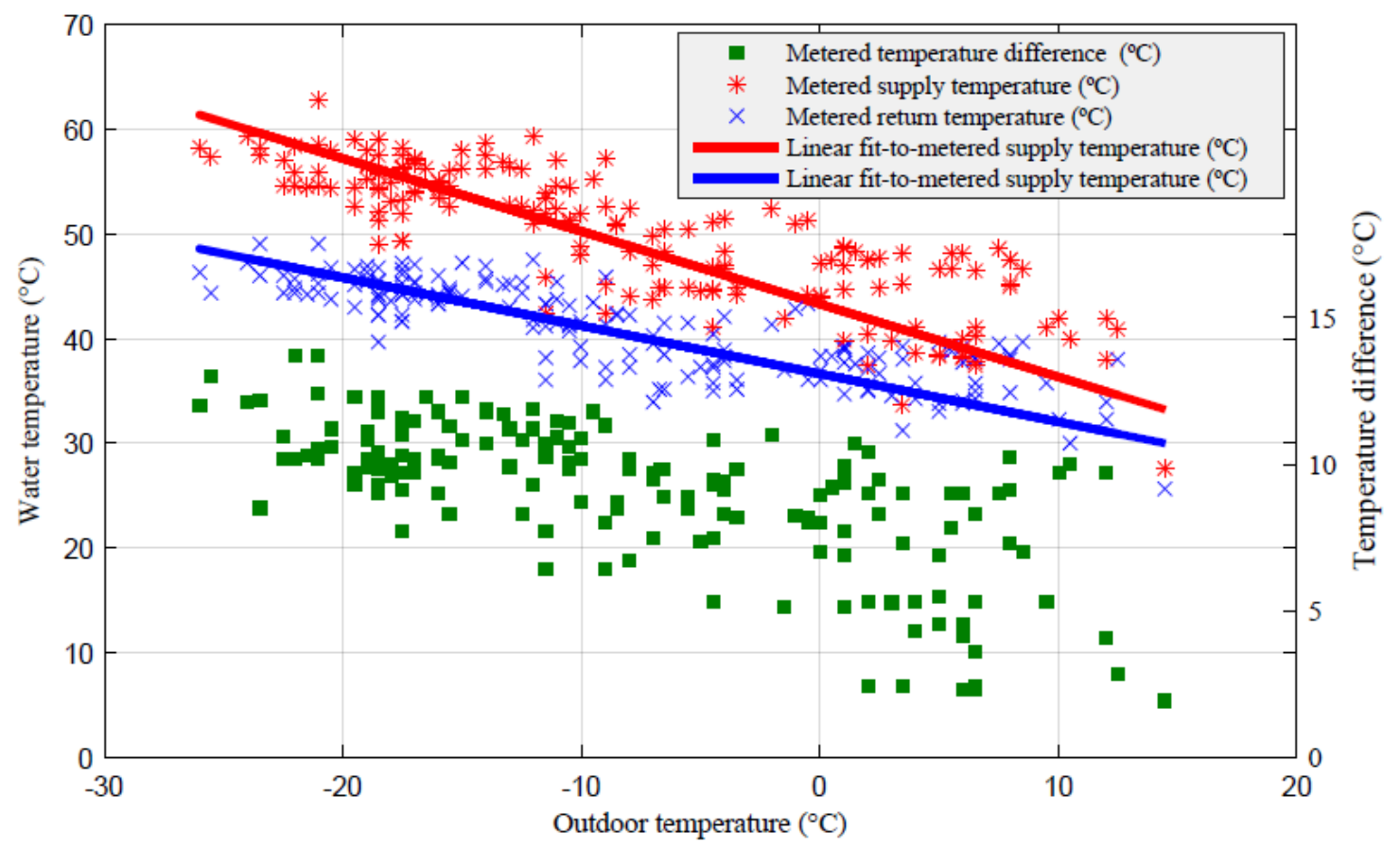

Figure 4. Supply and return temperatures of a substation in Case-Harbin during the 2013-2014 heating period

\subsection{The proposed approach}

To reduce the excess heat supply, an integrated approach was introduced that included the control devices: TRVs with pre-setting function, and automatic balancing valves. The $\mathrm{SH}$ systems considered in this paper are two-pipe radiator systems, and all the apartments have their own heating loops. A schematic configuration of the apartment heating loop applied in the integrated approach is illustrated in Figure 5. The number of the radiator might be different based on the particular apartment.

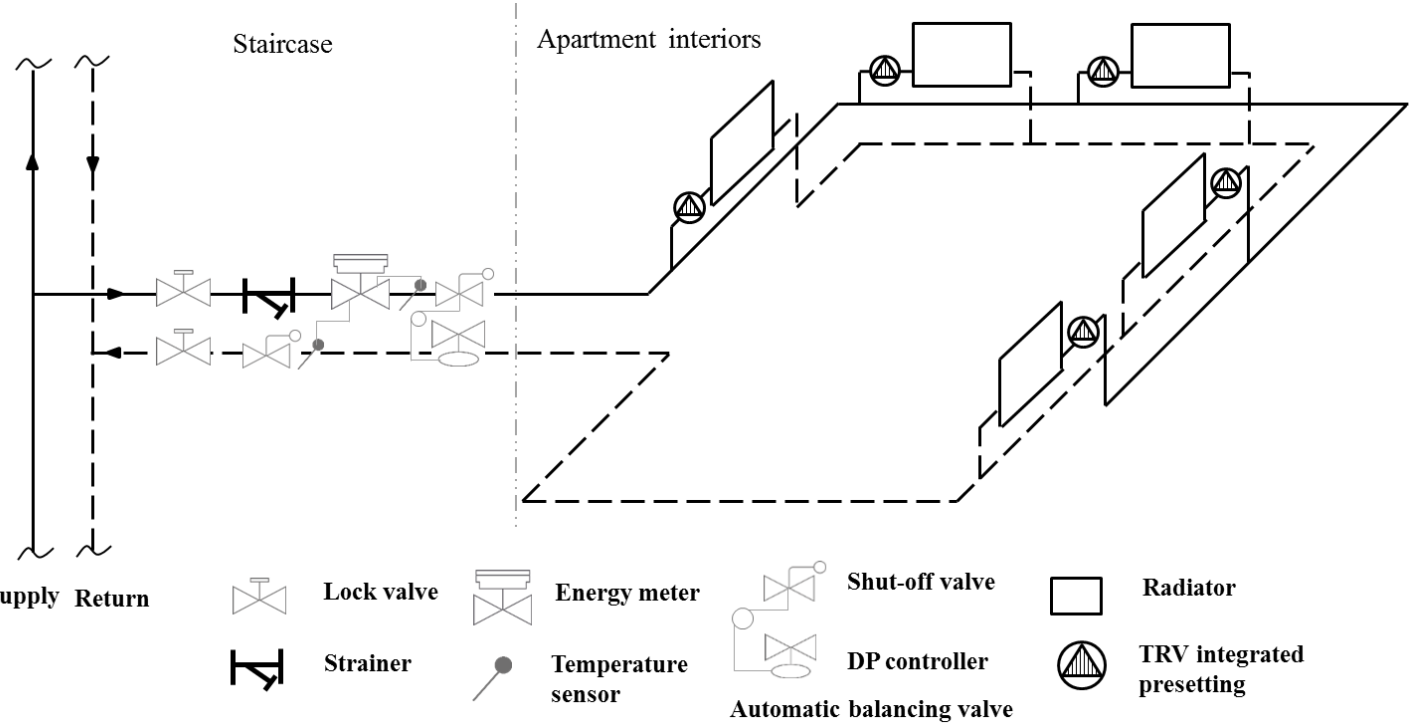


Figure 5. Schematic configuration of the apartment heating loop

TRVs consist of a thermostat and a radiator valve. The radiator valve is a flow control device. The degree of valve opening determines how much water flows through the valve into the radiator. This is controlled by the thermostat, which reacts to changes in room temperature.

The radiator valve with integrated pre-setting is a flow-limiting device that is fitted into the valve body to pre-set the maximum water flow through the radiator. The pre-setting values correspond to the scales marked on the radiator valve and the range is from 1 to 7 and $\mathrm{N}$, which represent gradually increasing maximum flow limits [38], see Figure 6. The pre-setting values can be set in accordance with the requested design flow through the radiator and the pressure drop across the valve. To ensure the optimal regulation of the radiator valve and quiet operation, it is important to achieve the desired differential pressure across the valve. According to EN 215 [25], a differential pressure setting of $10 \mathrm{kPa}$ is commonly used for radiator applications. Automatic balancing valves were therefore also applied in this approach to ensure the optimum operation of the radiator valve.
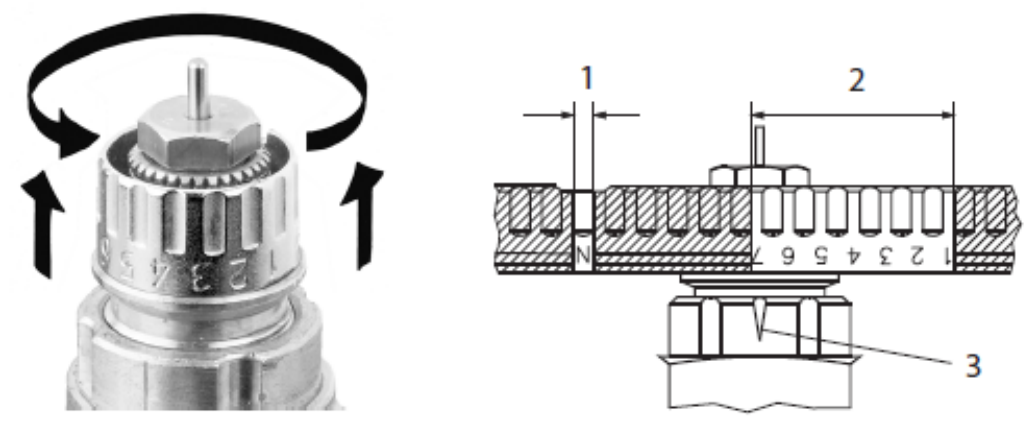

1. Factory setting

2. Presetting range

3. Reference mark

Figure 6. Pre-setting scales of radiator valve [38]

Automatic balancing valves consist of a self-acting differential pressure (DP) controller and an associated partner valve. The valves are linked to each other by a capillary tube. In this case, the partner valve was designed to shut off the pipe flow, and the DP controller was designed to maintain a constant differential pressure across a loop. The constant differential pressure across the controlled loop protects downstream control valves from excess pressures and offsets the effects of pressure variations caused by the movement of the control valves in other branches. By installing automatic balancing valves, all the controlled loops become pressure-independent zones [39]. This eliminates any problems caused by high or excess system pressures, including noise from the valves and poor control of room temperature.

Pre-setting radiator valves combined with automatic balancing valves equalize the flow distribution among the radiators and establish hydraulic balance at peak load. The thermostat function stabilizes the indoor temperature with regard to weather variations and free heat gains. By moving the system from centrally planned heat delivery to demand-driven heat delivery, the excess heat supply can be reduced, which can consequently reduce the energy consumption of Chinese DH systems and lead to positive environmental impacts. 


\subsection{Verification of the proposed approach}

The technical feasibility of this approach and the improvements in indoor temperature control were verified by means of a field test (Case-Beijing-B) and building simulation software IDA Indoor Climate and Energy (IDA-ICE) 4.6.2 [37].

\subsubsection{Field test in Beijing for flow control}

The basic idea of the field test was to examine the flow control effect of using the radiator valve in combination with automatic balancing valves. With these two devices, the hydraulic balance is established and the flow distributed to each radiator can be controlled around the design value.

\section{3.1.1 Configuration of the field test}

This field test (Case-Beijing-B) was carried out in a new 18-storey high-rise residential building in Beijing, which is structurally similar to Case-Beijing-A. The building's appearance is shown in

Figure 7 (left). The heating installation configuration for each apartment is illustrated in

Figure 7 (right). Details of the devices used are listed in Table 1. It should be mentioned that the radiator valves and the automatic balancing valves either need to be pre-set, or set during commissioning when the heating season starts, so that the radiators can achieve the required design flow under peak load. The set values of these two devices would be kept throughout the heating season or slightly adjusted if necessary. This field test focuses on the flow control effect of using these two devices, so the thermostats were removed for the experiment. In addition, automatic weather compensation control was applied at substation level for Case-Beijing-B to control the supply temperature, and variable speed pumps were available on the secondary-side of this DH system.

Table 1. Details of the relevant devices installed in tested apartment

\begin{tabular}{llll}
\hline \multicolumn{2}{c}{ Device name } & \multicolumn{1}{c}{ Type } & Dimension \\
\hline Radiator valve & & RA-N[21] & DN15 (mm) \\
Auto balancing & \multicolumn{1}{c}{ DP controller } & ASV-PV[23] & DN20 (mm) \\
valves & \multicolumn{1}{c}{ Partner valve } & ASV-M[23] & DN20 (mm) \\
Ultrasonic energy meter & SONOMETER 1100[24] & DN20 (mm) \\
\hline
\end{tabular}

The radiator valves were mounted on the radiator pipework. All the other devices mentioned above were installed in the staircase/hall (see

Figure 7 (right)), which was the location of the heat entry point for the apartment heating systems. 


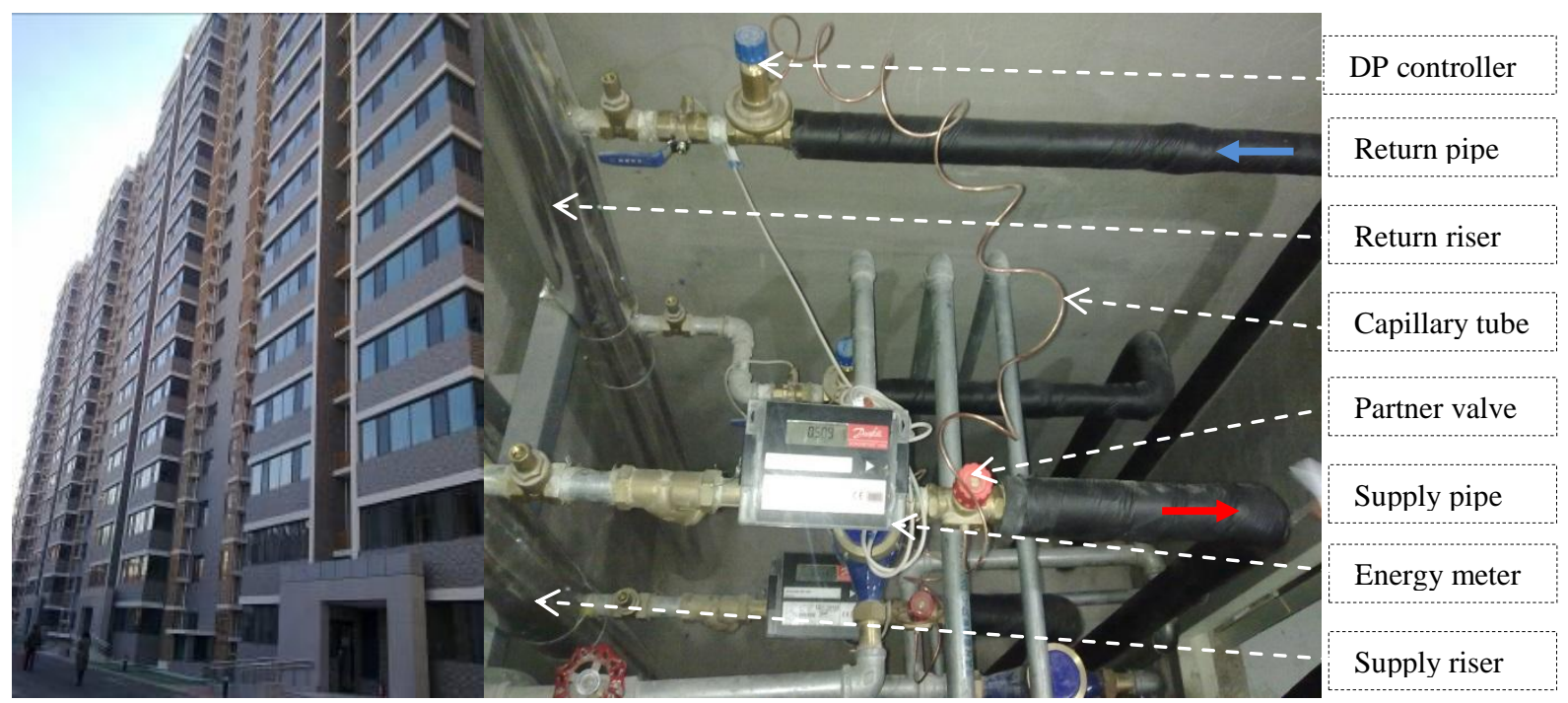

Figure 7. Real test case for the flow control approach

\section{3.1.2 Implementation of the field test}

The field test consisted of two parts: Test I considered three apartments as test objects and focused on the pressure control function of the DP controller. Test II considered one apartment as the test object and focused on the flow limitation function of the radiator valve pre-setting function. Throughout the test, the other apartments' heating systems in this building were operating normally.

In Test I, three apartments with identical heating areas were chosen as the test objects. They were located on the right-hand side of the $2^{\text {nd }}$ floor (201), the left-hand side of the $2^{\text {nd }}$ floor (202), and the right-hand side of the $17^{\text {th }}$ floor (1701). During the test, all the radiator valves were pre-set to $\mathrm{N}$, i.e. the radiator valves were fully open.

The apartment loop flows were measured for apartments 201, 202, and 1701 when the DP controllers were in turn set at $5,10,15,20$, and $25 \mathrm{kPa}$. The ultrasonic energy meter of each apartment was used to measure the flow and investigate: 1) the hydraulic situation along the vertical pipe; 2) the flow changes in one apartment loop resulting from changing the set points of the DP controller at random or completely shutting off the loop flow of the other two apartments.

In Test II, one of the apartments was chosen as the test object. The aim of Test II was to investigate how the pre-setting function of the radiator valve controls the flow rate of the heating system. This apartment had five rooms with their own radiators and was located on the $2^{\text {nd }}$ floor. Basic data about the apartment are given in Table 2. Each radiator was equipped with a radiator valve with pre-setting function. Test II was performed with the DP controller set at $10 \mathrm{kPa}$ in accordance with EN 215 [25]. The design parameters of this heating system (supply/return/indoor temperature) were $75 / 60 / 18{ }^{\circ} \mathrm{C}$. The design flow for each radiator could therefore be calculated and is given in Table 2. Based on the pressure drop of the heating loop and the design flow of the radiator, the pre-set scales of the radiator valve were determined and are listed in Table 2 . The 
schematic configuration of the apartment-heating loop is illustrated in Figure 5. A Testo 925 [40] was used for measuring the indoor temperature.

Table 2. Basic information about the apartment tested

\begin{tabular}{llllll}
\hline Room name & $\begin{array}{l}\text { Floor area } \\
\left(\mathrm{m}^{2}\right)\end{array}$ & Heat load $(\mathrm{W})$ & $\begin{array}{l}\text { Desired operating } \\
\text { temperature } \\
\text { difference }\left({ }^{\circ} \mathrm{C}\right)\end{array}$ & $\begin{array}{l}\text { Desired flow } \\
(\mathrm{l} / \mathrm{h})\end{array}$ & $\begin{array}{l}\text { Pre-set values } \\
\text { of the radiator } \\
\text { valve }\end{array}$ \\
\hline Living Room & 18 & 810 & 15 & 46.4 & 3 \\
Bedroom A & 14.5 & 654 & 15 & 37.5 & 2.5 \\
Bedroom B & 8.7 & 391 & 15 & 22.5 & 1.5 \\
Bathroom & 3.4 & 168 & 15 & 9.6 & 1 \\
Kitchen & 4 & 180 & 15 & 10.3 & 1 \\
Total & 48.6 & 2203 & & 126 & \\
\hline
\end{tabular}

\subsubsection{IDA-ICE simulation for indoor temperature control}

For the indoor temperature control investigation, a simulation model of an eight-storey residential building was developed using IDA-ICE 4.2.6 [37]. To develop this building model, the building layout and building materials of one of the buildings in Case-Harbin were used. The building envelope properties and the thermal characteristics were as specified in China's energy conservation design standard JGJ26-95 [41]. One of the apartments was modelled as a multi-zone model. Each room in the apartment was a separate zone. The room height was $2.7 \mathrm{~m}$. This multizone model contained five heated zone areas: Bedroom N (north), Bathroom, Bedroom S (south), Kitchen, and Living Room, as well as three non-heated balconies and a non-heated staircase/hall (see Figure 8). The outdoor heating design temperature was $-26^{\circ} \mathrm{C}$ for Harbin and the indoor design room temperature was $18{ }^{\circ} \mathrm{C}$. Based on the information, we run the multi-zone model equipped with ideal radiators, and obtained the peak heat load of each zone. 


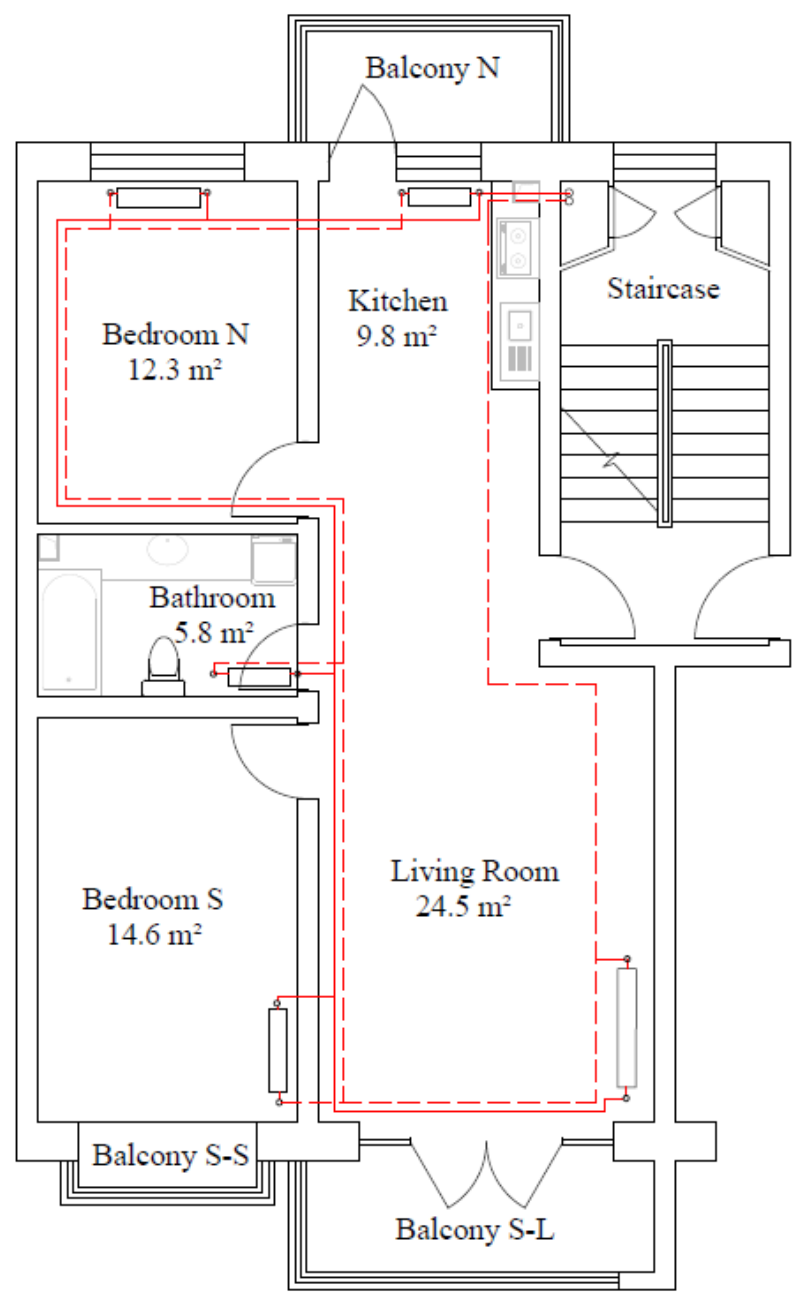

Figure 8. Multi-zone model

We dimensioned the radiators in accordance with Chinese standard [10]. In each zone, an M132type radiator [42] was modelled as the room heating unit as in Case-Harbin. The design parameters of the SH system were the same as those for Case-Harbin: 80/60/18 ${ }^{\circ} \mathrm{C}$ (supply/return/indoor air temperatures). Correction factors were derived to correct for the actual output of each radiator. Accordingly, the maximum power of each radiator was determined, and the design flow limitation through the radiators and the design heat load for the SH system were defined.

Linear fit-to-metered supply temperatures were chosen in relationship to the outdoor temperatures shown in Figure 4. Here the secondary supply temperature is assumed to have been optimized by applying the weather compensation control at the substation and variable speed pumps in the secondary network of this system. To reflect the real conditions, an internal heat gain of $5.0 \mathrm{~W} / \mathrm{m}^{2}$ was considered [41]. Real weather data in Harbin city in 2014 was used to estimate the energy consumption for heating using EnergyPlus [43]. Two scenarios were considered: 1) without TRVs fitted to the radiators, which is the most common situation in Chinese SH systems; and 2) with TRVs fitted to the radiators to adjust the indoor temperature by setting the thermostat of the 
TRVs. The room temperature of each zone, the energy consumption including heat consumption, and the electricity consumption of the pumps as well as the volume flow of the heating system were all compared based on the simulation results.

\section{Results and Discussion}

\subsection{Field test in Beijing}

\subsubsection{Test I: Differential pressure control of the apartment heating loop}

The test objects for Test I were three apartments 201, 202, and 1701.

The first aim of the investigation was to test whether the three test heating loops had the same distributed flow when the set points of the DP controllers were the same. The measurement results are shown in Figure 9. When the DP controllers of the three apartments loop were given the same set point (separately set at 5,10,15,20, and $25 \mathrm{kPa}$ ), the three loops had a similar volume flow as expected. The deviation of the individual loop flow from the average flow of these three loops at the same set points was within $\pm 15 \%$ (see Figure 9). This deviation can be considered as acceptable, because the set points of the DP controllers were adjusted by manually turning the spindle and there were no pressure gauges in the supply and return pipes to measure the pressure drop of the loops directly. Moreover, mechanical hysteresis influences the variations and causes a difference in the measured flow rates. The $2^{\text {nd }}$ floor and $17^{\text {th }}$ floor have identical floor heating areas, so theoretically the distributed flow could be the same. It can therefore be concluded that the hydraulic imbalance along the vertical riser was reduced after the installation of the DP controllers.

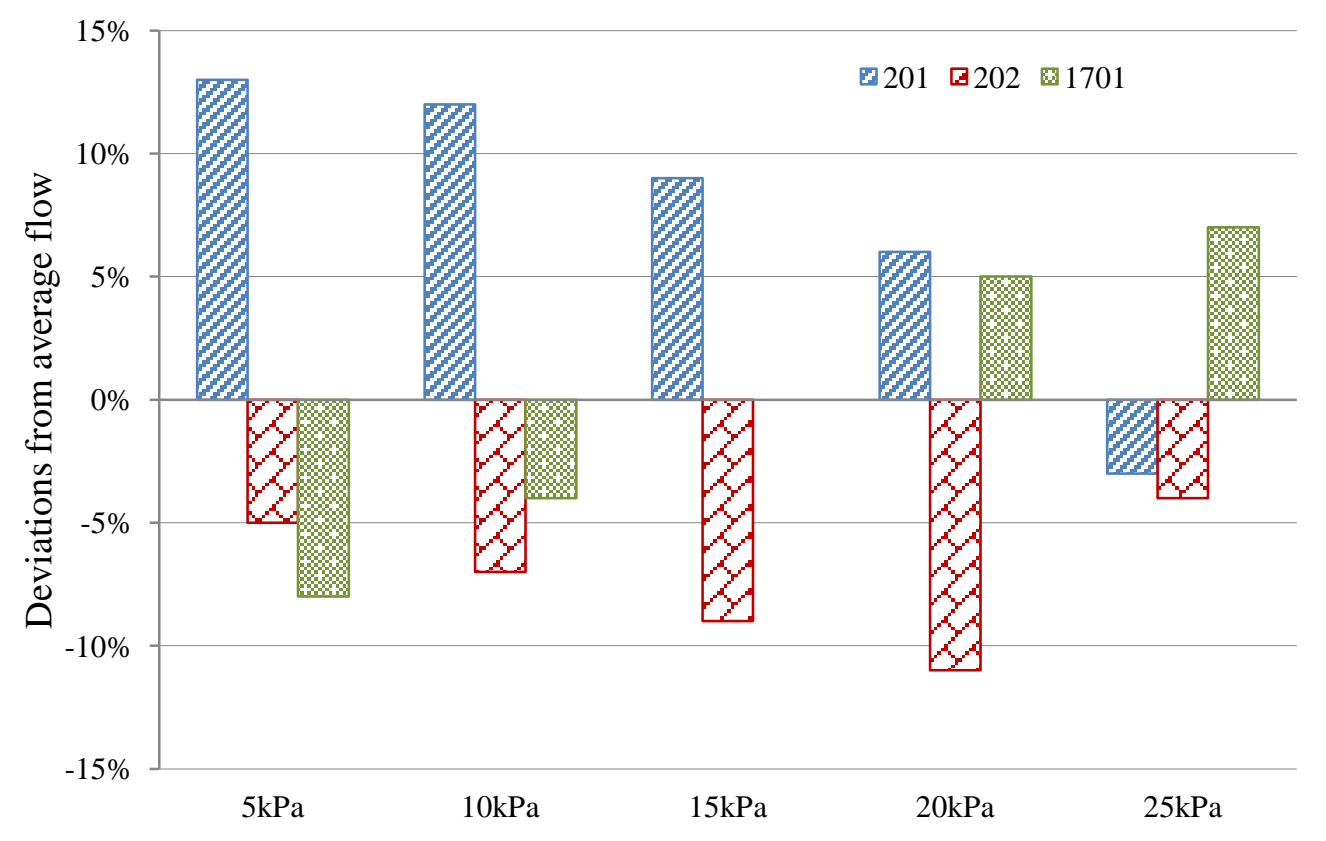

Figure 9. Deviations from the average flows of 201, 202, and 1701 at various set values of the DP controllers

The second aim of Test I was to test whether one of the heating loops was pressure-independent 
when the differential pressure of the other two heating loops changed. The results show that when the differential pressure of the other two tested heating loops was changed by adjusting the set points of the DP controllers or by completely shutting off the loops, the other apartments' heating systems kept operating normally and the flow of the third tested loop was not influenced or changed. This means that the automatic balancing valves were able to separate each heating loop as an independent pressure zone, and maintain the constant differential pressure in the controlled loop. It also implies that the DP controller controls the differential pressure across the controlled loop, which will ensure an optimal differential pressure across the downstream control valves. In this way, the flow within the controlled loop would not be affected by any system load changes, and noise would be avoided.

\subsubsection{Test II: The pre-setting function of the radiator valves}

For Test II, the test object was one apartment.

The apartment loop's mass flow, the supply and return temperatures, and the indoor temperature were measured with the set point of the DP controller at $10 \mathrm{kPa}$. The measurements were first carried out without radiator valves pre-set, and after that with them all pre-set. The mass flow measurement results (see Table 3) showed that after the radiator valves were pre-set, the total flow supplied to the apartment was reduced to $1 / 3$, from $5571 / \mathrm{h}$ with no pre-setting to $181 \mathrm{l} / \mathrm{h}$ with pre-set. This implies that the flow rate through each radiator was limited dramatically by the presetting function. The flow rate in the case of pre-setting was close to the design flow rate of 126 $1 / \mathrm{h}$. This indicates that flow control by pre-setting the radiator valves on the terminal heat units is effective. The temperature measurement results showed that the temperature difference of the controlled loop increased by nearly $100 \%$ with the radiator valves pre-set, changing from $9{ }^{\circ} \mathrm{C}$ to $17.3^{\circ} \mathrm{C}$. Test II focused on the hydraulic control effect of pre-setting the radiator valves. The results clearly show that the large flow and small temperature difference problem which is typical in Chinese DH systems has been significantly relieved. This is the most important result that the test aimed to get. It also reflects the great energy-saving potential if the excess flow can be controlled.

In addition, at the start of the test, when there was no pre-setting of the radiator valves, the room temperature was $22.6^{\circ} \mathrm{C}$ (see Table 3), with heating power of $5.8 \mathrm{~kW}$. The design capacity is 2.2 $\mathrm{kW}$ for $-9^{\circ} \mathrm{C}$ outdoor air temperature. Due to lack of individual controls, the tenants regulate the room temperature by opening windows, which explains why the room temperature was no higher. After the pre-setting of the radiator valves, the delivered capacity was $3.6 \mathrm{~kW}$ and the room temperature went down to $22^{\circ} \mathrm{C}$ within two hours. A further decrease might be expected, but the $3.6 \mathrm{~kW}$ would be more than enough to sustain $18^{\circ} \mathrm{C}$ room temperature, seen in relation to the design capacity.

Table 3. Temperature measurement comparison between with and without pre-setting in Test II

\begin{tabular}{lll}
\hline Parameter of tested apartment loop & No pre-setting & Pre-setting \\
\hline Total flow of apartment loop $(\mathrm{l} / \mathrm{h})$ & 557 & 181 \\
Supply temperature $\left({ }^{\circ} \mathrm{C}\right)$ & 62.6 & 62 \\
Return temperature $\left({ }^{\circ} \mathrm{C}\right)$ & 53.6 & 44.7 \\
Delta $\mathrm{T}\left({ }^{\circ} \mathrm{C}\right)$ & 9 & 17.3
\end{tabular}




\begin{tabular}{lll} 
Average indoor temperature $\left({ }^{\circ} \mathrm{C}\right)$ & 22.6 & 22 \\
Outdoor temperature $\left({ }^{\circ} \mathrm{C}\right)$ & -4 & -4 \\
\hline
\end{tabular}

The field test showed that pre-setting radiator valves combined with the automatic balancing valves could control the loop flow close to the design level. Within the apartment loop, presetting the radiator valves limited the maximum flow of each radiator and created the right balance among the radiators. Flow limitation for each terminal heat unit prevented insufficient flow at distal units and excess flow at proximal ones. It reduces the total supplied flow and consequently the pump electricity consumption.

The differential pressure limitation of the automatic balancing valves provided the appropriate pressure drop over the radiator valves. The hydraulic imbalance along the vertical riser was reduced, and it guaranteed to set the thermostat properly to adjust the indoor temperature. At the same time, the noise from the radiator valves was avoided. Further adjustments of the room temperature towards the desired temperature could be achieved by adding a thermostat to the radiator valve, which would adjust the valve depending on the deviation from the set-point temperature of the TRVs.

In this field test, a dynamic hydraulic balance was created in the heating system by using pre-set radiator valves combined with automatic balancing valves. Every loop received the required flow and excess flow and insufficient flow were avoided. Every room received the required heat. Flow limitation improved the efficiency of the pump, and increased the temperature drop across the radiator. This field test indicates that the excess heat loss can be reduced through establishing dynamic hydraulic balancing in the building heating system.

\subsection{IDA-ICE simulation}

\subsubsection{Model validation}

The radiator heating system in the multi-zone model was designed in accordance with the Chinese design standard. The "linear fit-to-metered supply temperature" from CASE-Harbin (see Figure 4) defined the supply temperatures of the simulated heating system during the heating period. As shown in Figure 10 , the simulated return temperatures were compared with the linear fit-to-metered return temperatures from Case-Harbin. The results show that the deviation between the simulation results and the linear fit-to-return temperatures from Case-Harbin was on average about $2{ }^{\circ} \mathrm{C}$. It should be mentioned that the measurements from Case-Harbin were acquired at the area substation and were the average return temperatures from all the connected buildings. The deviation between the model outputs and the measured return temperatures were therefore considered to be acceptable and the model was considered valid. 


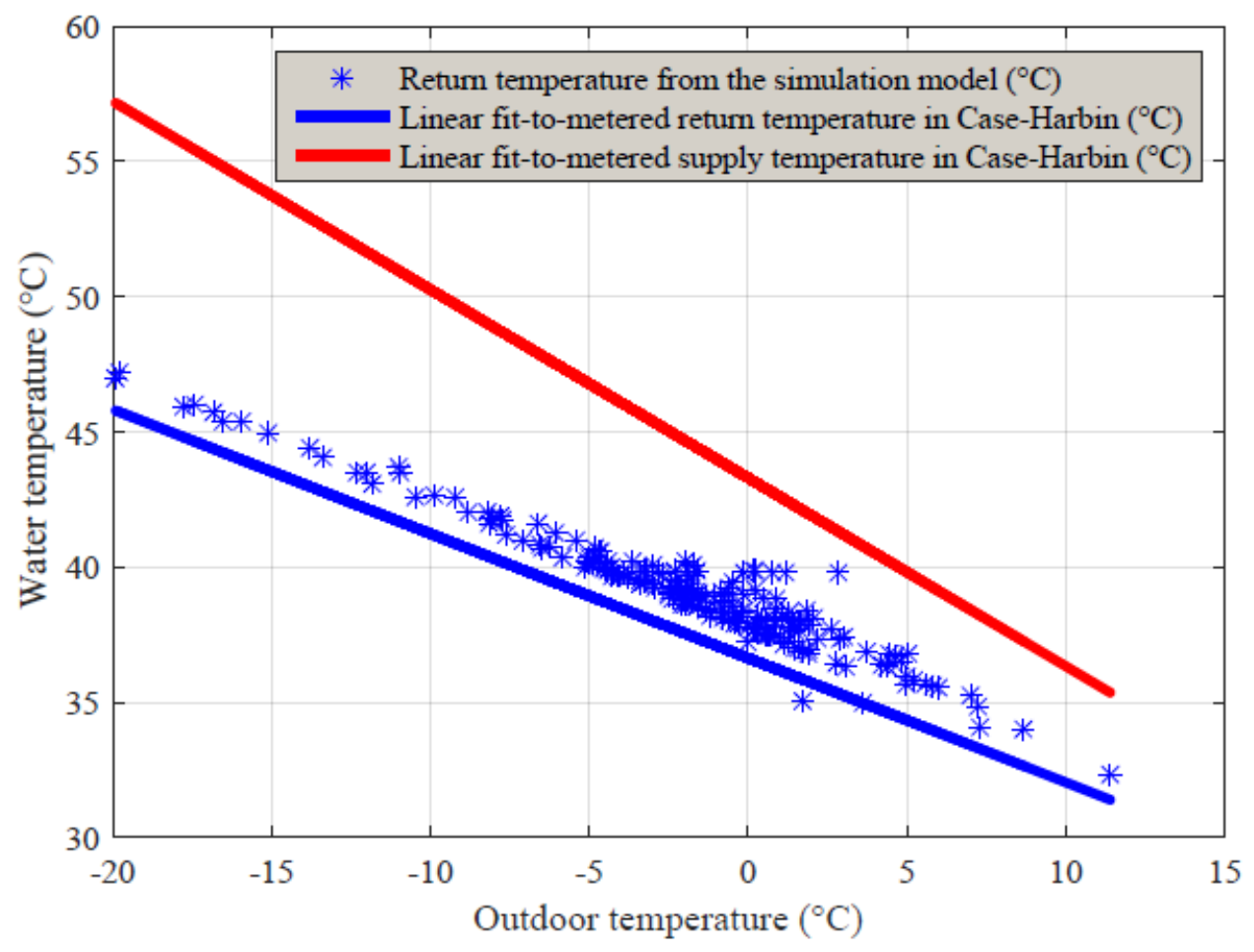

Figure 10. Supply and return temperatures for the model of the SH system

\subsubsection{IDA-ICE simulation results}

A simulation was carried out for the heating period in Harbin for two scenarios: radiators without TRVs and with TRVs. Several factors were considered in the simulation: room temperatures, heat consumption, pump electricity consumption, and the flow rate in the heating system.

Firstly, in terms of the room temperatures, the general results showed that without TRVs the room temperatures in all the zones were much higher than $18{ }^{\circ} \mathrm{C}$ except for a few hours at the beginning of the heating period. The average room temperatures in all five zones over the entire heating period were around $22^{\circ} \mathrm{C}$. With TRV control, the room temperatures in all the zones were constant at around $18{ }^{\circ} \mathrm{C}$. There are some minor deviations between the set temperature and the simulated room temperature, due to the $0.5^{\circ} \mathrm{C}$ proportional band (P-band). Because TRVs are proportional temperature controllers, they respond to any deviation from the set temperature by increasing or decreasing the flow into the radiators until the required room temperature is achieved. Figure 11shows the simulation results for two typical rooms in the multi-zone model: the northern room 'Bedroom N' and the largest room the 'Living Room', which reflects these small variations particularly clearly. The indoor air temperature can also be seen to have lagged a few days behind outdoor temperatures changes because of the thermal inertia of the building envelope materials. 


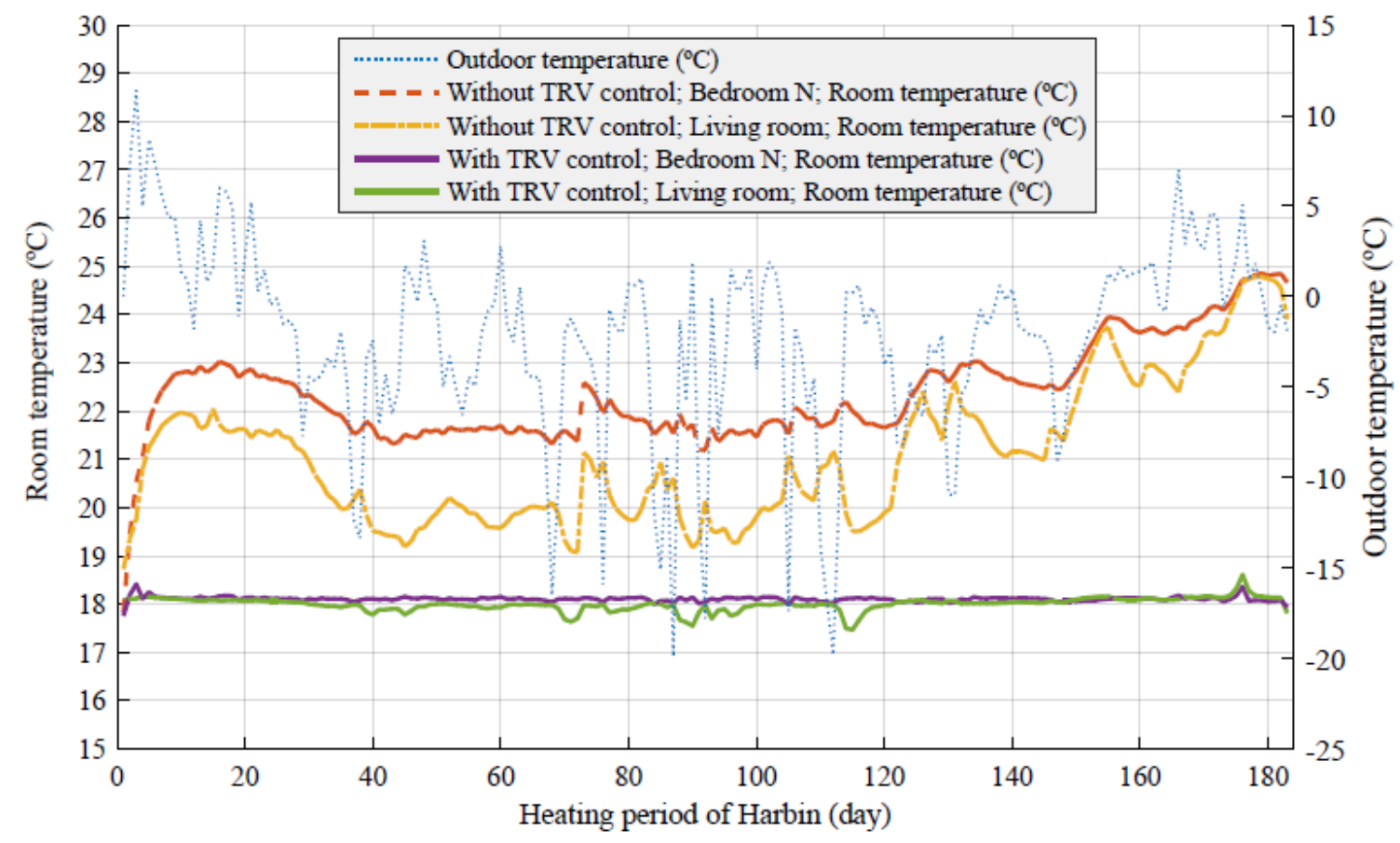

Figure 11. Zone room temperature of Bedroom $N$ and the Living Room during the heating period

As shown in the simulation results, the application of TRVs provides the practical possibility for the room occupants to adjust the room temperature. When the rooms are overheated, the indoor temperature can be adjusted by setting the thermostat rather than opening the windows. Thermal comfort can imply multiple factors like indoor temperature, humidity, and draught [44]. But in the heating supply context, thermal comfort mainly refers to the indoor room temperature. In an unbalanced system, the thermal discomfort means excess heating for users close to the substation and insufficient heating for users far away from the substation. Through the implementation of the technical approach presented here, the indoor temperatures for rooms in different locations are balanced and close to the design room temperatures. We therefore conclude that the indoor thermal comfort is improved.

Correct use of TVRs has the potential to achieve great energy-saving effects. In some cases, heat consumers might not know how to use the TRVs correctly and might simply use the maximum set point, which will compromise the energy savings potential. The set points can be protected and locked by inserting the pins on the dial, and an energy-saving type of TRV can be used with a maximum set point of $20^{\circ} \mathrm{C}$ [45].

Secondly, the monthly heat consumption and pump electricity consumption were compared for the two scenarios, and the results are shown in Figure 12. Since the heating season is fixed in Harbin city and does not include May to September, no data were collected for those months. In terms of annual energy consumption, which was obtained by accumulating the monthly energy consumption over the heating season, the results imply that applying TRVs can reduce annual 
heat consumption by $17 \%$ and annual pump electricity consumption by $42.8 \%$ for this particular apartment. Here it should be noted that the pump energy consumption is very small compared to the heating energy consumption, only $0.1 \%$ of the heat energy delivered.

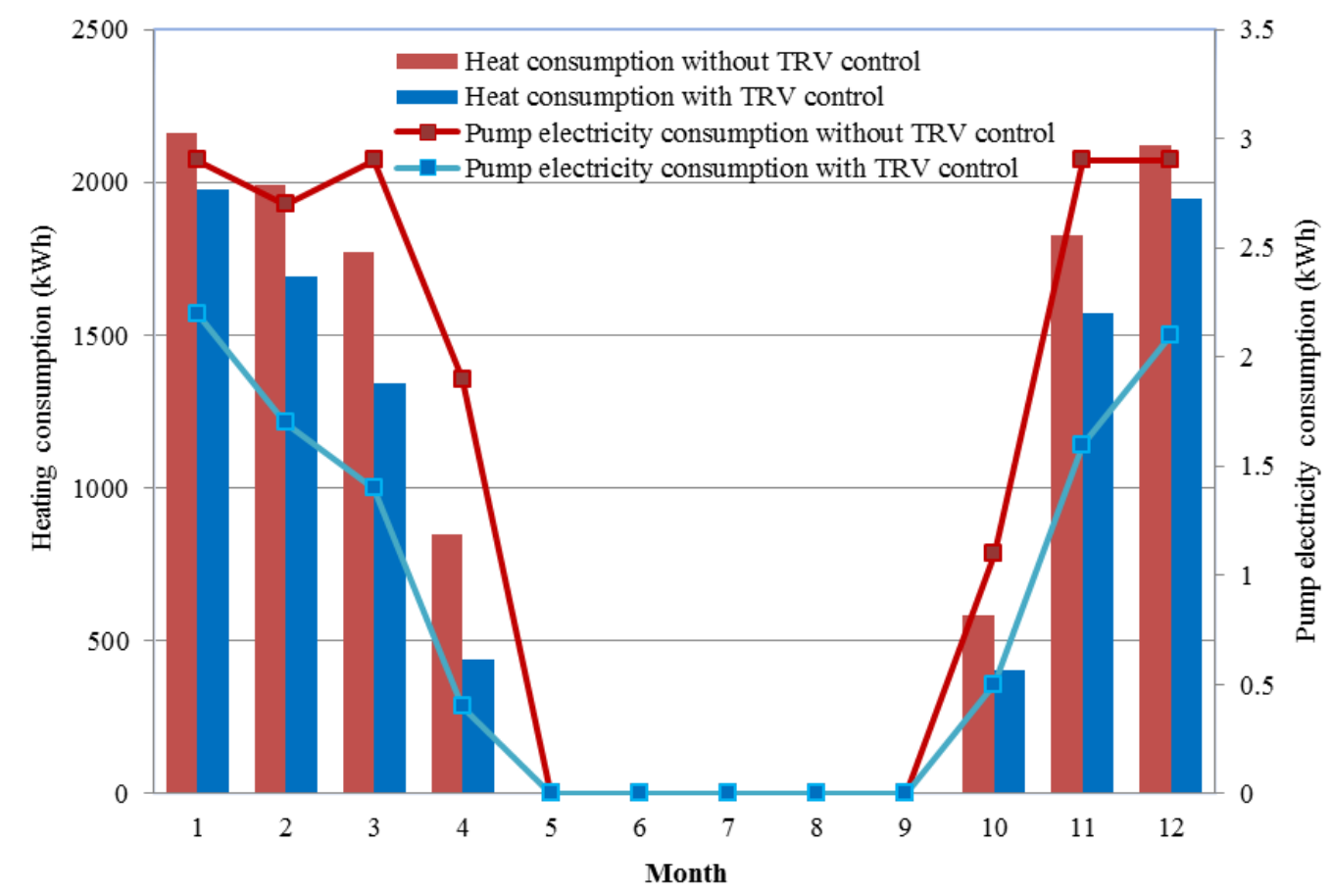

Figure 12. Heat consumption comparison between the scenarios with and without TRV control

Coal is the dominant DH fuel, and the dominant fuel for Chinese power plants. Burning coal is one of the main causes of air pollution in China [46]. Hydraulic balance can achieve $17 \%$ heat savings and $42.8 \%$ pump electricity savings. This will result in positive environmental impacts. In Case-Harbin, the total heating area in 2013-2014 heating season was $442,340 \mathrm{~m}^{2}$. The measured seasonal heat consumption per $\mathrm{m}^{2}$ was $0.7 \mathrm{GJ} / \mathrm{m}^{2}$, and the seasonal pump electricity consumption was $2.1 \mathrm{kWh} / \mathrm{m}^{2}$. This reflects the currently unbalanced system situation. With hydraulic balance, the simulation results show that the seasonal heat consumption could be reduced by $0.12 \mathrm{GJ} / \mathrm{m}^{2}$, and the seasonal pump electricity consumption could be reduced by $0.9 \mathrm{kWh} / \mathrm{m}^{2}$. The results imply that the total emission reduction for Case-Harbin could have been 4837 ton of $\mathrm{CO}_{2}, 44.7$ tons of $\mathrm{SO}_{2}$, and 13 tons of $\mathrm{NO}_{\mathrm{x}}$ in the 2013-2014 heating season if hydraulic balance had been achieved. Therefore, the seasonal environmental impacts would reflect the reduction of $11 \mathrm{~kg} \mathrm{CO}_{2}$, $0.1 \mathrm{~g} \mathrm{SO}_{2}$, and $0.03 \mathrm{~g} \mathrm{NO}_{\mathrm{x}}$ per heating square metre.

Moreover, with regard to the system's operation, it is important to note that applying TRVs changes the SH system from constant flow to variable flow (see Figure 13). 


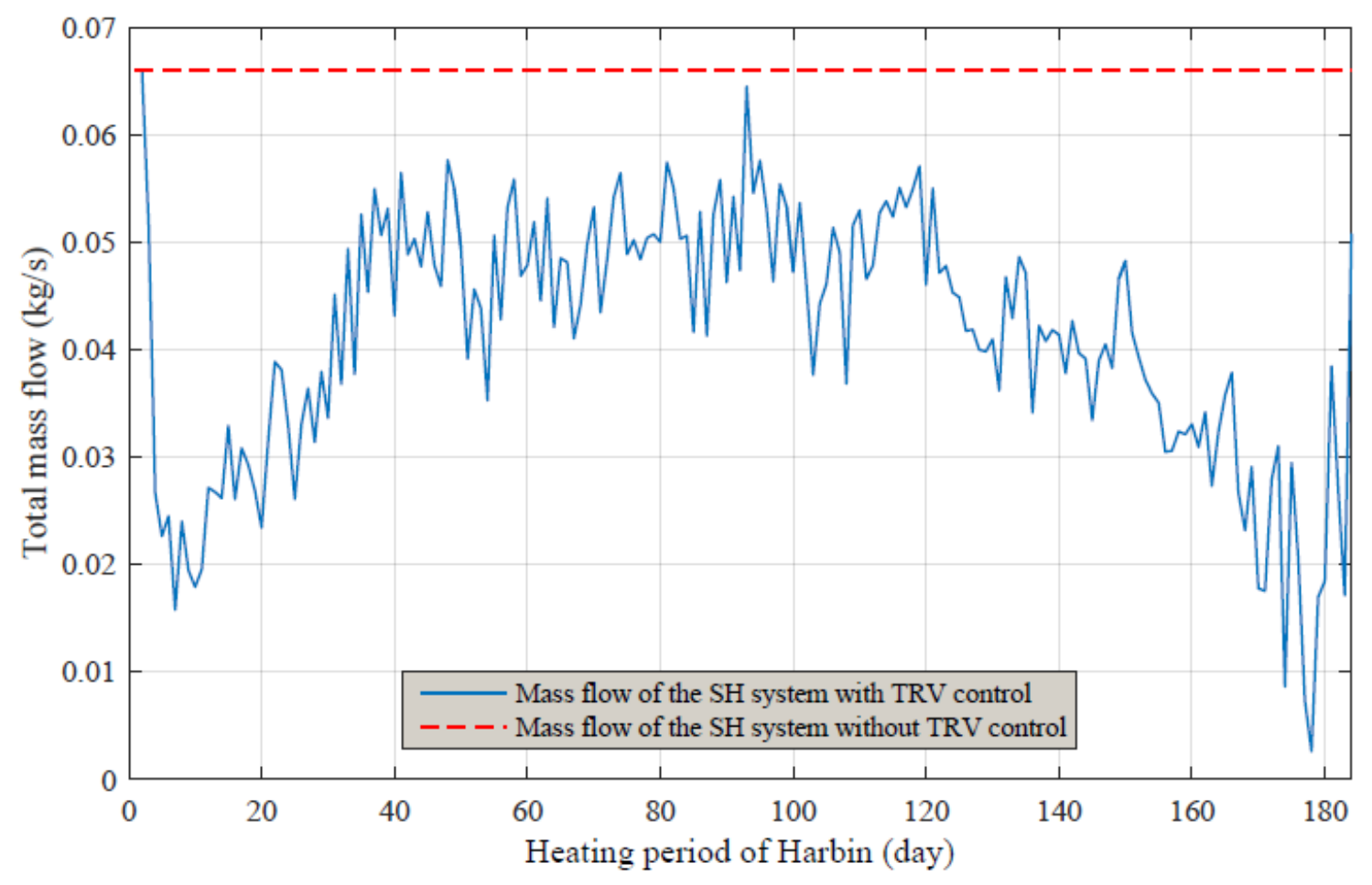

Figure 13. Total mass flow comparison between scenarios with and without TRV control

According to the results from the field test and the IDA-ICE simulation, the excess heat loss can be reduced by achieving hydraulic balance and optimizing indoor air temperature control at the building level.

In this study, the research object was the building heating system. Energy reduction at the building level will inevitably impact the whole DH system, reducing the amount of heat that areasubstations have to deliver to a group of buildings and that the heat source plants have to deliver to the area-substations.

Dynamic hydraulic balancing ensures the apartment heating loops distribute the requested flow, with neither excess flow nor inadequate flow. Moreover, it means that the apartment heating loops are not influenced by each other if adjustments are made. Temperature control stabilizes the room temperature at comfort levels and avoids the room overheating. The integrated technical approach therefore reduces excess heat supply and excess heat loss. This means lower fuel consumption and less polluting emissions due to the fossil fuels heavily used in China. The economic benefits and environmental effects achieved will be considerable.

In the future, along with the energy consumption reduction in space heating systems, it is expected that Chinese DH systems will transition from the current centrally planned heat supply to demand-driven heat generation, which will also give increased comfort for users. In addition to this improvement in quality of life, DHW could also be integrated into DH systems to supply hot water in the future. This would be possible because the reduction in excess heat supply will result in large energy savings. 
The high building density in Chinese' cities and the continuously expanding heating areas with rapid urbanization mean that there will be significant heat demands that need to be fulfilled. This emphasizes the significance of the kind of reductions in energy consumption in Chinese DH systems discussed in this paper.

\section{Conclusions}

To conclude, the proposed approach of combining the use of TRVs with an integrated pre-setting function and automatic balancing valves has been shown to be both feasible and effective in practice.

Firstly, a field test showed that pre-setting radiator valves combined with automatic balancing valves can establish dynamic hydraulic balance in a building heating system. Each controlled loop becomes an independent zone. The pre-setting of the radiator valve is an important function to equalize the flow distribution among the terminal heating units. Moreover, automatic balancing valves enable the radiator valves to work at optimum differential pressure level. As a result, the problems of excess flow and insufficient flow are avoided in the heating system. At the same time, the return temperature was decreased, and the temperature drop across the radiator was increased.

Secondly, IDA-ICE simulation results indicate that TRVs stabilize the room temperature. Wide use of TRVs in Chinese buildings can reduce heat consumption by $17 \%$ and pump electricity consumption by $42.8 \%$, compared to a scenario without TRV control. In addition, adjusting TRVs transform the system from constant flow to variable flow. Variable speed pumps can be applied with variable flow rate. As coal is the dominant fuel for DH plants and power plants in China, the savings on both heat consumption and pump electricity consumption imply the positive environmental impacts.

Traditional Chinese DH systems seldom have control at the consumer end. By moving the control close to the end users, it is possible to bring the heating supply into line with the heating demand. The integrated assessment method and field test show that a well-balanced DH system can improve consumer thermal comfort and at the same time save significant pumping power. A wellbalanced DH system allows heat users to pay less if the heating is charged on the basis of the real consumption. The heat users are satisfied also due to the improved room temperature control. At the same time, it would also be cost-effective for DH utilities, who could increase their profits by avoiding excess heat loss.

The developed integrated approach will help the decision makers and stakeholders to plan new or renovated district heating projects to be more energy efficient and cost effective. It would make a considerable contribution to energy supply security and air pollution abatement for Chinese society by giving smart control to district heating systems.

\section{Acknowledgements}

The authors would like to thank Professor David P. Wyon for his valuable comments on this paper. The research reported here was carried out with financial support from the Danish Agency for Science, Technology and Innovation (DASTI) and from Danfoss A/S through the Industrial $\mathrm{PhD}$ Programme for China. This financial support is gratefully acknowledged. 


\section{References}

[1] M. Münster, P. E. Morthorst, H. V. Larsen, L. Bregnbæk, J. Werling, H. H. Lindboe, and H. Ravn, "The role of district heating in the future Danish energy system," Energy, vol. 48, no. 1, pp. 47-55, Dec. 2012.

[2] H. Lund, S. Werner, R. Wiltshire, S. Svendsen, J. E. Thorsen, F. Hvelplund, and B. V. Mathiesen, "4th Generation District Heating (4GDH): Integrating smart thermal grids into future sustainable energy systems," Energy, vol. 68, pp. 1-11, Apr. 2014.

[3] D. Connolly, H. Lund, B. V. Mathiesen, S. Werner, B. Möller, U. Persson, T. Boermans, D. Trier, P. A. Østergaard, and S. Nielsen, "Heat Roadmap Europe: Combining district heating with heat savings to decarbonise the EU energy system," Energy Policy, vol. 65, pp. 475-489, Feb. 2014.

[4] U. Persson and S. Werner, "District heating in sequential energy supply," Appl. Energy, vol. 95, pp. 123-131, Jul. 2012.

[5] U. Persson and S. Werner, "Heat distribution and the future competitiveness of district heating,” Appl. Energy, vol. 88, no. 3, pp. 568-576, Mar. 2011.

[6] EURO HEAT \& POWER, "Euroheat \& power - Statistics," 2013. [Online]. Available: http://www.euroheat.org/Statistics-69.aspx. [Accessed: 26-Oct-2015].

[7] A. Baeumler, E. Ijjasz-vasquez, and S. Mehndiratta, "Sustainable Low-Carbon City Development in China," World Bank, 2012.

[8] Tsinghua University Building Energy Research Center, 2011 Annual Report on China Building Energy Efficiency. 2011.

[9] X. Chen, L. Wang, L. Tong, S. Sun, X. Yue, S. Yin, and L. Zheng, "Energy saving and emission reduction of China's urban district heating," Energy Policy, vol. 55, pp. 677682, Apr. 2013.

[10] Y. Lu, Practical Handbook of heating and air conditioning design. Beijing, China: China Building Industry Press, 2008.

[11] Ministry of Housing and Urban-Rural Development of China, "Industry standard JGJ 262010: Design standard for energy efficiency of residential buildings in severe cold and cold zones." China Building Industry Press, Beijing, China, CHINA, 2010.

[12] Ministry of Construction of China \& General Administration of Quality Supervision Inspection and Quarantine of the P. R. China, China national standard GB 50019-2012: Design code of heating ventilation and air conditioning. Beijing: China Architecture and Building Press, 2012. 
[13] Tsinghua University Building Energy Research Center, 2015 Annual Report on China Building Energy Efficiency. 2015.

[14] China National Bureau of Statistics, "National Bureau of statistics data." [Online]. Available: http://www.stats.gov.cn/.

[15] G. Deng, "The effect of occupant behaviors on evaluating adaptability of centralized building energy saving technologies," Beijing University of Technology, 2013.

[16] Ministry of Housing and Urban-Rural Development, "Ministry of Housing and UrbanRural Development." [Online]. Available: http://www.mohurd.gov.cn/.

[17] Z. Lipeng, O. Gudmundsson, H. Li, and S. Svendsen, "Comparison of District Heating systems used in China and Denmark," EuroHeat \& Power (English Edition), vol. 10, no.4, pp. 12-19, Jan. 2013.

[18] F. Sun, L. Fu, S. Zhang, and J. Sun, "New waste heat district heating system with combined heat and power based on absorption heat exchange cycle in China," Appl. Therm. Eng., vol. 37, pp. 136-144, May 2012.

[19] H. Fang, J. Xia, K. Zhu, Y. Su, and Y. Jiang, "Industrial waste heat utilization for low temperature district heating," Energy Policy, vol. 62, pp. 236-246, 2013.

[20] H. Wang, W. Jiao, R. Lahdelma, and P. Zou, "Techno-economic analysis of a coal-fired CHP based combined heating system with gas-fired boilers for peak load compensation," Energy Policy, vol. 39, no. 12, pp. 7950-7962, 2011.

[21] Z. X. Jing, X. S. Jiang, Q. H. Wu, W. H. Tang, and B. Hua, "Modelling and optimal operation of a small-scale integrated energy based district heating and cooling system," Energy, vol. 73, pp. 399-415, Aug. 2014.

[22] P. Jie, N. Zhu, and D. Li, "Operation optimization of existing district heating systems," Appl. Therm. Eng., vol. 78, pp. 278-288, Mar. 2015.

[23] X. S. Jiang, Z. X. Jing, Y. Z. Li, Q. H. Wu, and W. H. Tang, "Modelling and operation optimization of an integrated energy based direct district water-heating system," Energy, vol. 64, pp. 375-388, Jan. 2014.

[24] P. Jie, Z. Tian, S. Yuan, and N. Zhu, "Modeling the dynamic characteristics of a district heating network," Energy, vol. 39, no. 1, pp. 126-134, Mar. 2012.

[25] B. Cao, Y. Zhu, M. Li, and Q. Ouyang, "Individual and district heating: A comparison of residential heating modes with an analysis of adaptive thermal comfort," Energy Build., vol. 78, pp. 17-24, Aug. 2014. 
[26] A. Yan, J. Zhao, Q. An, Y. Zhao, H. Li, and Y. J. Huang, "Hydraulic performance of a new district heating systems with distributed variable speed pumps," Appl. Energy, vol. 112, pp. 876-885, Dec. 2013.

[27] H. Wang and D. Li, "Optimal configuration of heating transmission and distribution system-research on distributed variable speed system," Heat Cool, vol. 12, no. 42, p. 6, 2003.

[28] Z. Ma and S. Wang, "Energy efficient control of variable speed pumps in complex building central air-conditioning systems," Energy Build., vol. 41, no.2, pp. 197-205, Feb. 2009.

[29] P. Xu, T. Xu, and P. Shen, "Energy and behavioral impacts of integrative retrofits for residential buildings: What is at stake for building energy policy reforms in northern China?," Energy Policy, vol. 52, pp. 667-676, Jan. 2013.

[30] J. Li, M. Colombier, and P.-N. Giraud, "Decision on optimal building energy efficiency standard in China-The case for Tianjin," Energy Policy, vol. 37, no. 7, pp. 2546-2559, Jul. 2009.

[31] B. Lin and H. Liu, "China's building energy efficiency and urbanization," Energy Build., vol. 86, pp. 356-365, 2015.

[32] D. Yan, T. Zhe, W. Yong, and Z. Neng, "Achievements and suggestions of heat metering and energy efficiency retrofit for existing residential buildings in northern heating regions of China," Energy Policy, vol. 39, no.9, pp. 4675-4682, 2011.

[33] B. Xu, L. Fu, and H. Di, "Field investigation on consumer behavior and hydraulic performance of a district heating system in Tianjin, China," Build. Environ., vol. 44, no. 2, pp. 249-259, Feb. 2009.

[34] B. Xu, L. Fu, and H. Di, "Dynamic simulation of space heating systems with radiators controlled by TRVs in buildings," Energy Build., vol. 40, no.9, pp. 1755-1764, Jan. 2008.

[35] L. Liu, L. Fu, Y. Jiang, and S. Guo, "Major issues and solutions in the heat-metering reform in China,” Renew. Sustain. Energy Rev., vol. 15, no.1, pp. 673-680, Jan. 2011.

[36] Nation Planning and Energy Commission, "Energy basic data compilation." 1999.

[37] EQUA, “IDA-ICE 4.2.6.” [Online]. Available: http://www.equa.se/index.php/en/ida-ice.

[38] Danfoss, "RA-N Valves with Pre-Setting," 2014. [Online]. Available: http://products.danfoss.com/productrange/list/heatingsolutions/radiatorthermostats/radiator-valves/pre-setting-valves/. [Accessed: 21-Jan-2015]. 
[39] Danfoss, “ASV Automatic Balancing Valves.” [Online]. Available: http://products.danfoss.com/productrange/heatingsolutions/balancing-controlvalves/automatic-balancing-valves/asv-automatic-balancing-valves/. [Accessed: 21-Jan2015].

[40] Testo, "Testo 925 - temperature measuring instrument." [Online]. Available: http://www.testo.org/en/home/products/productdetailpage.jsp?productNo=0560+9250. [Accessed: 12-Feb-2015].

[41] Ministry of Housing and Urban-Rural Development of China, JGJ26-95:Design standard for energy efficiency of residential buildings in severe cold and cold zones. CHINA, 1995.

[42] P. He, G. Sun, F. Wang, and H. X. Wu, Heating Engineering(4th edition). Beijing, China: China Building Industry Press.

[43] EnergyPlus, “CHN_Heilongjiang.Harbin.509530_CSWD.” [Online]. Available: http://apps1.eere.energy.gov/buildings/energyplus/weatherdata_about.cfm.

[44] X. B. Yang, D. F. Sun, X. J. Zhou, L. L. Cai, and Y. Ji, "Indoor thermal comfort and its effect on building energy consumption,” Appl. Mech. Mater., vol. 71-78, pp. 3516-3519, 2011.

[45] Danfoss, "Thermostatic Sensors RTW," 2011. [Online]. Available: http://fheprod.danfoss.com/PCMPDF/VD31F202_RTW_teamcent.pdf. [Accessed: 21Jan-2015].

[46] H. Zhang, B. Zhang, and J. Bi, "More efforts, more benefits: Air pollutant control of coal-fired power plants in China," Energy, vol. 80, pp. 1-9, Feb. 2015. 
Method for reducing excess heat supply experienced in typical Chinese district heating systems by achieving hydraulic balance and improving indoor air temperature control at the building level

\title{
Lipeng Zhang ${ }^{\mathrm{a}, \mathrm{b} 1}$, Oddgeir Gudmundsson ${ }^{\mathrm{b}}$, Jan Eric Thorsen ${ }^{\mathrm{b}}$, Hongwei $\mathrm{Li}^{\mathrm{a}}$, Xiaopeng $\mathrm{Li}^{\mathrm{c}}$, Svend Svendsen ${ }^{\mathrm{a}}$,
}

${ }^{a}$ Civil Engineering Department, Technical University of Denmark, Anker Engelunds Vej Building 118, 2800 Kgs. Lyngby, Denmark

${ }^{b}$ Danfoss A/S, Heating segment, Application Center. Nordborgvej 81,Nordborg,6430 Denmark

${ }^{c}$ Danfoss Automatic Controls Management (Shanghai) Co., Ltd. F2O, Building A, No.2A Gong Ti Bei Lu, Chaoyang District, Beijing,100027, China

\begin{abstract}
A common problem with Chinese district heating systems is that they supply more heat than the actual heat demand. The reason for this excess heat supply is the general failure to use control devices to adjust the indoor temperature and flow in the building heating systems in accordance with the actual heat demand. This results in $15-30 \%$ of the total supplied heat being lost. This paper proposes an integrated approach that aims to reduce the excess heat loss by introducing preset thermostatic radiator valves combined with automatic balancing valves. Those devices establish hydraulic balance, and stabilize indoor temperatures. The feasibility and the energy consumption reduction of this approach were verified by means of simulation and a field test. By moving the system from centrally planned heat delivery to demand-driven heat delivery, excess heat loss can be significantly reduced. Results show that once the hydraulic balance is achieved and indoor temperatures are controlled with this integrated approach, $17 \%$ heat savings and $42.8 \%$ pump electricity savings can be achieved. The energy savings will also have a positive environmental effect with seasonal reductions of $11 \mathrm{~kg} \mathrm{CO}_{2}, 0.1 \mathrm{~g} \mathrm{SO}_{2}$, and $0.03 \mathrm{~g} \mathrm{NO}_{\mathrm{x}}$ per heating square meter for a typical case in Harbin.
\end{abstract}

Key words: district heating, excess heat supply reduction, pre-set thermostatic radiator valves, automatic balancing valves, hydraulic balance, differential pressure control

\section{Introduction}

Research has shown that district heating (DH) is playing an important role in the societal goal of realizing an effective and sustainable energy system [1][2][3][4][5]. Along with the rapid growth of urbanization and industrialization, China has become one of the largest DH markets in the world in the last two decades. Statistics indicate that the total DH production in 2013 amounted to 3,197,032 TJ [6]. This number is still increasing steadily due to the process of rapid urbanization, expansion of the building area, enhancement of building services, and increases in comfort level. On the other hand, according to a World Bank report in 2012, the consumption of heating energy in China per square metre of floor area is almost twice that in developed countries at the same

${ }^{*}$ Corresponding author. Tel.: +8610 85352485 .

E-mail address: lipz@byg.dtu.dk; zhanglipeng@danfoss.com (L.Zhang) 
latitude. Nevertheless, the resulting room thermal comfort in China is still unsatisfactory [7]. Furthermore, the 2011 Annual Report on China Building Energy Efficiency [8] reports that 15\% $30 \%$ of the total heat is being lost due to excess heat supply in northern China's DH systems. These high losses are primarily due to a failure to use control devices to control the heating supply in accordance with the actual heating demand. There is an urgent need to apply appropriate technical approaches to improve the Chinese DH efficiency to create the maximum synergy between energy supply security and air pollution abatement, which are the two most important challenges for China today [9].

Chinese DH systems are very different from European DH systems. Structurally, a typical Chinese DH system is like this: pressurized hot water as the heat medium is produced in the central heat source and distributed to a few area substations (the primary side of the DH system). Each area substation then serves a number of multi-storey or high-rise buildings (the secondary side of the DH system). The heat entrance is the interface connecting the large-area substation to the building heating system (see Figure 1). It is usually equipped with shut-off valves, and measurement devices like thermometers, pressure gauges and heat meters, etc. [10].

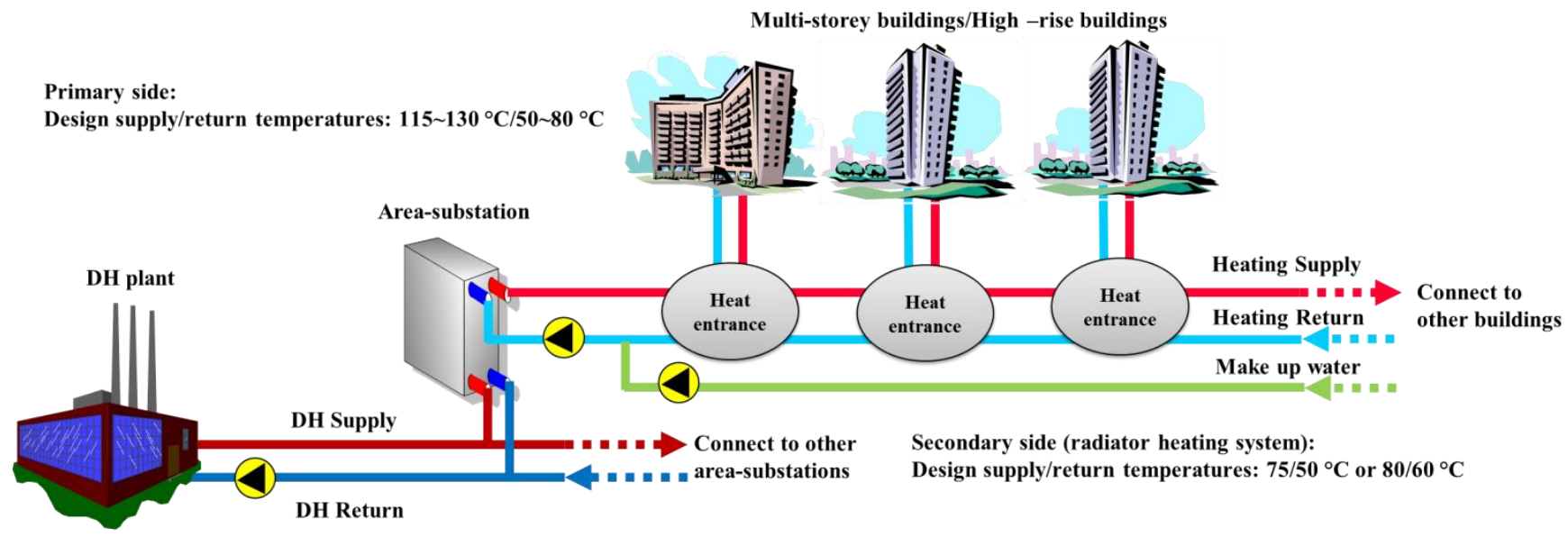

Figure 1. Typical district heating system used in China

In terms of temperatures, China's national design code [11] states that the DH primary side network should be designed with supply temperatures of $115^{\circ} \mathrm{C} \sim 130^{\circ} \mathrm{C}$ and return temperatures of $50 \sim 80^{\circ} \mathrm{C}$. The design code does not state any minimum design temperature difference. For the radiator space heating $(\mathrm{SH})$ systems, the design supply/return temperatures are recommended as $75 / 50{ }^{\circ} \mathrm{C}$ or $80 / 60{ }^{\circ} \mathrm{C}$ [12]. In practice, $\mathrm{DH}$ systems generally operate with different temperatures based on various conditions for the particular DH systems.

In terms of heat sources, the main heating production facilities are the coal-fired boilers and Combined Heat and Power (CHP) plants. For instance, in 2013, 48\% of DH came from coal-fired boilers, $42 \%$ CHP plants, $8 \%$ gas-fired boilers, and the remaining $2 \%$ came from scattered and individual heating facilities. Furthermore, coal is the dominant DH fuel in China [13]. Statistics show that $91 \%$ of the total energy supply to DH systems came from coal in 2008 [14].

Moreover, unlike European DH systems where DH supply covers both SH and Domestic Hot Water (DHW), approx. 90\% of Chinese DH systems supply SH without DHW [15]. 
These important characteristics make it possible to understand why excess heat supply occurs in typical Chinese DH systems.

From the perspective of temperature control, room temperature regulation and control functions are not available in approx. 84\% of the total heating area in China [16]. According to the national code [12], $18{ }^{\circ} \mathrm{C}$ is the standard room temperature for heat consumers in northern China to evaluate whether the heating effect is up to the required standard. The DH utility usually increases the secondary circulation flow rate until at least critical consumers attain this standard, which often result in the systems operating with large volume flow and small temperature differences between the supply and return streams. Moreover, once the heat demands of the critical consumers are fulfilled, the secondary flow rate often remains constant, with the varying SH demand being met by adjusting the secondary side supply temperature. Furthermore, there is a lack of automatic weather compensation control in some cases at substation level. Manual adjustment may be applied. e.g., tentatively adjusting the opening of the control valve installed on the primary side of the DH system, which is eventually reflected in changes in secondary supply temperatures. Such manual operation is based on the experience of past years and the level of complaints from critical users of the system, and the purpose of adjusting the supply temperature is to correlate the heat supply with the outdoor air temperature. Consequently, when the supply temperature to the SH system is higher than required, consumers will open windows to get comfortable indoor temperatures. In some cases, TRVs are installed in the DH systems. However, they are typically left fully open. Due to the fixed heating charges based on heating area, not actual heat consumption, there is no incentive for consumers to consciously reduce the TRV settings in an oversupply situation. They would generally regulate the indoor temperature by opening the windows. All these factors mean that consumers are either unable to control their room heating supply or lack motivation for energy conservation, which means excess heat supplied is wasted.

From the perspective of flow control in the secondary DH network and at building level, there are no automatic flow control devices, which results in an uneven flow distribution in the secondaryside DH network. Buildings close to the substation receive more flow than needed and become overheated, whereas buildings located in distal parts of the network receive less flow than required and are unable to fulfil their heating requirements. There is a lack of hydraulic balance inside the buildings. Specifically, the secondary side of Chinese DH systems generally operates on a constant flow and pressure basis. The pressure head at the pump is controlled to maintain constant differential pressure at area-substations. In addition, the constant flow operation principle makes the pumps run at constant speed. Although there are some variable-speed pumps, they are mainly used to correct the deviation between the design and operation conditions in terms of the pressure head and flow rate. Large volume flow leads therefore to higher than necessary electricity consumption in circulation pumps, small temperature differences, high return temperatures, and network heat losses.

In summary, it can be said that the general failure to use temperature and flow control devices in Chinese DH systems is the direct cause of excess heat loss, which subsequently compromises the efficiency of Chinese DH systems. 
Studies have investigated how to improve the efficiency of Chinese DH systems by focusing on various DH elements [17][18][19][20][21][22][23][24][25][26][27][28]. With the heat reform in 2006 in China, 16\% of the total heating area in China was given a heat metering retrofit [16] to install Thermostatic Radiator Valves (TRVs) by the year 2012. A lot of research has been carried out on TRV application in Chinese heating systems [29][30][31][32][33][34][35]. For instance, $\mathrm{Xu}$ et al. [33] investigated how hydraulic performance and energy consumption in individual apartments and the whole system were influenced when TRVs were regulated and when windows were opened. Xu et al. [34] developed a dynamic model and simulated the thermal and hydraulic behaviour of SH systems employing TRV-controlled radiators in multi-family buildings. Liu et al. [35] analysed the heat metering methods currently available in China and proposed a new method for metering the heat consumption of individual households in accordance with the accumulated on-time as well as the floor space of each household.

However, when we examine the previous research mentioned above, there is still a lack of expertise or knowledge on optimizing building heating systems by correctly using the flow control and temperature control functions of TRVs, including their inherent relationship with energy consumption reduction and indoor temperature improvement.

In this paper, an integrated approach has been developed and applied to a real project in northern China. The technical feasibility is shown and the advantages are quantified. This could give enhanced understanding and guidance for renovating future Chinese DH systems.

\section{Methodology}

The research objects in this study were the building heating systems. The central hypothesis of this study rests on the idea that the flow and temperature control functions of TRVs combined with differential pressure management can reduce the excess heat supply experienced in current Chinese DH systems while reducing their energy consumption. This idea is reflected in the research question: how large is the potential for reducing excess heat consumption by using temperature and flow control in the heating system of buildings?

Chinese energy statistics usually use the unit "metric tons of standard coal equivalent" (tce) because the primary energy source for DH systems in China is coal, and one tce equals 29.31 GJ. Burning 1 ton Chinese standard coal (29.3GJ/tce) releases about $2600 \mathrm{~kg} \mathrm{CO}_{2}, 24 \mathrm{~kg} \mathrm{SO}_{2}$, and $7 \mathrm{~kg} \mathrm{NO}_{\mathrm{x}}$ [36]. If the proposed controls were applied in Chinese DH systems, energy consumption reduction would be achieved which would have considerable positive environmental impacts due to the heavy reliance on coal as DH fuel in China.

To show the inter-relationship between excess heat supply, overheating of rooms, and the hydraulic imbalance, we analysed the data from two real cases, Case-Beijing-A and Case-Harbin, and proposed a technical approach to solve the excess heat supply.

We performed a two-step analysis. Firstly, a field test was made to demonstrate the technical feasibility of the approach. The field test was carried out in a high-rise building in Beijing (CaseBeijing-B), which is structurally similar to Case-Beijing-A. Secondly, simulations for scenarios analysis were carried out using building simulation software: IDA Indoor Climate and Energy [37]. The prototype of the building model is one of the multi-storey residential buildings in Case- 
Harbin. The linear fit-to-metered secondary supply temperatures from Case-Harbin were used as input for the model to run the simulation. The flowchart shown in Figure 2 illustrates the integrated design approach in this paper.

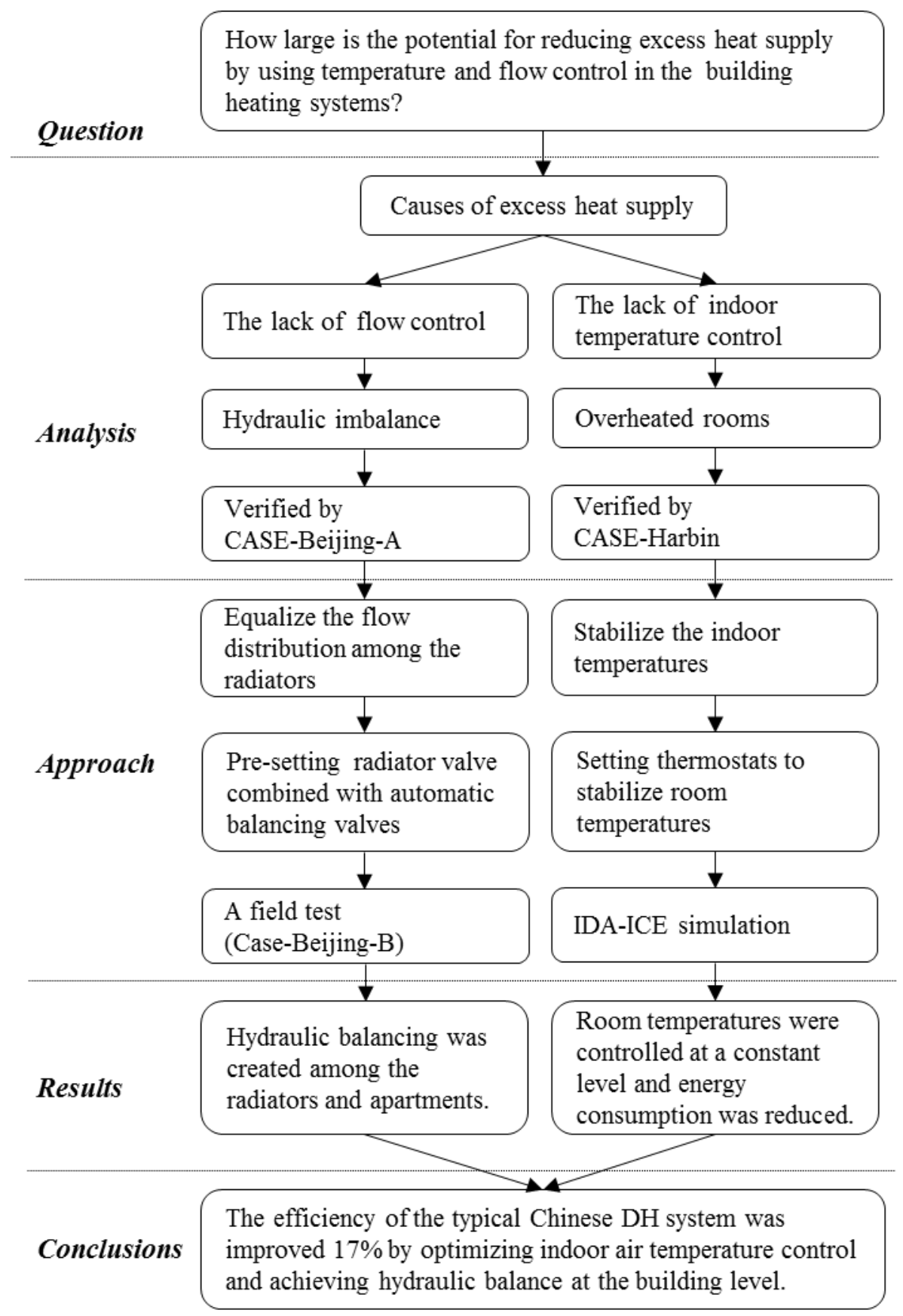

Figure 2. Flowchart of methods used in the study 


\subsection{Current situation from real cases}

First, the data from two real cases were analysed to present the excess heat supply experienced in Chinese DH systems.

Case-Beijing-A refers to a $\mathrm{DH}$ system in Beijing. The data from a residential high-rise building heating system were used to indicate the link between hydraulic imbalance and excess heat supply. Case-Harbin refers to a DH system in Harbin. The data from the secondary side of one substation were obtained to verify the causal link between overheated rooms and excess heat loss.

\subsubsection{Case-Beijing-A: Hydraulic imbalance and excess heat loss}

To understand the hydraulic situation in high-rise building heating systems, the volume flow data from a 21-floor residential building in Case-Beijing-A were obtained. The DH water from an area substation flows into the building via the heat entrance, where manual balancing valves are used as the only flow control device to manage the flow distribution among the connected buildings. DH utilities usually use a flow index to determine the required volume flow of each building in accordance with the heating area served. The manual balancing valves are set at the beginning of the heating season according to the estimated flow and differential pressure across the controlled loop. After initial commissioning is finalized, the setting values of these manual balancing valves are kept for the whole heating season, except for minor adjustments.

In this high-rise building, each floor had the same heating area. The instantaneous volume flows per square metre along one of vertical supply risers were measured by using a hand-held ultrasonic flow meter. The volume flows along the risers were measured on the 1st, 6th, and 13th floors and on the 14th, 18th, and 20th floors, as shown in Figure 3. The results show how the volume flow per square metre decreased along the supply water direction.
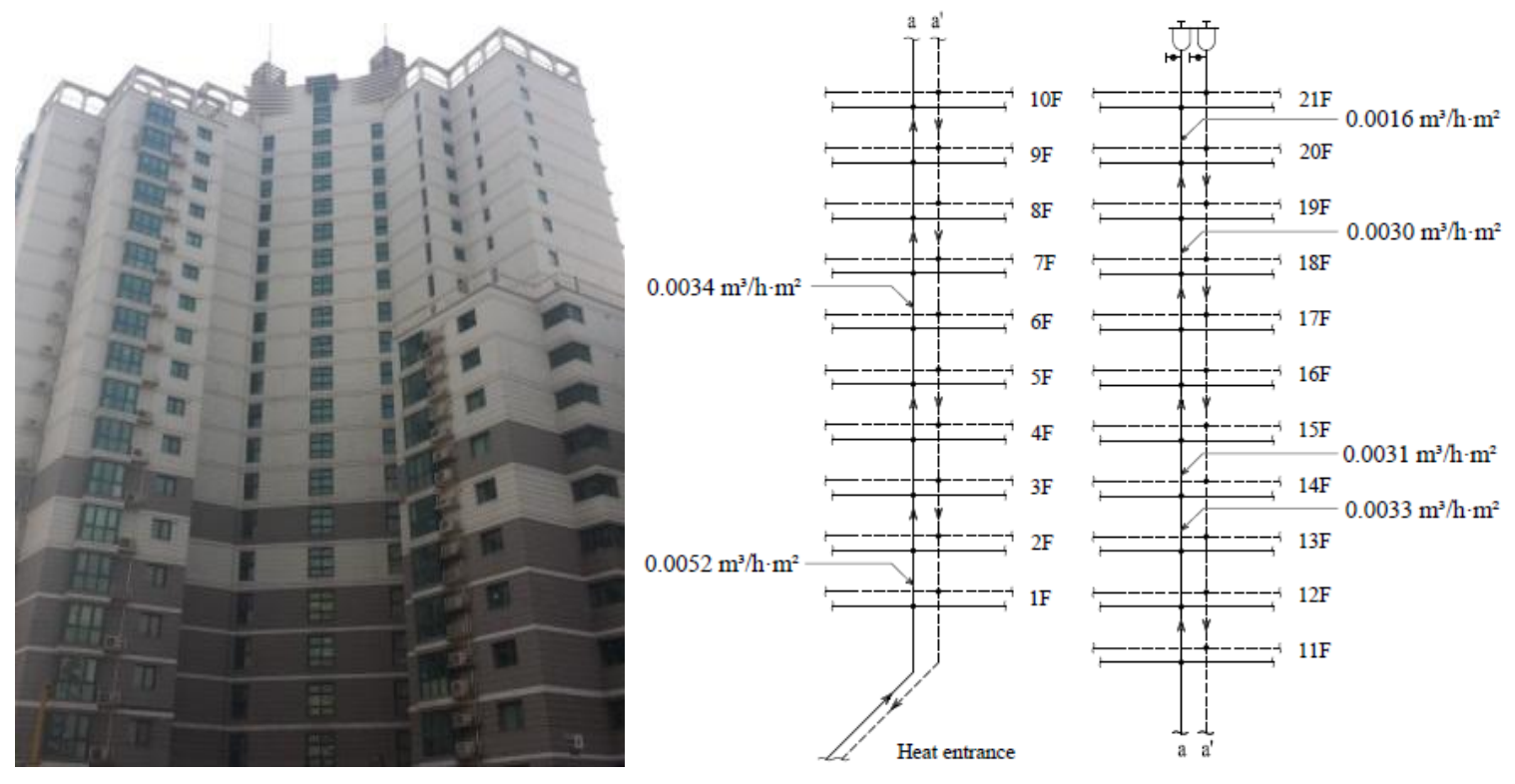

Figure 3. Flow measurement of a high-rise building in Beijing 
The top floor should have a higher heat demand because of its larger exterior surface, but in reality, it was supplied with the least volume flow. Even though the volume flow per square metre on the top floor was less than $1 / 3^{\text {rd }}$ that of the first floor, few thermal comfort complaints were reported. As a complaint over the phone is the most common way for Chinese heat consumers to inform the DH utilities about the heat effects, it can therefore be assumed that the floors below the top floor were receiving a higher volume flow than they actually required. These floors would be overheated. This case illustrates the excess heat supply caused by hydraulic imbalance in a building heating network where no flow control devices were used.

\subsubsection{Case-Harbin: Overheated rooms and excess heat supply}

To understand the relation between the overheated rooms and excess heat supply, the data from one of the area-substations of Case-Harbin were obtained. The data included the supply and return temperatures of the area substation and the corresponding outdoor temperatures. The data covered the entire heating period from 20 October 2013 to 20 April 2014. This area substation supplied heat to 14 multi-storey buildings with a heating area of $124,150 \mathrm{~m}^{2}$.

The control situation in this case was that no indoor temperature control devices were applied in the SH system. In addition, automatic weather compensation control was not available at the substation, and the system was operating under constant flow rate. The secondary supply temperature was manually adjusted based on the average daily outdoor temperatures from metrological data and past years' experience in relation to the level of complaints from heat consumers.

The data presented in Figure 4 reveals the relationship between the supply temperature and outdoor air temperature being scattered when the manual control was applied. For the same outdoor temperature, the temperature differences between supply and return varied a lot.

According to the records of the DH utility, very few complaints were received from the occupants during the heating period, and this implies that most consumers had room temperatures above $18{ }^{\circ} \mathrm{C}$. This also implies that, for a given outdoor temperature, the lowest temperature difference has met the heat demand. All other temperature differences higher than the lowest values imply the buildings were overheated, since the constant flow principle was being applied in the secondary DH network. All heat supplied in excess of the lowest value can be regarded as heat loss due to excess heat supply. Due to the lack of the individual control for the indoor terminal heat units, overheated rooms inevitably leads to window opening, which also explains why several different temperature differences exist under the same outdoor temperature. 


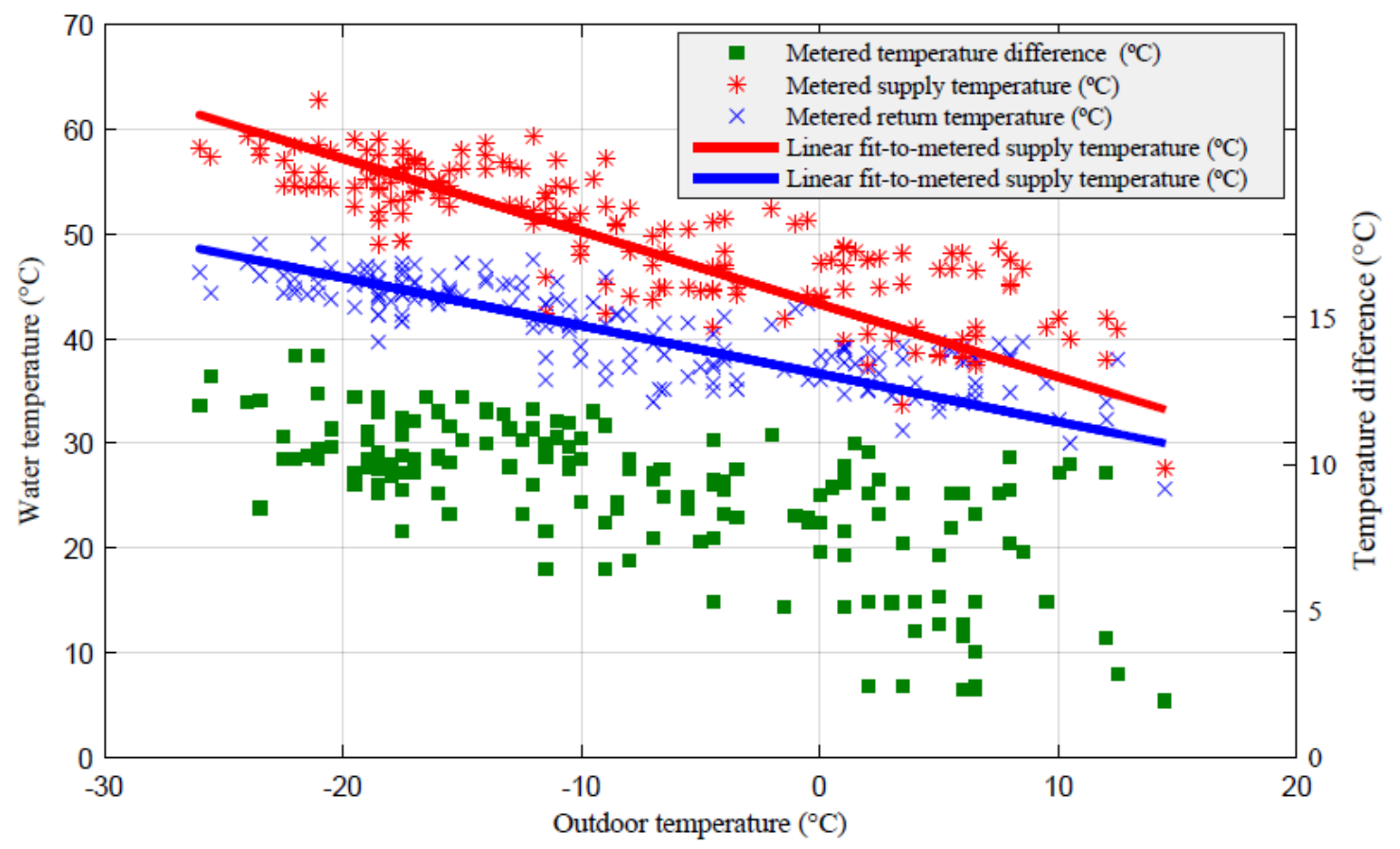

Figure 4. Supply and return temperatures of a substation in Case-Harbin during the 2013-2014 heating period

\subsection{The proposed approach}

To reduce the excess heat supply, an integrated approach was introduced that included the control devices: TRVs with pre-setting function, and automatic balancing valves. The $\mathrm{SH}$ systems considered in this paper are two-pipe radiator systems, and all the apartments have their own heating loops. A schematic configuration of the apartment heating loop applied in the integrated approach is illustrated in Figure 5. The number of the radiator might be different based on the particular apartment.

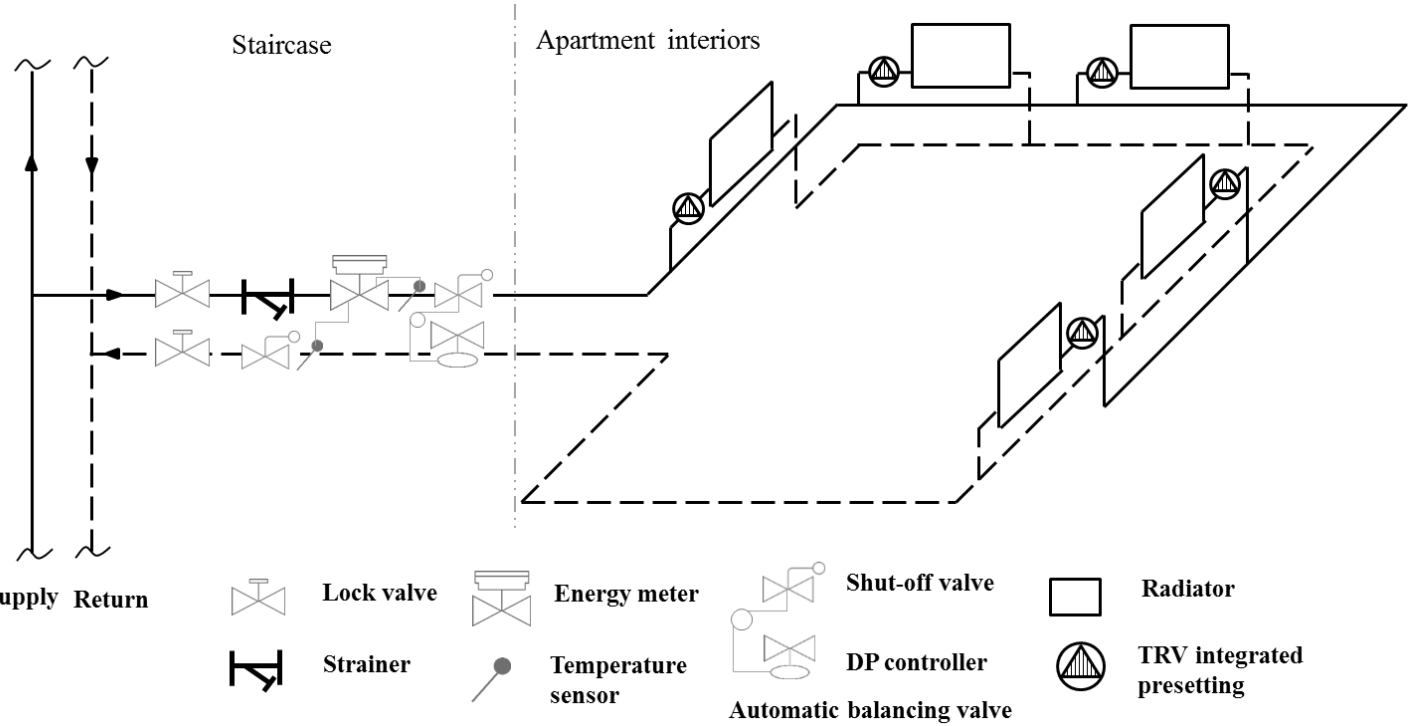


Figure 5. Schematic configuration of the apartment heating loop

TRVs consist of a thermostat and a radiator valve. The radiator valve is a flow control device. The degree of valve opening determines how much water flows through the valve into the radiator. This is controlled by the thermostat, which reacts to changes in room temperature.

The radiator valve with integrated pre-setting is a flow-limiting device that is fitted into the valve body to pre-set the maximum water flow through the radiator. The pre-setting values correspond to the scales marked on the radiator valve and the range is from 1 to 7 and $\mathrm{N}$, which represent gradually increasing maximum flow limits [38], see Figure 6. The pre-setting values can be set in accordance with the requested design flow through the radiator and the pressure drop across the valve. To ensure the optimal regulation of the radiator valve and quiet operation, it is important to achieve the desired differential pressure across the valve. According to EN 215 [25], a differential pressure setting of $10 \mathrm{kPa}$ is commonly used for radiator applications. Automatic balancing valves were therefore also applied in this approach to ensure the optimum operation of the radiator valve.
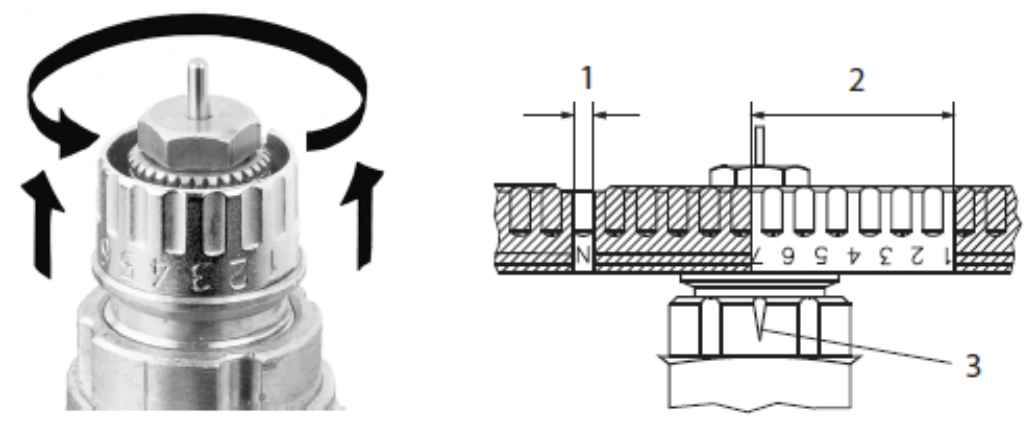

1. Factory setting

2. Presetting range

3. Reference mark

Figure 6. Pre-setting scales of radiator valve [38]

Automatic balancing valves consist of a self-acting differential pressure (DP) controller and an associated partner valve. The valves are linked to each other by a capillary tube. In this case, the partner valve was designed to shut off the pipe flow, and the DP controller was designed to maintain a constant differential pressure across a loop. The constant differential pressure across the controlled loop protects downstream control valves from excess pressures and offsets the effects of pressure variations caused by the movement of the control valves in other branches. By installing automatic balancing valves, all the controlled loops become pressure-independent zones [39]. This eliminates any problems caused by high or excess system pressures, including noise from the valves and poor control of room temperature.

Pre-setting radiator valves combined with automatic balancing valves equalize the flow distribution among the radiators and establish hydraulic balance at peak load. The thermostat function stabilizes the indoor temperature with regard to weather variations and free heat gains. By moving the system from centrally planned heat delivery to demand-driven heat delivery, the excess heat supply can be reduced, which can consequently reduce the energy consumption of Chinese DH systems and lead to positive environmental impacts. 


\subsection{Verification of the proposed approach}

The technical feasibility of this approach and the improvements in indoor temperature control were verified by means of a field test (Case-Beijing-B) and building simulation software IDA Indoor Climate and Energy (IDA-ICE) 4.6.2 [37].

\subsubsection{Field test in Beijing for flow control}

The basic idea of the field test was to examine the flow control effect of using the radiator valve in combination with automatic balancing valves. With these two devices, the hydraulic balance is established and the flow distributed to each radiator can be controlled around the design value.

\section{3.1.1 Configuration of the field test}

This field test (Case-Beijing-B) was carried out in a new 18-storey high-rise residential building in Beijing, which is structurally similar to Case-Beijing-A. The building's appearance is shown in

Figure 7 (left). The heating installation configuration for each apartment is illustrated in

Figure 7 (right). Details of the devices used are listed in Table 1. It should be mentioned that the radiator valves and the automatic balancing valves either need to be pre-set, or set during commissioning when the heating season starts, so that the radiators can achieve the required design flow under peak load. The set values of these two devices would be kept throughout the heating season or slightly adjusted if necessary. This field test focuses on the flow control effect of using these two devices, so the thermostats were removed for the experiment. In addition, automatic weather compensation control was applied at substation level for Case-Beijing-B to control the supply temperature, and variable speed pumps were available on the secondary-side of this DH system.

Table 1. Details of the relevant devices installed in tested apartment

\begin{tabular}{llll}
\hline \multicolumn{2}{c}{ Device name } & \multicolumn{1}{c}{ Type } & Dimension \\
\hline Radiator valve & & RA-N[21] & DN15 (mm) \\
Auto balancing & \multicolumn{1}{c}{ DP controller } & ASV-PV[23] & DN20 (mm) \\
valves & \multicolumn{1}{c}{ Partner valve } & ASV-M[23] & DN20 (mm) \\
Ultrasonic energy meter & SONOMETER 1100[24] & DN20 (mm) \\
\hline
\end{tabular}

The radiator valves were mounted on the radiator pipework. All the other devices mentioned above were installed in the staircase/hall (see

Figure 7 (right)), which was the location of the heat entry point for the apartment heating systems. 


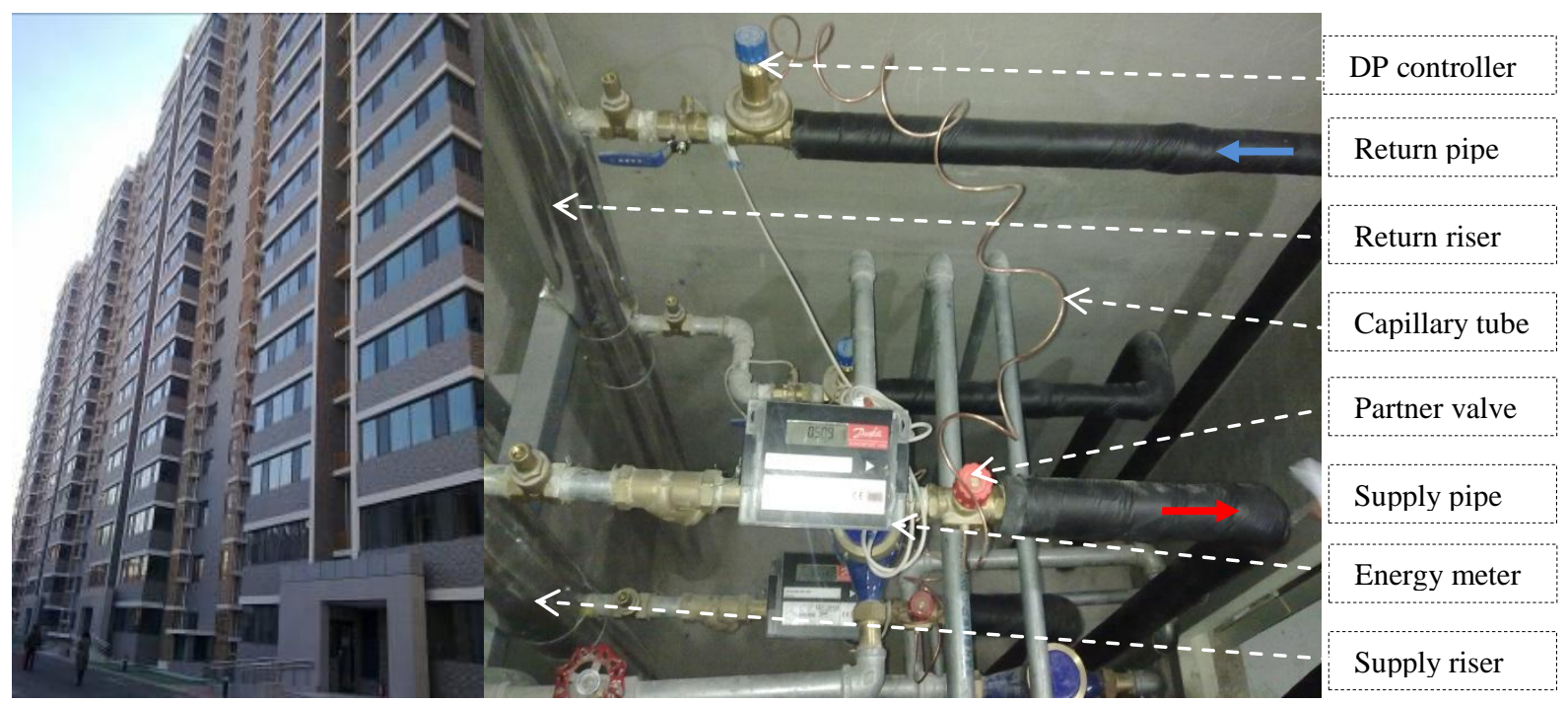

Figure 7. Real test case for the flow control approach

\section{3.1.2 Implementation of the field test}

The field test consisted of two parts: Test I considered three apartments as test objects and focused on the pressure control function of the DP controller. Test II considered one apartment as the test object and focused on the flow limitation function of the radiator valve pre-setting function. Throughout the test, the other apartments' heating systems in this building were operating normally.

In Test I, three apartments with identical heating areas were chosen as the test objects. They were located on the right-hand side of the $2^{\text {nd }}$ floor (201), the left-hand side of the $2^{\text {nd }}$ floor (202), and the right-hand side of the $17^{\text {th }}$ floor (1701). During the test, all the radiator valves were pre-set to $\mathrm{N}$, i.e. the radiator valves were fully open.

The apartment loop flows were measured for apartments 201, 202, and 1701 when the DP controllers were in turn set at $5,10,15,20$, and $25 \mathrm{kPa}$. The ultrasonic energy meter of each apartment was used to measure the flow and investigate: 1) the hydraulic situation along the vertical pipe; 2) the flow changes in one apartment loop resulting from changing the set points of the DP controller at random or completely shutting off the loop flow of the other two apartments.

In Test II, one of the apartments was chosen as the test object. The aim of Test II was to investigate how the pre-setting function of the radiator valve controls the flow rate of the heating system. This apartment had five rooms with their own radiators and was located on the $2^{\text {nd }}$ floor. Basic data about the apartment are given in Table 2. Each radiator was equipped with a radiator valve with pre-setting function. Test II was performed with the DP controller set at $10 \mathrm{kPa}$ in accordance with EN 215 [25]. The design parameters of this heating system (supply/return/indoor temperature) were $75 / 60 / 18{ }^{\circ} \mathrm{C}$. The design flow for each radiator could therefore be calculated and is given in Table 2. Based on the pressure drop of the heating loop and the design flow of the radiator, the pre-set scales of the radiator valve were determined and are listed in Table 2 . The 
schematic configuration of the apartment-heating loop is illustrated in Figure 5. A Testo 925 [40] was used for measuring the indoor temperature.

Table 2. Basic information about the apartment tested

\begin{tabular}{llllll}
\hline Room name & $\begin{array}{l}\text { Floor area } \\
\left(\mathrm{m}^{2}\right)\end{array}$ & Heat load $(\mathrm{W})$ & $\begin{array}{l}\text { Desired operating } \\
\text { temperature } \\
\text { difference }\left({ }^{\circ} \mathrm{C}\right)\end{array}$ & $\begin{array}{l}\text { Desired flow } \\
(\mathrm{l} / \mathrm{h})\end{array}$ & $\begin{array}{l}\text { Pre-set values } \\
\text { of the radiator } \\
\text { valve }\end{array}$ \\
\hline Living Room & 18 & 810 & 15 & 46.4 & 3 \\
Bedroom A & 14.5 & 654 & 15 & 37.5 & 2.5 \\
Bedroom B & 8.7 & 391 & 15 & 22.5 & 1.5 \\
Bathroom & 3.4 & 168 & 15 & 9.6 & 1 \\
Kitchen & 4 & 180 & 15 & 10.3 & 1 \\
Total & 48.6 & 2203 & & 126 & \\
\hline
\end{tabular}

\subsubsection{IDA-ICE simulation for indoor temperature control}

For the indoor temperature control investigation, a simulation model of an eight-storey residential building was developed using IDA-ICE 4.2.6 [37]. To develop this building model, the building layout and building materials of one of the buildings in Case-Harbin were used. The building envelope properties and the thermal characteristics were as specified in China's energy conservation design standard JGJ26-95 [41]. One of the apartments was modelled as a multi-zone model. Each room in the apartment was a separate zone. The room height was $2.7 \mathrm{~m}$. This multizone model contained five heated zone areas: Bedroom N (north), Bathroom, Bedroom S (south), Kitchen, and Living Room, as well as three non-heated balconies and a non-heated staircase/hall (see Figure 8). The outdoor heating design temperature was $-26^{\circ} \mathrm{C}$ for Harbin and the indoor design room temperature was $18{ }^{\circ} \mathrm{C}$. Based on the information, we run the multi-zone model equipped with ideal radiators, and obtained the peak heat load of each zone. 


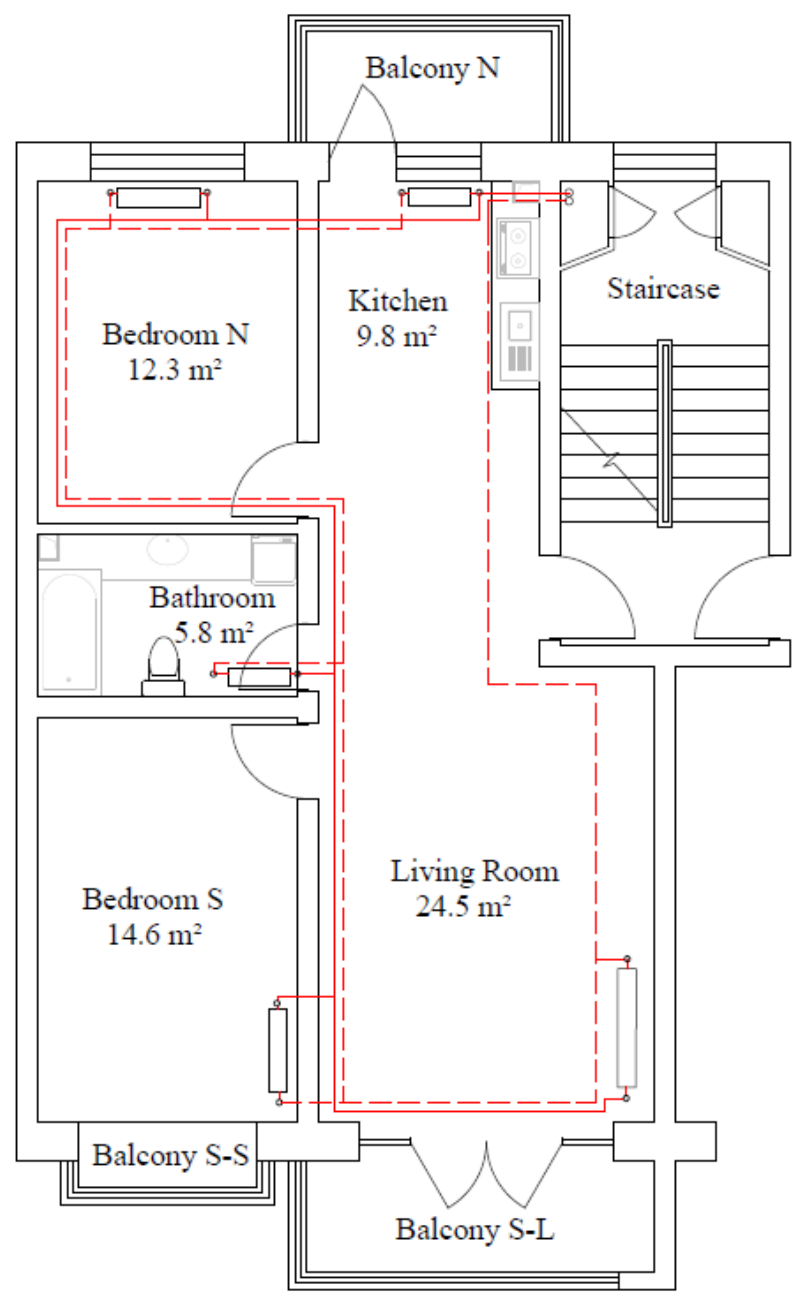

Figure 8. Multi-zone model

We dimensioned the radiators in accordance with Chinese standard [10]. In each zone, an M132type radiator [42] was modelled as the room heating unit as in Case-Harbin. The design parameters of the SH system were the same as those for Case-Harbin: 80/60/18 ${ }^{\circ} \mathrm{C}$ (supply/return/indoor air temperatures). Correction factors were derived to correct for the actual output of each radiator. Accordingly, the maximum power of each radiator was determined, and the design flow limitation through the radiators and the design heat load for the SH system were defined.

Linear fit-to-metered supply temperatures were chosen in relationship to the outdoor temperatures shown in Figure 4. Here the secondary supply temperature is assumed to have been optimized by applying the weather compensation control at the substation and variable speed pumps in the secondary network of this system. To reflect the real conditions, an internal heat gain of $5.0 \mathrm{~W} / \mathrm{m}^{2}$ was considered [41]. Real weather data in Harbin city in 2014 was used to estimate the energy consumption for heating using EnergyPlus [43]. Two scenarios were considered: 1) without TRVs fitted to the radiators, which is the most common situation in Chinese SH systems; and 2) with TRVs fitted to the radiators to adjust the indoor temperature by setting the thermostat of the 
TRVs. The room temperature of each zone, the energy consumption including heat consumption, and the electricity consumption of the pumps as well as the volume flow of the heating system were all compared based on the simulation results.

\section{Results and Discussion}

\subsection{Field test in Beijing}

\subsubsection{Test I: Differential pressure control of the apartment heating loop}

The test objects for Test I were three apartments 201, 202, and 1701.

The first aim of the investigation was to test whether the three test heating loops had the same distributed flow when the set points of the DP controllers were the same. The measurement results are shown in Figure 9. When the DP controllers of the three apartments loop were given the same set point (separately set at 5,10,15,20, and $25 \mathrm{kPa}$ ), the three loops had a similar volume flow as expected. The deviation of the individual loop flow from the average flow of these three loops at the same set points was within $\pm 15 \%$ (see Figure 9). This deviation can be considered as acceptable, because the set points of the DP controllers were adjusted by manually turning the spindle and there were no pressure gauges in the supply and return pipes to measure the pressure drop of the loops directly. Moreover, mechanical hysteresis influences the variations and causes a difference in the measured flow rates. The $2^{\text {nd }}$ floor and $17^{\text {th }}$ floor have identical floor heating areas, so theoretically the distributed flow could be the same. It can therefore be concluded that the hydraulic imbalance along the vertical riser was reduced after the installation of the DP controllers.

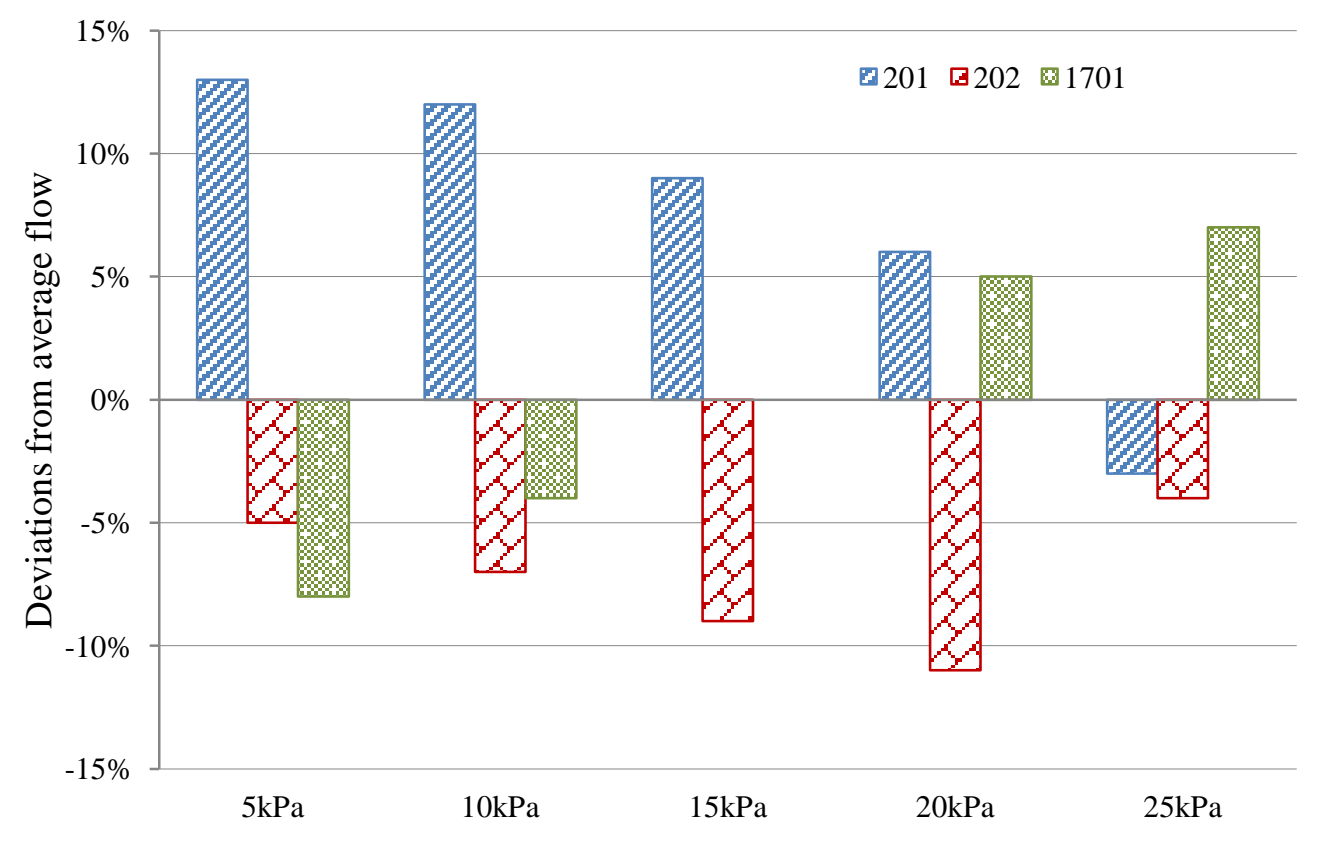

Figure 9. Deviations from the average flows of 201, 202, and 1701 at various set values of the DP controllers

The second aim of Test I was to test whether one of the heating loops was pressure-independent 
when the differential pressure of the other two heating loops changed. The results show that when the differential pressure of the other two tested heating loops was changed by adjusting the set points of the DP controllers or by completely shutting off the loops, the other apartments' heating systems kept operating normally and the flow of the third tested loop was not influenced or changed. This means that the automatic balancing valves were able to separate each heating loop as an independent pressure zone, and maintain the constant differential pressure in the controlled loop. It also implies that the DP controller controls the differential pressure across the controlled loop, which will ensure an optimal differential pressure across the downstream control valves. In this way, the flow within the controlled loop would not be affected by any system load changes, and noise would be avoided.

\subsubsection{Test II: The pre-setting function of the radiator valves}

For Test II, the test object was one apartment.

The apartment loop's mass flow, the supply and return temperatures, and the indoor temperature were measured with the set point of the DP controller at $10 \mathrm{kPa}$. The measurements were first carried out without radiator valves pre-set, and after that with them all pre-set. The mass flow measurement results (see Table 3) showed that after the radiator valves were pre-set, the total flow supplied to the apartment was reduced to $1 / 3$, from $5571 / \mathrm{h}$ with no pre-setting to $181 \mathrm{l} / \mathrm{h}$ with pre-set. This implies that the flow rate through each radiator was limited dramatically by the presetting function. The flow rate in the case of pre-setting was close to the design flow rate of 126 $1 / \mathrm{h}$. This indicates that flow control by pre-setting the radiator valves on the terminal heat units is effective. The temperature measurement results showed that the temperature difference of the controlled loop increased by nearly $100 \%$ with the radiator valves pre-set, changing from $9{ }^{\circ} \mathrm{C}$ to $17.3^{\circ} \mathrm{C}$. Test II focused on the hydraulic control effect of pre-setting the radiator valves. The results clearly show that the large flow and small temperature difference problem which is typical in Chinese DH systems has been significantly relieved. This is the most important result that the test aimed to get. It also reflects the great energy-saving potential if the excess flow can be controlled.

In addition, at the start of the test, when there was no pre-setting of the radiator valves, the room temperature was $22.6^{\circ} \mathrm{C}$ (see Table 3), with heating power of $5.8 \mathrm{~kW}$. The design capacity is 2.2 $\mathrm{kW}$ for $-9^{\circ} \mathrm{C}$ outdoor air temperature. Due to lack of individual controls, the tenants regulate the room temperature by opening windows, which explains why the room temperature was no higher. After the pre-setting of the radiator valves, the delivered capacity was $3.6 \mathrm{~kW}$ and the room temperature went down to $22^{\circ} \mathrm{C}$ within two hours. A further decrease might be expected, but the $3.6 \mathrm{~kW}$ would be more than enough to sustain $18^{\circ} \mathrm{C}$ room temperature, seen in relation to the design capacity.

Table 3. Temperature measurement comparison between with and without pre-setting in Test II

\begin{tabular}{lll}
\hline Parameter of tested apartment loop & No pre-setting & Pre-setting \\
\hline Total flow of apartment loop $(\mathrm{l} / \mathrm{h})$ & 557 & 181 \\
Supply temperature $\left({ }^{\circ} \mathrm{C}\right)$ & 62.6 & 62 \\
Return temperature $\left({ }^{\circ} \mathrm{C}\right)$ & 53.6 & 44.7 \\
Delta $\mathrm{T}\left({ }^{\circ} \mathrm{C}\right)$ & 9 & 17.3
\end{tabular}




\begin{tabular}{lll} 
Average indoor temperature $\left({ }^{\circ} \mathrm{C}\right)$ & 22.6 & 22 \\
Outdoor temperature $\left({ }^{\circ} \mathrm{C}\right)$ & -4 & -4 \\
\hline
\end{tabular}

The field test showed that pre-setting radiator valves combined with the automatic balancing valves could control the loop flow close to the design level. Within the apartment loop, presetting the radiator valves limited the maximum flow of each radiator and created the right balance among the radiators. Flow limitation for each terminal heat unit prevented insufficient flow at distal units and excess flow at proximal ones. It reduces the total supplied flow and consequently the pump electricity consumption.

The differential pressure limitation of the automatic balancing valves provided the appropriate pressure drop over the radiator valves. The hydraulic imbalance along the vertical riser was reduced, and it guaranteed to set the thermostat properly to adjust the indoor temperature. At the same time, the noise from the radiator valves was avoided. Further adjustments of the room temperature towards the desired temperature could be achieved by adding a thermostat to the radiator valve, which would adjust the valve depending on the deviation from the set-point temperature of the TRVs.

In this field test, a dynamic hydraulic balance was created in the heating system by using pre-set radiator valves combined with automatic balancing valves. Every loop received the required flow and excess flow and insufficient flow were avoided. Every room received the required heat. Flow limitation improved the efficiency of the pump, and increased the temperature drop across the radiator. This field test indicates that the excess heat loss can be reduced through establishing dynamic hydraulic balancing in the building heating system.

\subsection{IDA-ICE simulation}

\subsubsection{Model validation}

The radiator heating system in the multi-zone model was designed in accordance with the Chinese design standard. The "linear fit-to-metered supply temperature" from CASE-Harbin (see Figure 4) defined the supply temperatures of the simulated heating system during the heating period. As shown in Figure 10 , the simulated return temperatures were compared with the linear fit-to-metered return temperatures from Case-Harbin. The results show that the deviation between the simulation results and the linear fit-to-return temperatures from Case-Harbin was on average about $2{ }^{\circ} \mathrm{C}$. It should be mentioned that the measurements from Case-Harbin were acquired at the area substation and were the average return temperatures from all the connected buildings. The deviation between the model outputs and the measured return temperatures were therefore considered to be acceptable and the model was considered valid. 


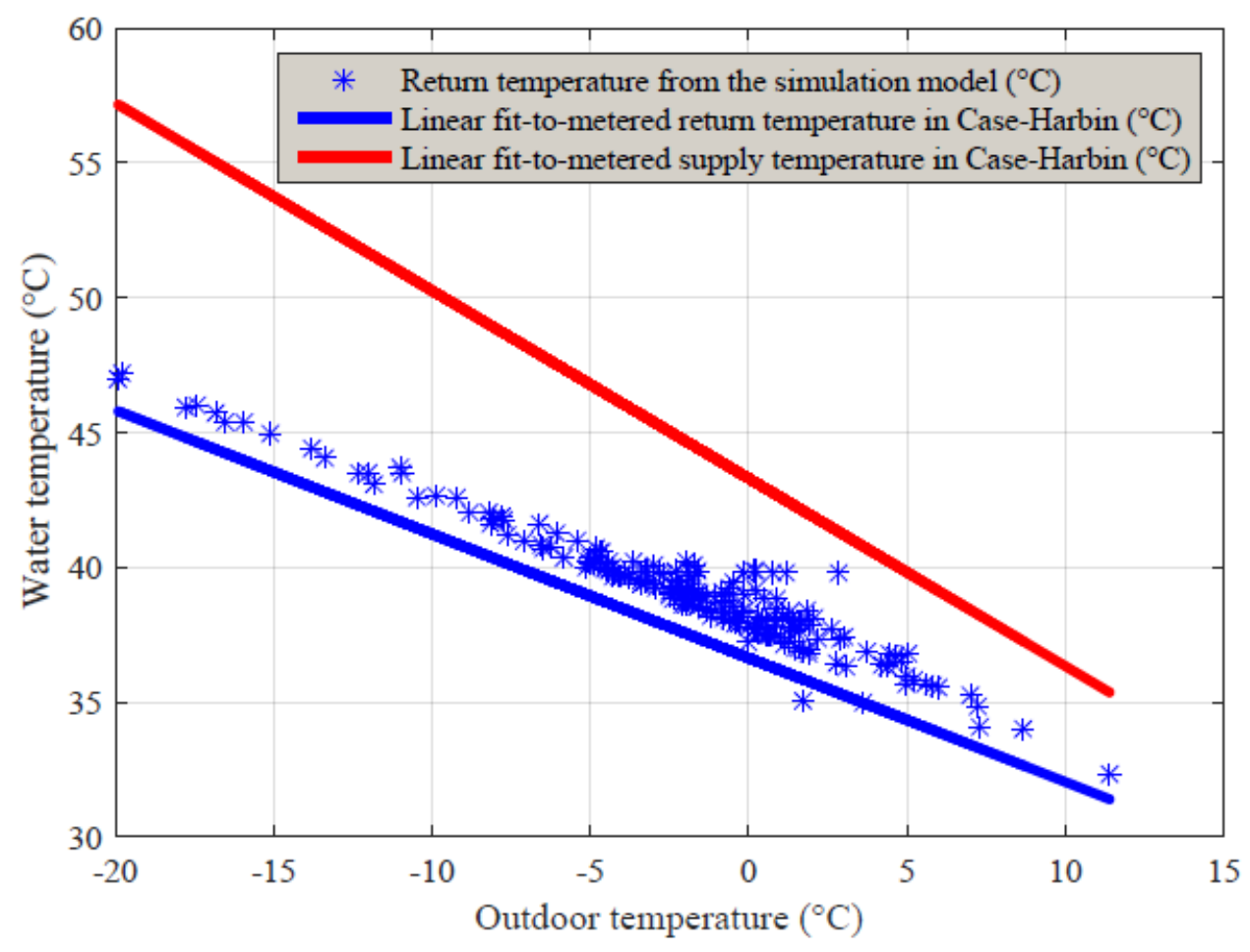

Figure 10. Supply and return temperatures for the model of the SH system

\subsubsection{IDA-ICE simulation results}

A simulation was carried out for the heating period in Harbin for two scenarios: radiators without TRVs and with TRVs. Several factors were considered in the simulation: room temperatures, heat consumption, pump electricity consumption, and the flow rate in the heating system.

Firstly, in terms of the room temperatures, the general results showed that without TRVs the room temperatures in all the zones were much higher than $18^{\circ} \mathrm{C}$ except for a few hours at the beginning of the heating period. The average room temperatures in all five zones over the entire heating period were around $22^{\circ} \mathrm{C}$. With TRV control, the room temperatures in all the zones were constant at around $18{ }^{\circ} \mathrm{C}$. There are some minor deviations between the set temperature and the simulated room temperature, due to the $0.5^{\circ} \mathrm{C}$ proportional band (P-band). Because TRVs are proportional temperature controllers, they respond to any deviation from the set temperature by increasing or decreasing the flow into the radiators until the required room temperature is achieved. Figure 11 shows the simulation results for two typical rooms in the multi-zone model: the northern room 'Bedroom N' and the largest room the 'Living Room', which reflects these small variations particularly clearly. The indoor air temperature can also be seen to have lagged a few days behind outdoor temperatures changes because of the thermal inertia of the building envelope materials. 


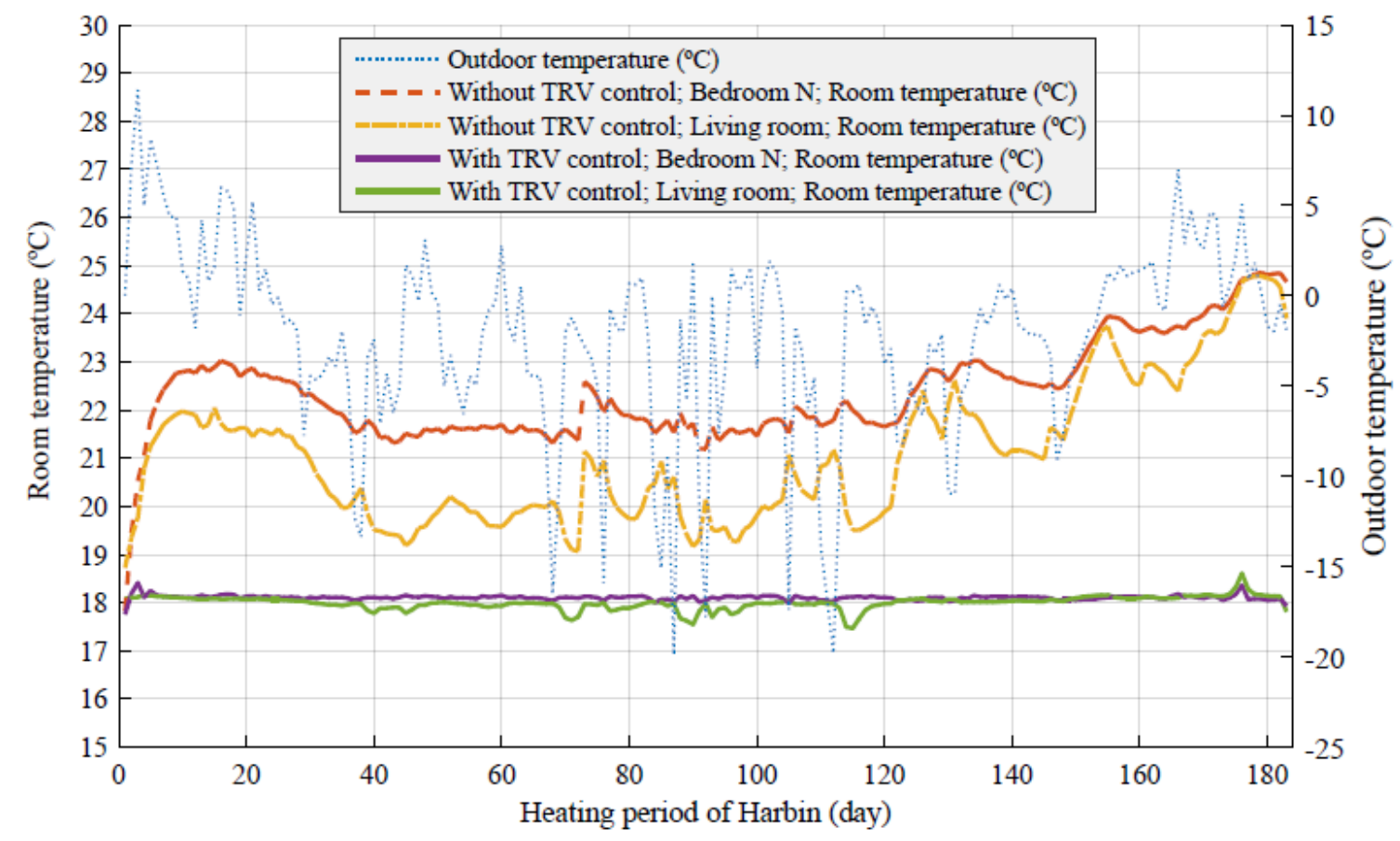

Figure 11. Zone room temperature of Bedroom $N$ and the Living Room during the heating period

As shown in the simulation results, the application of TRVs provides the practical possibility for the room occupants to adjust the room temperature. When the rooms are overheated, the indoor temperature can be adjusted by setting the thermostat rather than opening the windows. Thermal comfort can imply multiple factors like indoor temperature, humidity, and draught [44]. But in the heating supply context, thermal comfort mainly refers to the indoor room temperature. In an unbalanced system, the thermal discomfort means excess heating for users close to the substation and insufficient heating for users far away from the substation. Through the implementation of the technical approach presented here, the indoor temperatures for rooms in different locations are balanced and close to the design room temperatures. We therefore conclude that the indoor thermal comfort is improved.

Correct use of TVRs has the potential to achieve great energy-saving effects. In some cases, heat consumers might not know how to use the TRVs correctly and might simply use the maximum set point, which will compromise the energy savings potential. The set points can be protected and locked by inserting the pins on the dial, and an energy-saving type of TRV can be used with a maximum set point of $20^{\circ} \mathrm{C}$ [45].

Secondly, the monthly heat consumption and pump electricity consumption were compared for the two scenarios, and the results are shown in Figure 12. Since the heating season is fixed in Harbin city and does not include May to September, no data were collected for those months. In terms of annual energy consumption, which was obtained by accumulating the monthly energy consumption over the heating season, the results imply that applying TRVs can reduce annual 
heat consumption by $17 \%$ and annual pump electricity consumption by $42.8 \%$ for this particular apartment. Here it should be noted that the pump energy consumption is very small compared to the heating energy consumption, only $0.1 \%$ of the heat energy delivered.

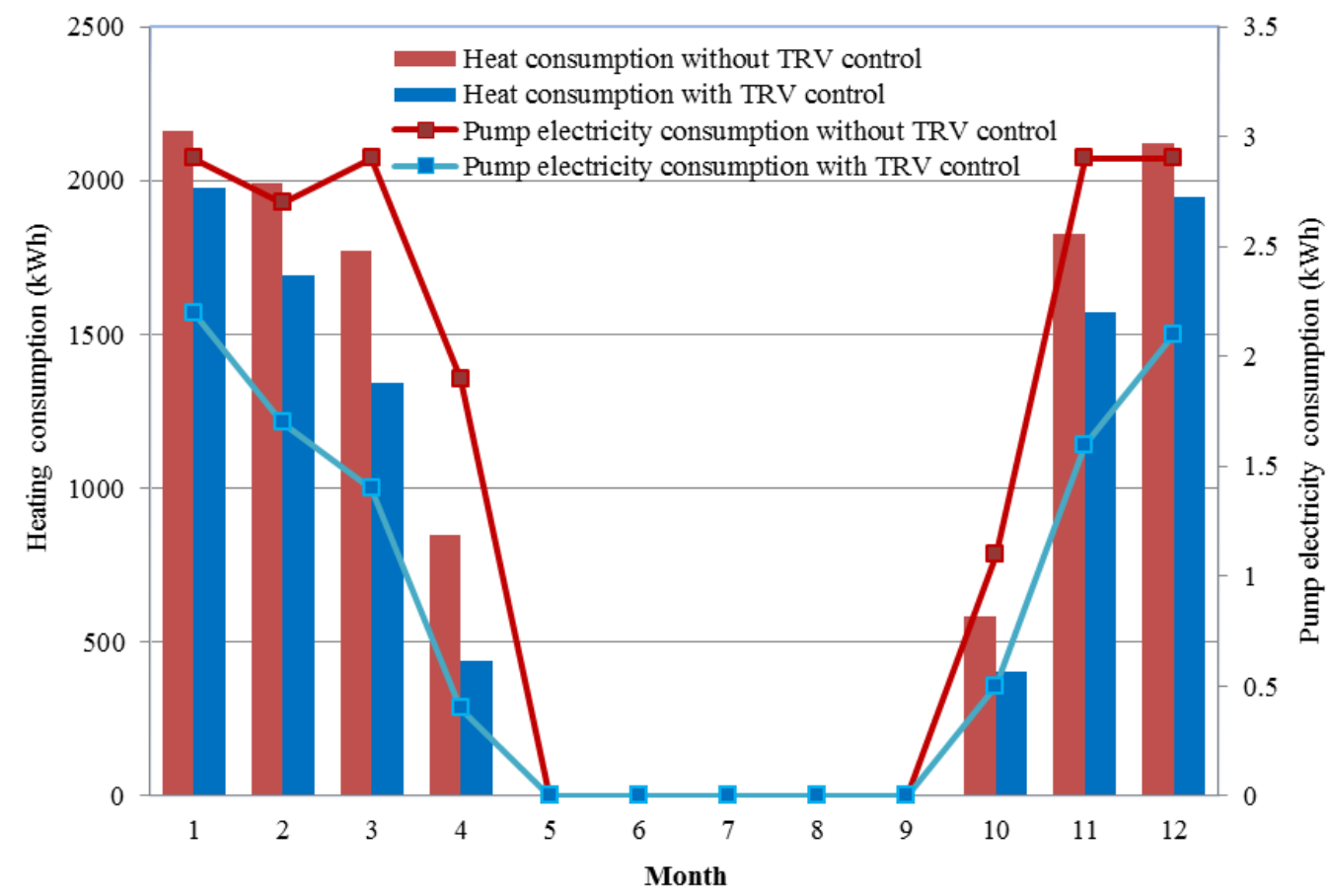

Figure 12. Heat consumption comparison between the scenarios with and without TRV control

Coal is the dominant DH fuel, and the dominant fuel for Chinese power plants. Burning coal is one of the main causes of air pollution in China [46]. Hydraulic balance can achieve $17 \%$ heat savings and $42.8 \%$ pump electricity savings. This will result in positive environmental impacts. In Case-Harbin, the total heating area in 2013-2014 heating season was $442,340 \mathrm{~m}^{2}$. The measured seasonal heat consumption per $\mathrm{m}^{2}$ was $0.7 \mathrm{GJ} / \mathrm{m}^{2}$, and the seasonal pump electricity consumption was $2.1 \mathrm{kWh} / \mathrm{m}^{2}$. This reflects the currently unbalanced system situation. With hydraulic balance, the simulation results show that the seasonal heat consumption could be reduced by $0.12 \mathrm{GJ} / \mathrm{m}^{2}$, and the seasonal pump electricity consumption could be reduced by $0.9 \mathrm{kWh} / \mathrm{m}^{2}$. The results imply that the total emission reduction for Case-Harbin could have been 4837 ton of $\mathrm{CO}_{2}, 44.7$ tons of $\mathrm{SO}_{2}$, and 13 tons of $\mathrm{NO}_{\mathrm{x}}$ in the 2013-2014 heating season if hydraulic balance had been achieved. Therefore, the seasonal environmental impacts would reflect the reduction of $11 \mathrm{~kg} \mathrm{CO}_{2}$, $0.1 \mathrm{~g} \mathrm{SO}_{2}$, and $0.03 \mathrm{~g} \mathrm{NO}_{\mathrm{x}}$ per heating square metre.

Moreover, with regard to the system's operation, it is important to note that applying TRVs changes the SH system from constant flow to variable flow (see Figure 13). 


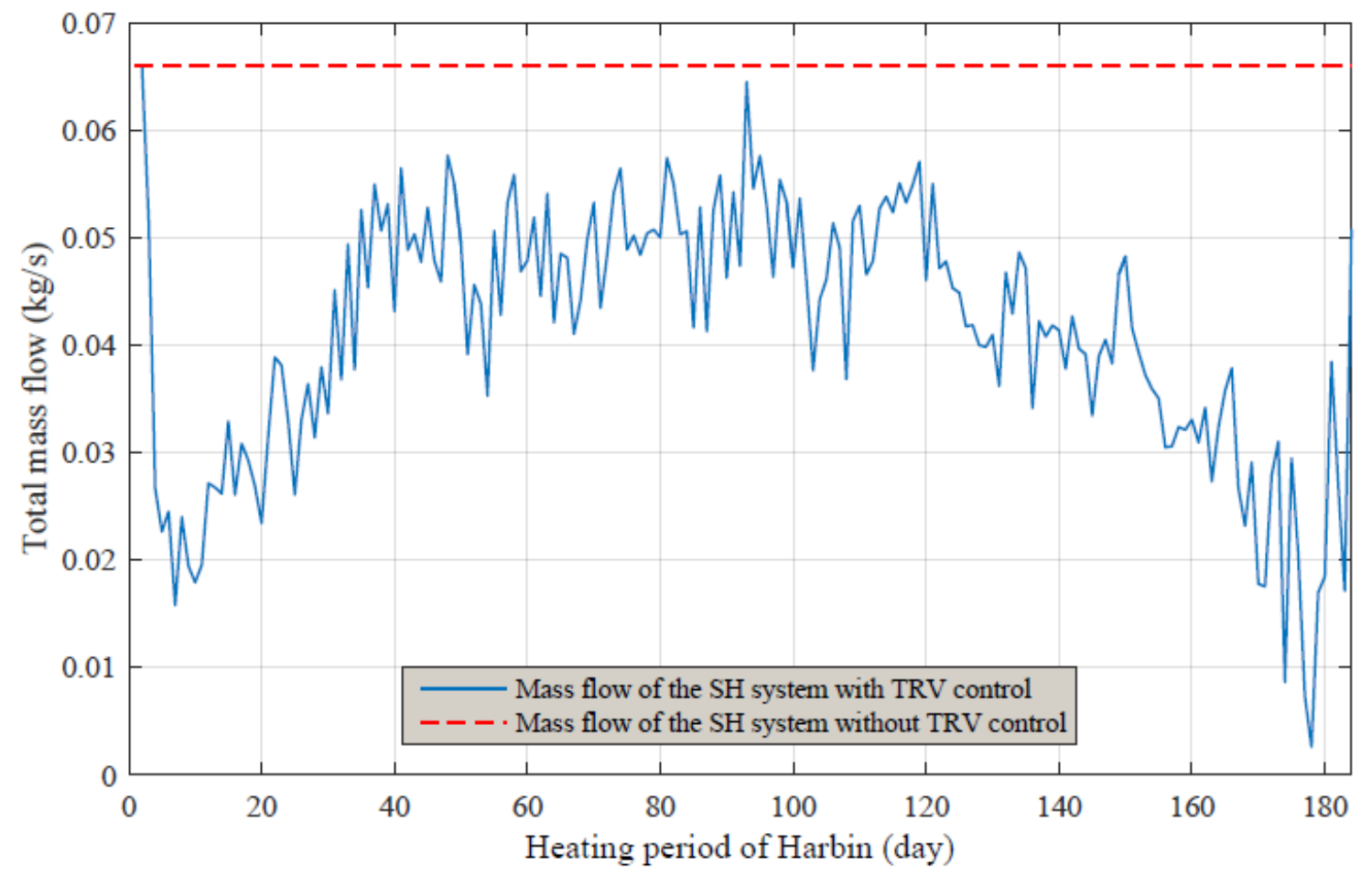

Figure 13. Total mass flow comparison between scenarios with and without TRV control

According to the results from the field test and the IDA-ICE simulation, the excess heat loss can be reduced by achieving hydraulic balance and optimizing indoor air temperature control at the building level.

In this study, the research object was the building heating system. Energy reduction at the building level will inevitably impact the whole DH system, reducing the amount of heat that areasubstations have to deliver to a group of buildings and that the heat source plants have to deliver to the area-substations.

Dynamic hydraulic balancing ensures the apartment heating loops distribute the requested flow, with neither excess flow nor inadequate flow. Moreover, it means that the apartment heating loops are not influenced by each other if adjustments are made. Temperature control stabilizes the room temperature at comfort levels and avoids the room overheating. The integrated technical approach therefore reduces excess heat supply and excess heat loss. This means lower fuel consumption and less polluting emissions due to the fossil fuels heavily used in China. The economic benefits and environmental effects achieved will be considerable.

In the future, along with the energy consumption reduction in space heating systems, it is expected that Chinese DH systems will transition from the current centrally planned heat supply to demand-driven heat generation, which will also give increased comfort for users. In addition to this improvement in quality of life, DHW could also be integrated into DH systems to supply hot water in the future. This would be possible because the reduction in excess heat supply will result in large energy savings. 
The high building density in Chinese' cities and the continuously expanding heating areas with rapid urbanization mean that there will be significant heat demands that need to be fulfilled. This emphasizes the significance of the kind of reductions in energy consumption in Chinese DH systems discussed in this paper.

\section{Conclusions}

To conclude, the proposed approach of combining the use of TRVs with an integrated pre-setting function and automatic balancing valves has been shown to be both feasible and effective in practice.

Firstly, a field test showed that pre-setting radiator valves combined with automatic balancing valves can establish dynamic hydraulic balance in a building heating system. Each controlled loop becomes an independent zone. The pre-setting of the radiator valve is an important function to equalize the flow distribution among the terminal heating units. Moreover, automatic balancing valves enable the radiator valves to work at optimum differential pressure level. As a result, the problems of excess flow and insufficient flow are avoided in the heating system. At the same time, the return temperature was decreased, and the temperature drop across the radiator was increased.

Secondly, IDA-ICE simulation results indicate that TRVs stabilize the room temperature. Wide use of TRVs in Chinese buildings can reduce heat consumption by $17 \%$ and pump electricity consumption by $42.8 \%$, compared to a scenario without TRV control. In addition, adjusting TRVs transform the system from constant flow to variable flow. Variable speed pumps can be applied with variable flow rate. As coal is the dominant fuel for DH plants and power plants in China, the savings on both heat consumption and pump electricity consumption imply the positive environmental impacts.

Traditional Chinese DH systems seldom have control at the consumer end. By moving the control close to the end users, it is possible to bring the heating supply into line with the heating demand. The integrated assessment method and field test show that a well-balanced DH system can improve consumer thermal comfort and at the same time save significant pumping power. A wellbalanced DH system allows heat users to pay less if the heating is charged on the basis of the real consumption. The heat users are satisfied also due to the improved room temperature control. At the same time, it would also be cost-effective for DH utilities, who could increase their profits by avoiding excess heat loss.

The developed integrated approach will help the decision makers and stakeholders to plan new or renovated district heating projects to be more energy efficient and cost effective. It would make a considerable contribution to energy supply security and air pollution abatement for Chinese society by giving smart control to district heating systems.

\section{Acknowledgements}

The authors would like to thank Professor David P. Wyon for his valuable comments on this paper. The research reported here was carried out with financial support from the Danish Agency for Science, Technology and Innovation (DASTI) and from Danfoss A/S through the Industrial $\mathrm{PhD}$ Programme for China. This financial support is gratefully acknowledged. 


\section{References}

[1] M. Münster, P. E. Morthorst, H. V. Larsen, L. Bregnbæk, J. Werling, H. H. Lindboe, and H. Ravn, "The role of district heating in the future Danish energy system," Energy, vol. 48, no. 1, pp. 47-55, Dec. 2012.

[2] H. Lund, S. Werner, R. Wiltshire, S. Svendsen, J. E. Thorsen, F. Hvelplund, and B. V. Mathiesen, "4th Generation District Heating (4GDH): Integrating smart thermal grids into future sustainable energy systems," Energy, vol. 68, pp. 1-11, Apr. 2014.

[3] D. Connolly, H. Lund, B. V. Mathiesen, S. Werner, B. Möller, U. Persson, T. Boermans, D. Trier, P. A. Østergaard, and S. Nielsen, "Heat Roadmap Europe: Combining district heating with heat savings to decarbonise the EU energy system," Energy Policy, vol. 65, pp. 475-489, Feb. 2014.

[4] U. Persson and S. Werner, "District heating in sequential energy supply," Appl. Energy, vol. 95, pp. 123-131, Jul. 2012.

[5] U. Persson and S. Werner, "Heat distribution and the future competitiveness of district heating,” Appl. Energy, vol. 88, no. 3, pp. 568-576, Mar. 2011.

[6] EURO HEAT \& POWER, "Euroheat \& power - Statistics," 2013. [Online]. Available: http://www.euroheat.org/Statistics-69.aspx. [Accessed: 26-Oct-2015].

[7] A. Baeumler, E. Ijjasz-vasquez, and S. Mehndiratta, "Sustainable Low-Carbon City Development in China," World Bank, 2012.

[8] Tsinghua University Building Energy Research Center, 2011 Annual Report on China Building Energy Efficiency. 2011.

[9] X. Chen, L. Wang, L. Tong, S. Sun, X. Yue, S. Yin, and L. Zheng, "Energy saving and emission reduction of China's urban district heating," Energy Policy, vol. 55, pp. 677682, Apr. 2013.

[10] Y. Lu, Practical Handbook of heating and air conditioning design. Beijing, China: China Building Industry Press, 2008.

[11] Ministry of Housing and Urban-Rural Development of China, "Industry standard JGJ 262010: Design standard for energy efficiency of residential buildings in severe cold and cold zones.” China Building Industry Press, Beijing, China, CHINA, 2010.

[12] Ministry of Construction of China \& General Administration of Quality Supervision Inspection and Quarantine of the P. R. China, China national standard GB 50019-2012: Design code of heating ventilation and air conditioning. Beijing: China Architecture and Building Press, 2012. 
[13] Tsinghua University Building Energy Research Center, 2015 Annual Report on China Building Energy Efficiency. 2015.

[14] China National Bureau of Statistics, "National Bureau of statistics data." [Online]. Available: http://www.stats.gov.cn/.

[15] G. Deng, "The effect of occupant behaviors on evaluating adaptability of centralized building energy saving technologies," Beijing University of Technology, 2013.

[16] Ministry of Housing and Urban-Rural Development, "Ministry of Housing and UrbanRural Development." [Online]. Available: http://www.mohurd.gov.cn/.

[17] Z. Lipeng, O. Gudmundsson, H. Li, and S. Svendsen, "Comparison of District Heating systems used in China and Denmark," EuroHeat \& Power (English Edition), vol. 10, no.4, pp. 12-19, Jan. 2013.

[18] F. Sun, L. Fu, S. Zhang, and J. Sun, "New waste heat district heating system with combined heat and power based on absorption heat exchange cycle in China," Appl. Therm. Eng., vol. 37, pp. 136-144, May 2012.

[19] H. Fang, J. Xia, K. Zhu, Y. Su, and Y. Jiang, "Industrial waste heat utilization for low temperature district heating," Energy Policy, vol. 62, pp. 236-246, 2013.

[20] H. Wang, W. Jiao, R. Lahdelma, and P. Zou, "Techno-economic analysis of a coal-fired CHP based combined heating system with gas-fired boilers for peak load compensation," Energy Policy, vol. 39, no. 12, pp. 7950-7962, 2011.

[21] Z. X. Jing, X. S. Jiang, Q. H. Wu, W. H. Tang, and B. Hua, "Modelling and optimal operation of a small-scale integrated energy based district heating and cooling system," Energy, vol. 73, pp. 399-415, Aug. 2014.

[22] P. Jie, N. Zhu, and D. Li, "Operation optimization of existing district heating systems," Appl. Therm. Eng., vol. 78, pp. 278-288, Mar. 2015.

[23] X. S. Jiang, Z. X. Jing, Y. Z. Li, Q. H. Wu, and W. H. Tang, "Modelling and operation optimization of an integrated energy based direct district water-heating system," Energy, vol. 64, pp. 375-388, Jan. 2014.

[24] P. Jie, Z. Tian, S. Yuan, and N. Zhu, "Modeling the dynamic characteristics of a district heating network," Energy, vol. 39, no. 1, pp. 126-134, Mar. 2012.

[25] B. Cao, Y. Zhu, M. Li, and Q. Ouyang, "Individual and district heating: A comparison of residential heating modes with an analysis of adaptive thermal comfort," Energy Build., vol. 78, pp. 17-24, Aug. 2014. 
[26] A. Yan, J. Zhao, Q. An, Y. Zhao, H. Li, and Y. J. Huang, "Hydraulic performance of a new district heating systems with distributed variable speed pumps," Appl. Energy, vol. 112, pp. 876-885, Dec. 2013.

[27] H. Wang and D. Li, "Optimal configuration of heating transmission and distribution system-research on distributed variable speed system," Heat Cool, vol. 12, no. 42, p. 6, 2003.

[28] Z. Ma and S. Wang, "Energy efficient control of variable speed pumps in complex building central air-conditioning systems," Energy Build., vol. 41, no.2, pp. 197-205, Feb. 2009.

[29] P. Xu, T. Xu, and P. Shen, "Energy and behavioral impacts of integrative retrofits for residential buildings: What is at stake for building energy policy reforms in northern China?," Energy Policy, vol. 52, pp. 667-676, Jan. 2013.

[30] J. Li, M. Colombier, and P.-N. Giraud, "Decision on optimal building energy efficiency standard in China-The case for Tianjin," Energy Policy, vol. 37, no. 7, pp. 2546-2559, Jul. 2009.

[31] B. Lin and H. Liu, "China's building energy efficiency and urbanization," Energy Build., vol. 86, pp. 356-365, 2015.

[32] D. Yan, T. Zhe, W. Yong, and Z. Neng, "Achievements and suggestions of heat metering and energy efficiency retrofit for existing residential buildings in northern heating regions of China," Energy Policy, vol. 39, no.9, pp. 4675-4682, 2011.

[33] B. Xu, L. Fu, and H. Di, "Field investigation on consumer behavior and hydraulic performance of a district heating system in Tianjin, China," Build. Environ., vol. 44, no. 2, pp. 249-259, Feb. 2009.

[34] B. Xu, L. Fu, and H. Di, "Dynamic simulation of space heating systems with radiators controlled by TRVs in buildings," Energy Build., vol. 40, no.9, pp. 1755-1764, Jan. 2008.

[35] L. Liu, L. Fu, Y. Jiang, and S. Guo, "Major issues and solutions in the heat-metering reform in China,” Renew. Sustain. Energy Rev., vol. 15, no.1, pp. 673-680, Jan. 2011.

[36] Nation Planning and Energy Commission, "Energy basic data compilation." 1999.

[37] EQUA, “IDA-ICE 4.2.6.” [Online]. Available: http://www.equa.se/index.php/en/ida-ice.

[38] Danfoss, "RA-N Valves with Pre-Setting," 2014. [Online]. Available: http://products.danfoss.com/productrange/list/heatingsolutions/radiatorthermostats/radiator-valves/pre-setting-valves/. [Accessed: 21-Jan-2015]. 
[39] Danfoss, “ASV Automatic Balancing Valves.” [Online]. Available: http://products.danfoss.com/productrange/heatingsolutions/balancing-controlvalves/automatic-balancing-valves/asv-automatic-balancing-valves/. [Accessed: 21-Jan2015].

[40] Testo, "Testo 925 - temperature measuring instrument." [Online]. Available: http://www.testo.org/en/home/products/productdetailpage.jsp?productNo=0560+9250. [Accessed: 12-Feb-2015].

[41] Ministry of Housing and Urban-Rural Development of China, JGJ26-95:Design standard for energy efficiency of residential buildings in severe cold and cold zones. CHINA, 1995.

[42] P. He, G. Sun, F. Wang, and H. X. Wu, Heating Engineering(4th edition). Beijing, China: China Building Industry Press.

[43] EnergyPlus, “CHN_Heilongjiang.Harbin.509530_CSWD.” [Online]. Available: http://apps1.eere.energy.gov/buildings/energyplus/weatherdata_about.cfm.

[44] X. B. Yang, D. F. Sun, X. J. Zhou, L. L. Cai, and Y. Ji, "Indoor thermal comfort and its effect on building energy consumption,” Appl. Mech. Mater., vol. 71-78, pp. 3516-3519, 2011.

[45] Danfoss, "Thermostatic Sensors RTW," 2011. [Online]. Available: http://fheprod.danfoss.com/PCMPDF/VD31F202_RTW_teamcent.pdf. [Accessed: 21Jan-2015].

[46] H. Zhang, B. Zhang, and J. Bi, "More efforts, more benefits: Air pollutant control of coal-fired power plants in China," Energy, vol. 80, pp. 1-9, Feb. 2015. 


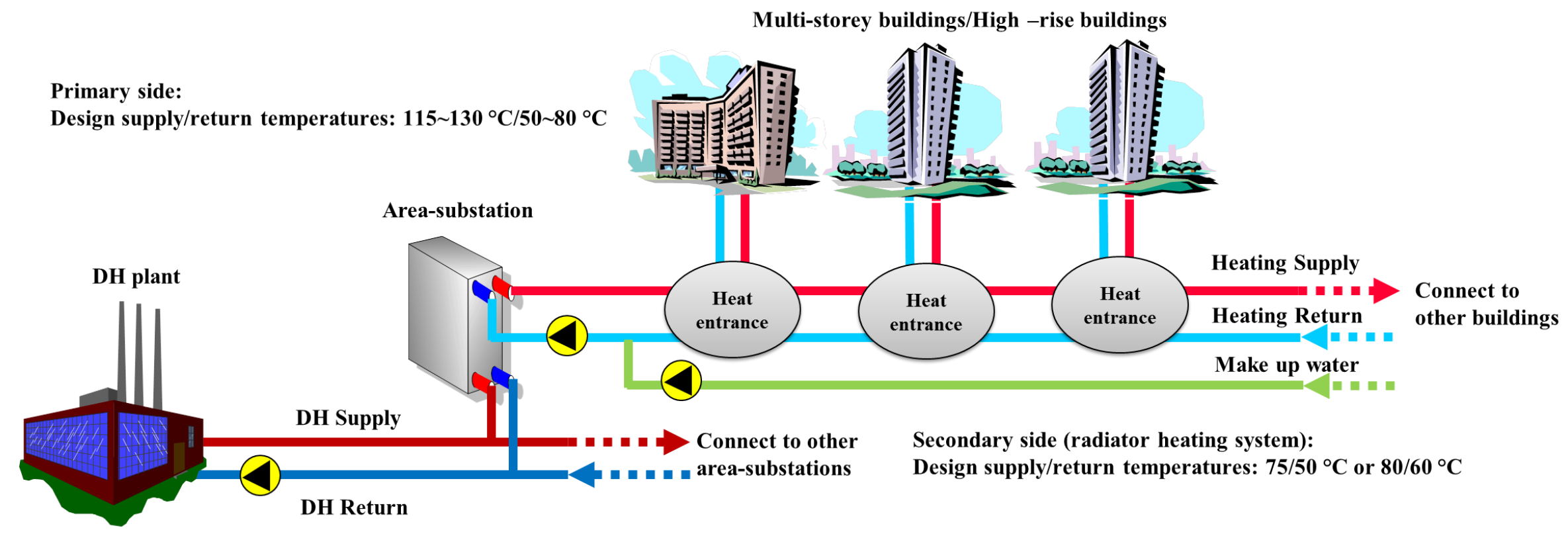


How large is the potential for reducing excess heat supply by using temperature and flow control in the building heating systems?

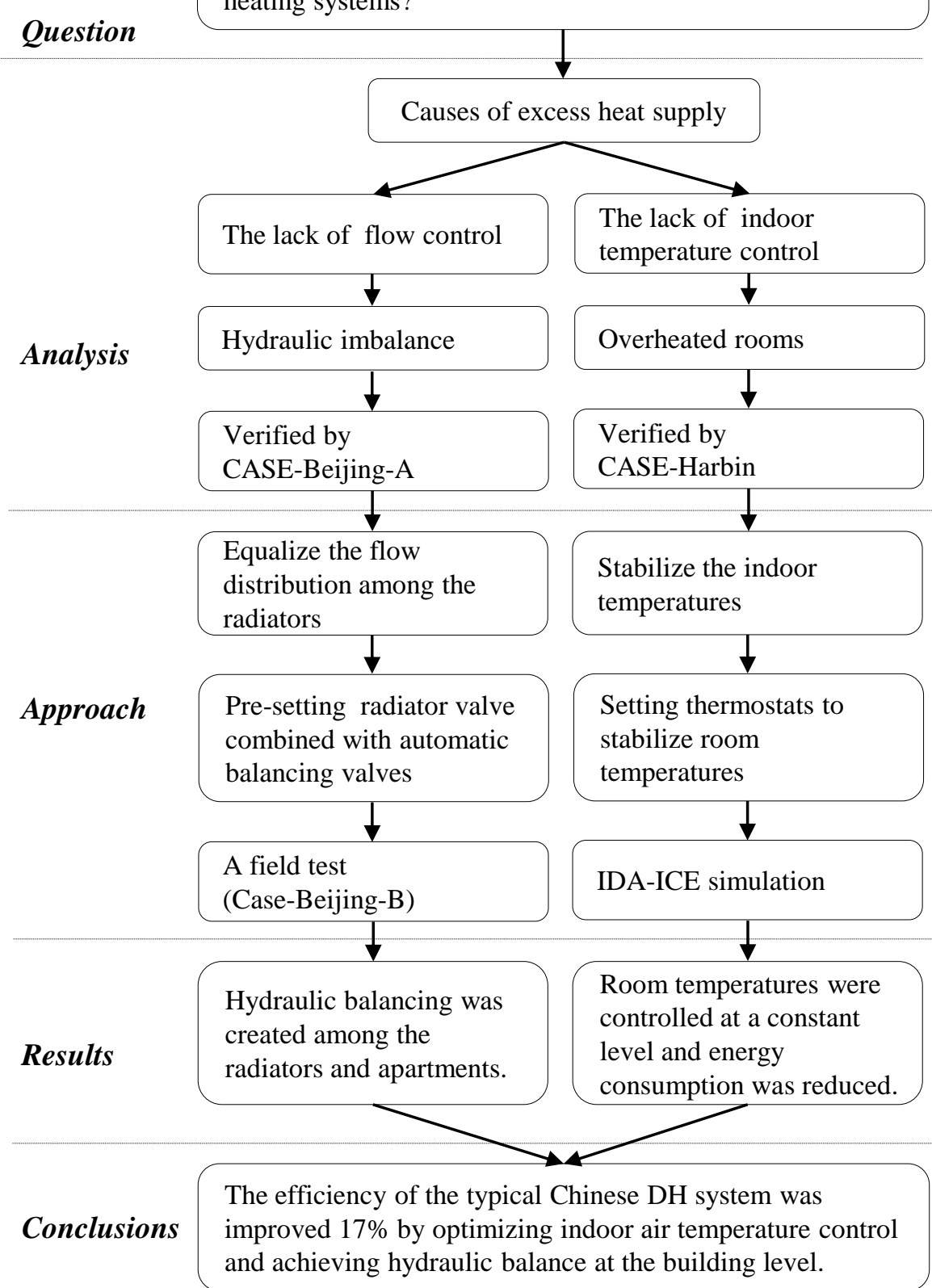

Figure 2. Flowchart of methods used in the study 
Figure

Click here to download high resolution image

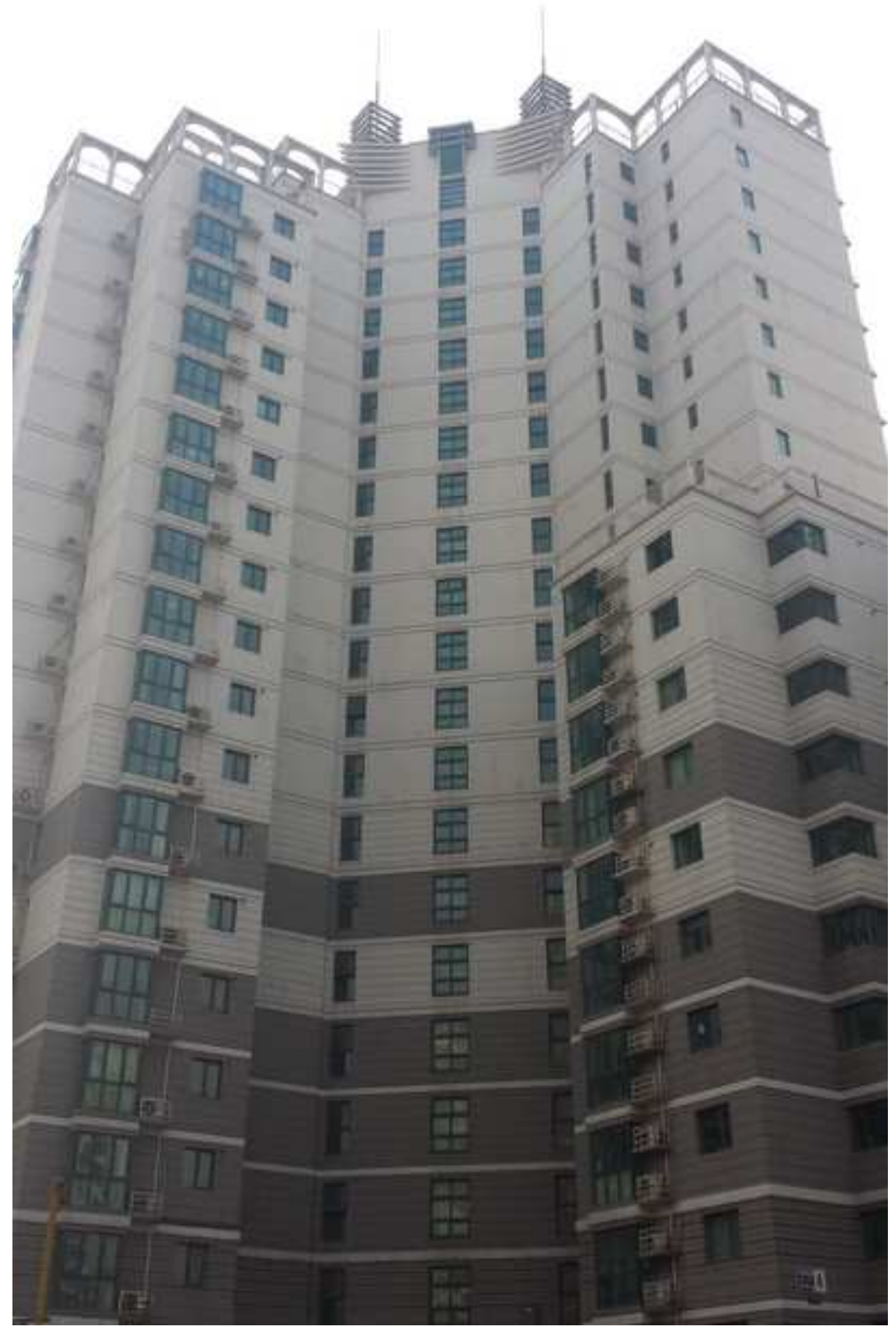



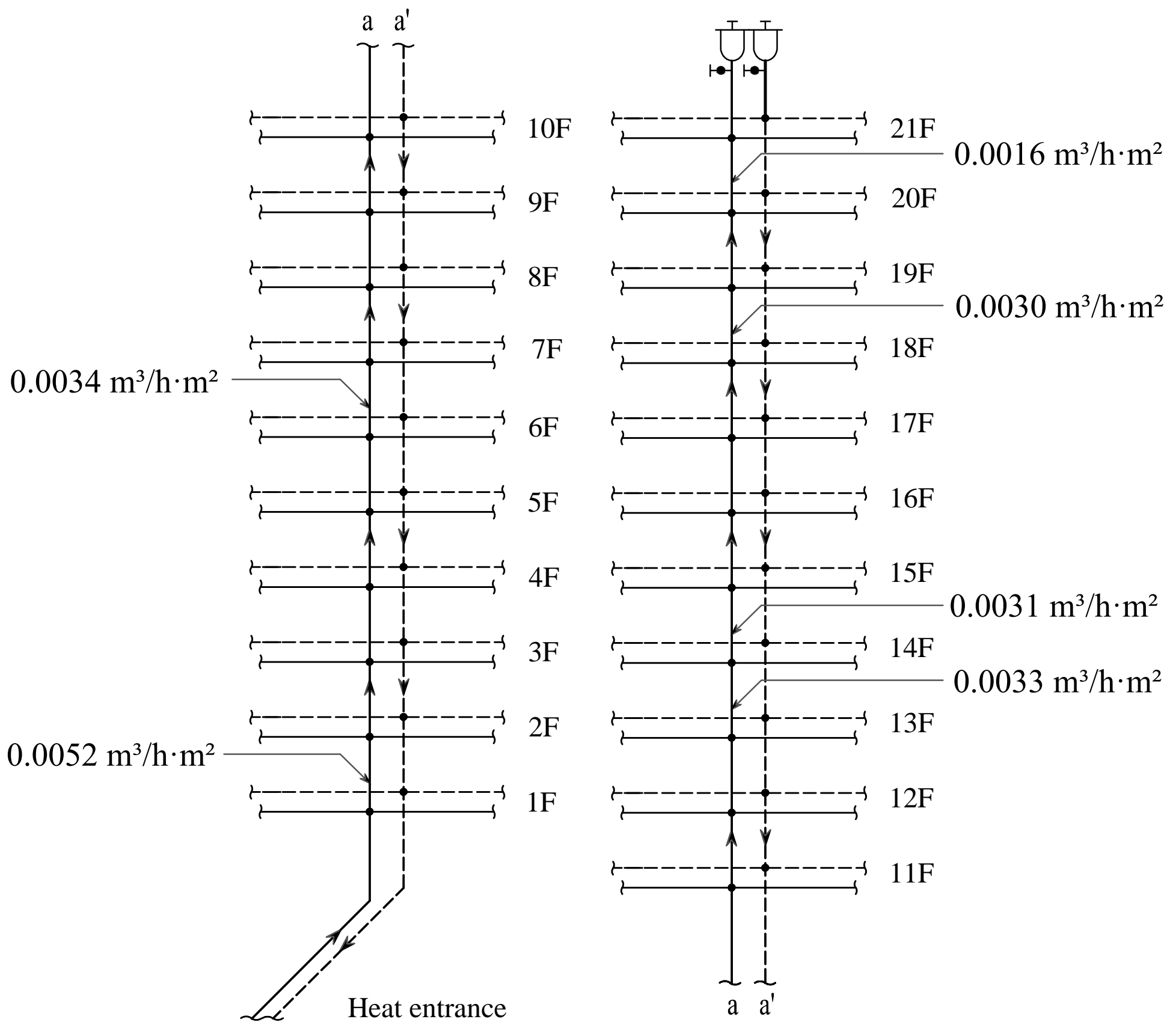


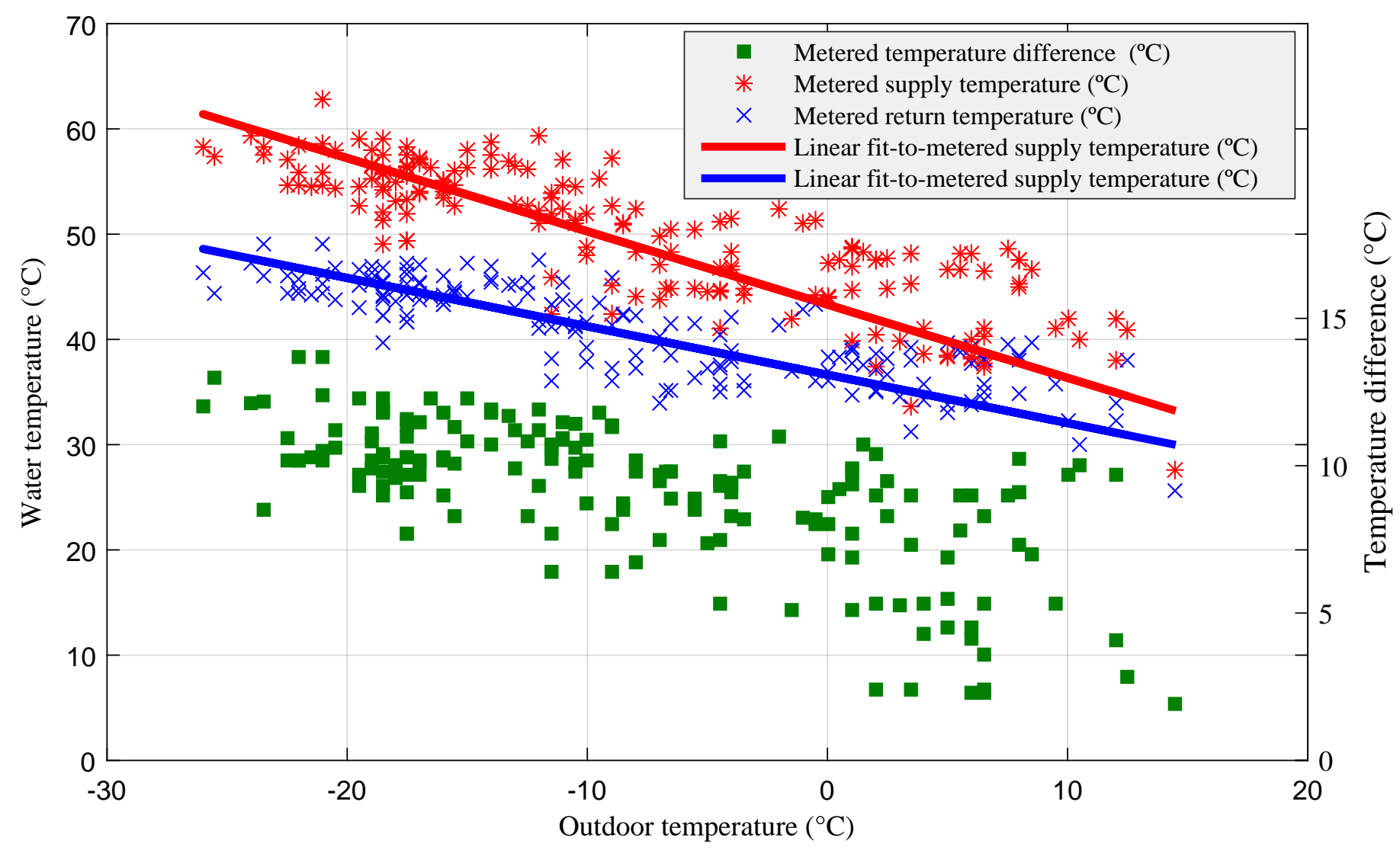




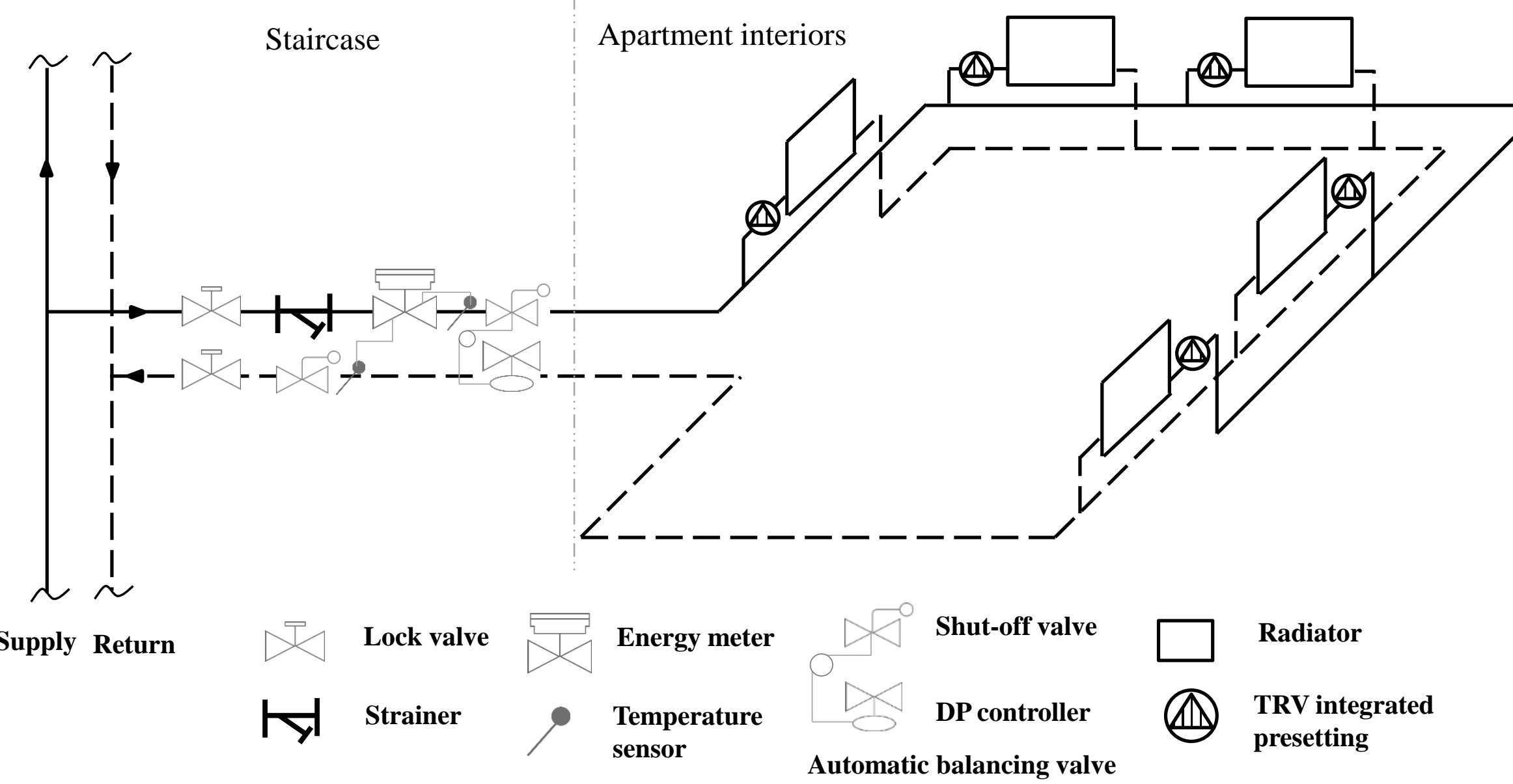

Figure 5. Schematic configuration of the apartment heating loop 

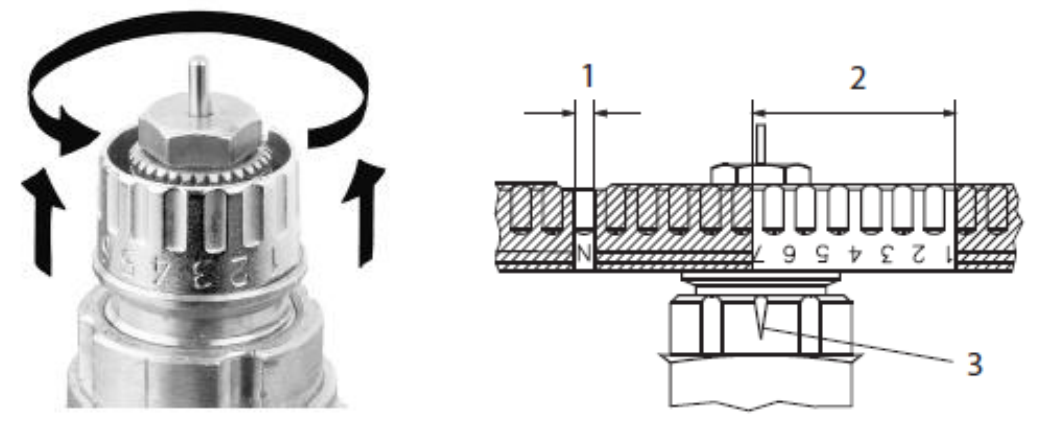

1. Factory setting

2. Presetting range

3. Reference mark

Figure 6. Pre-setting scales of radiator valve [38] 


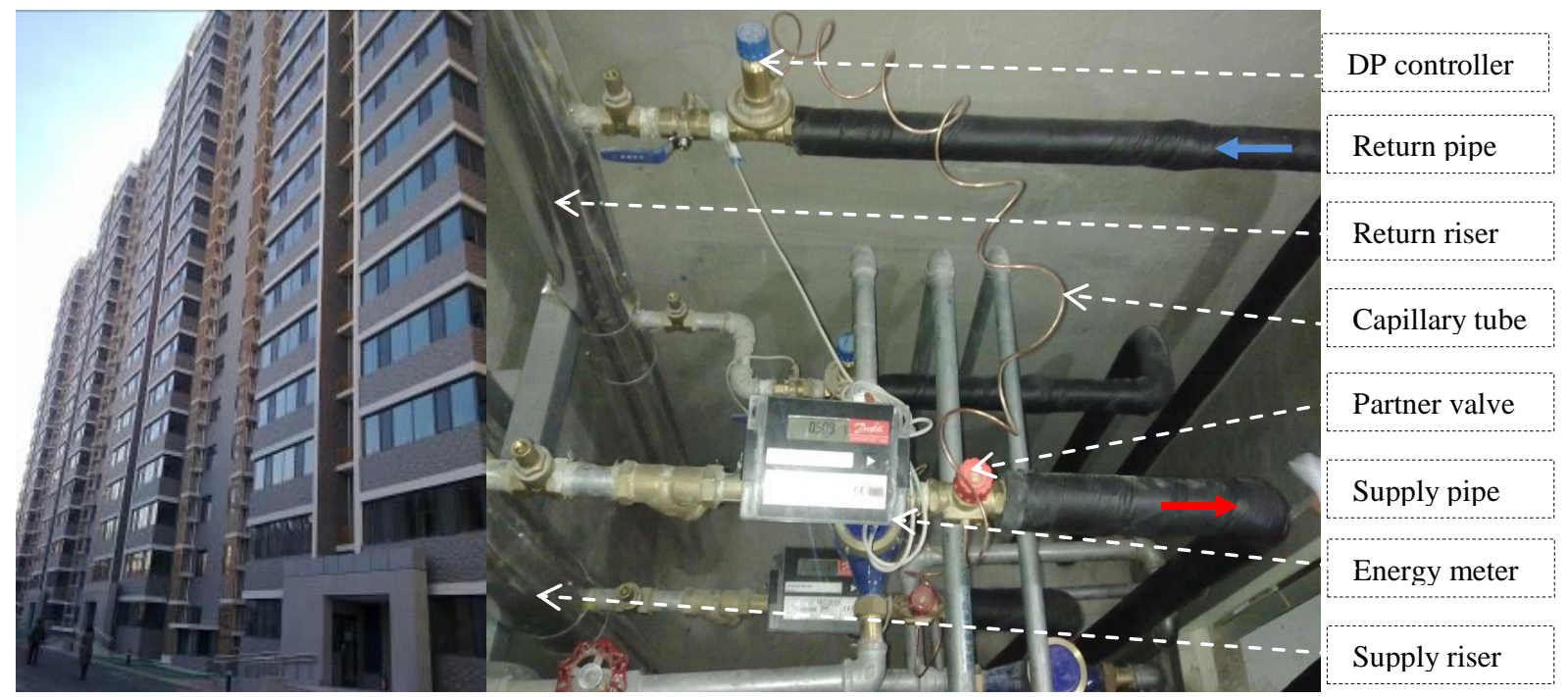

Figure 7. Real test case for the flow control approach 


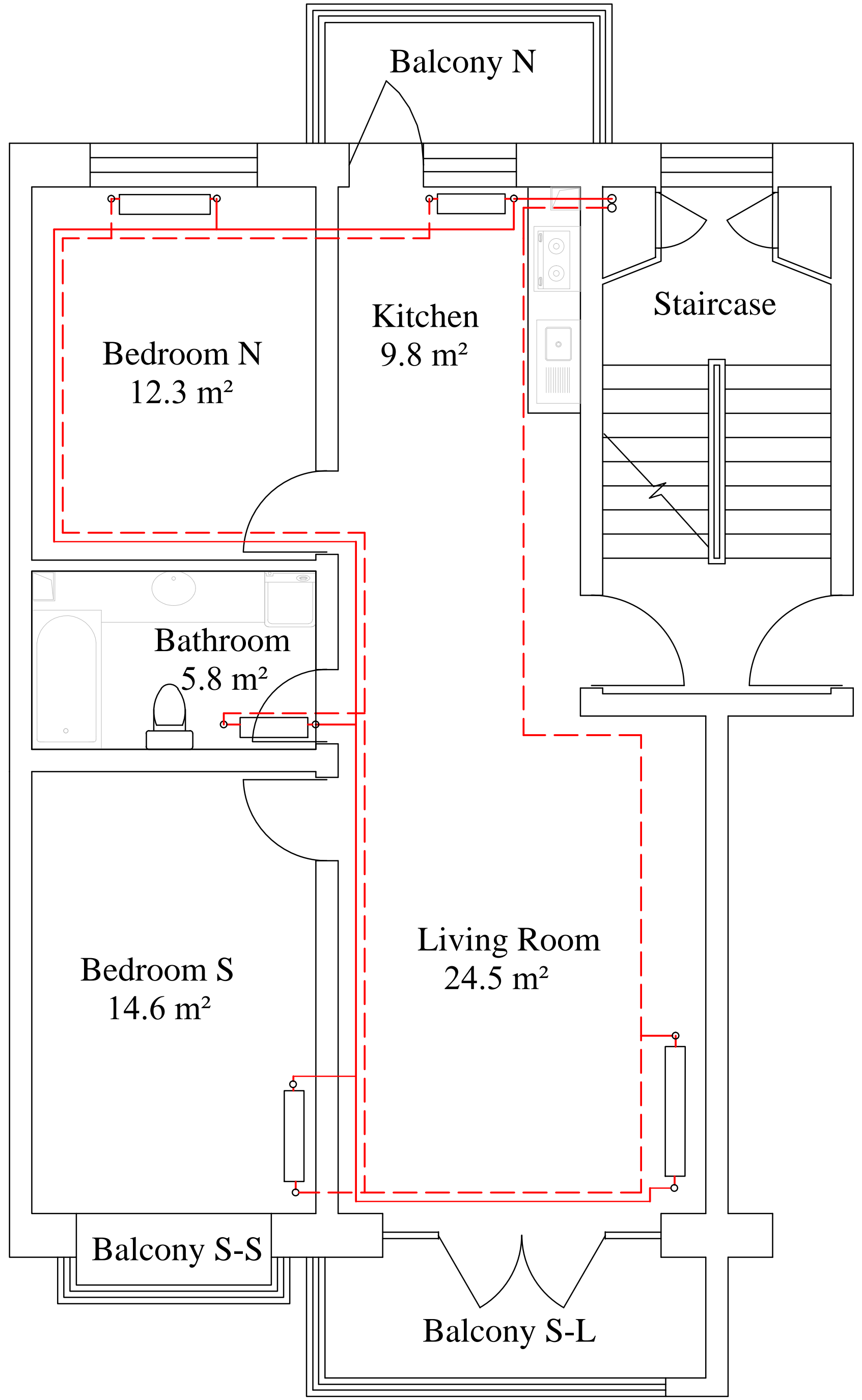




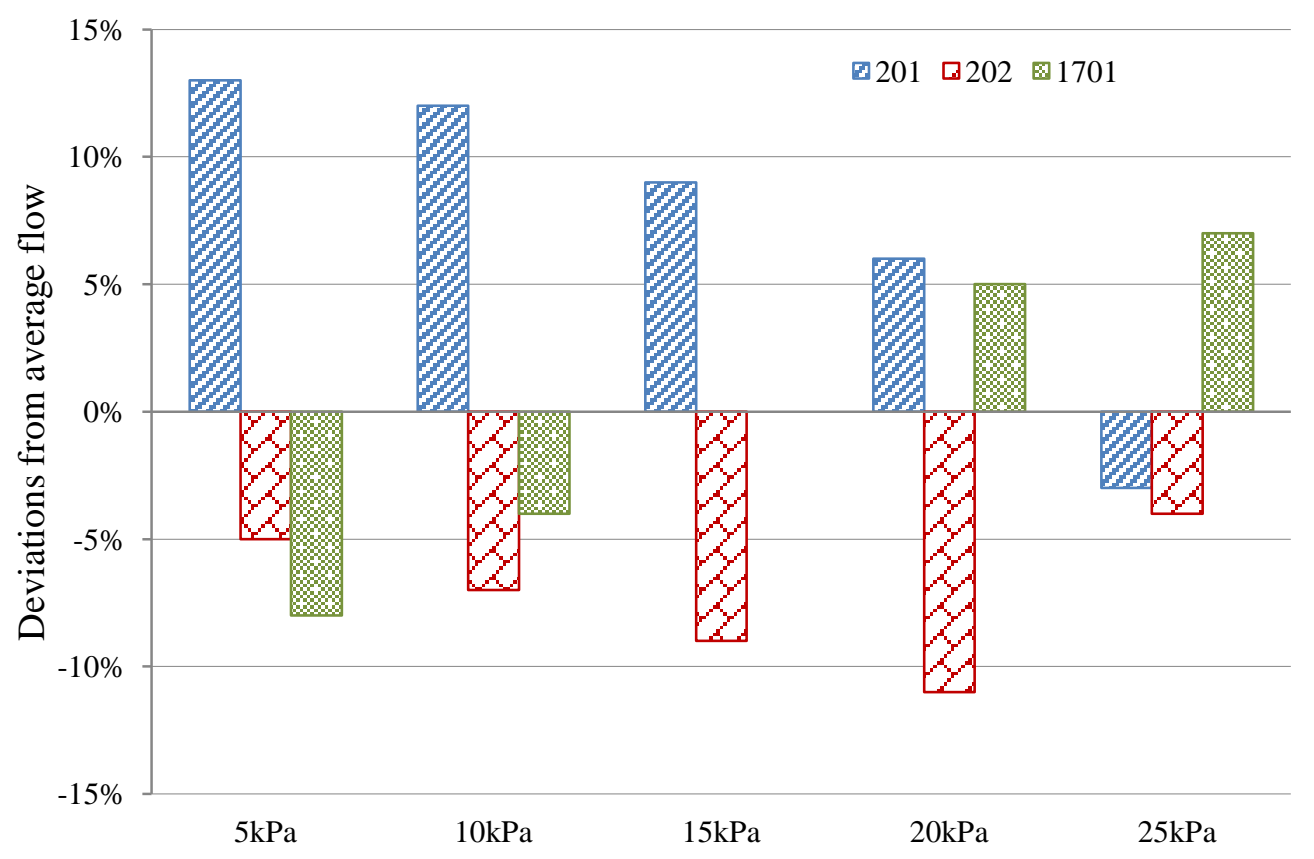

Figure 9. Deviations from the average flows of 201,202, and 1701 at various set values of the DP controllers 


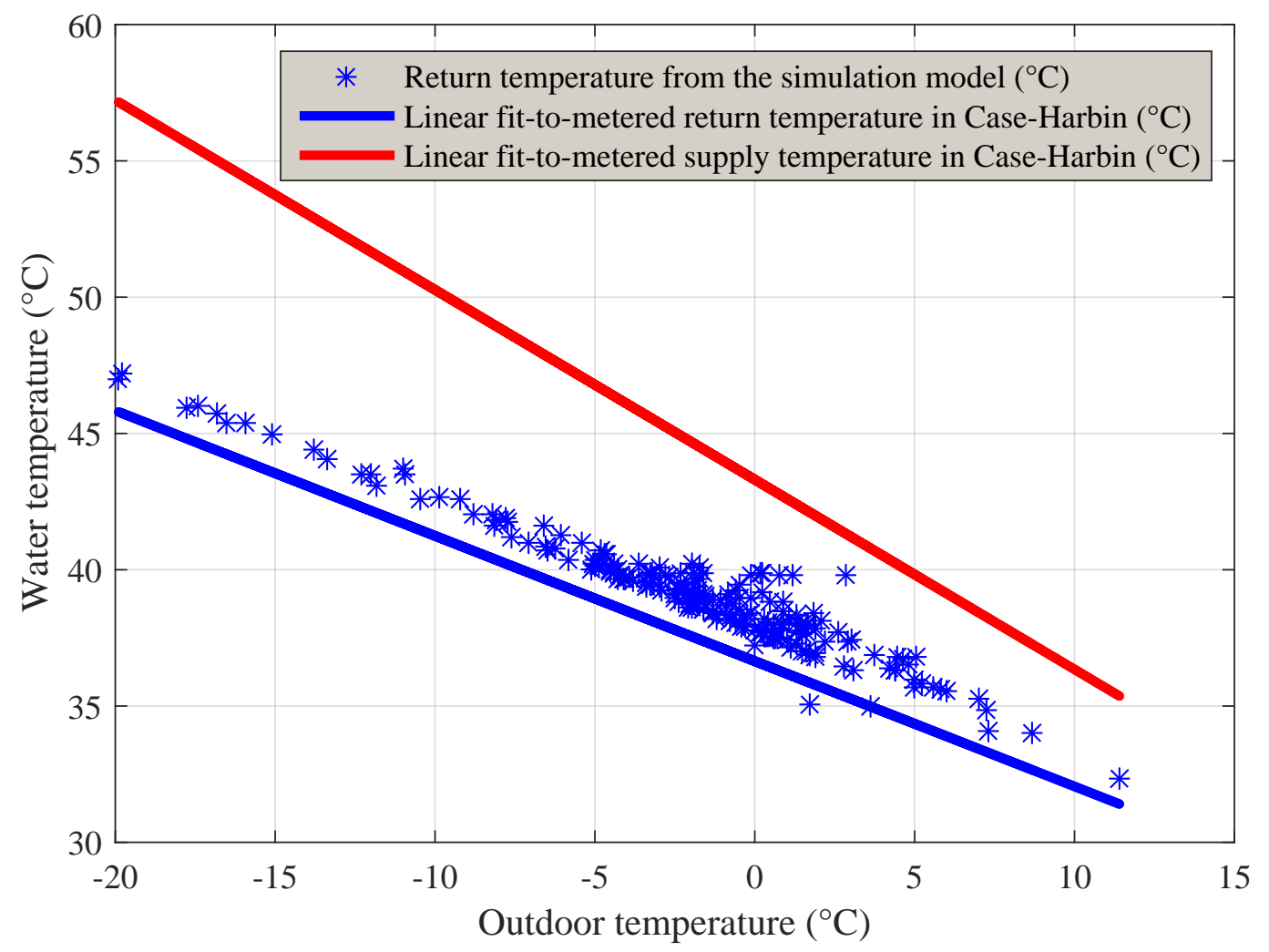




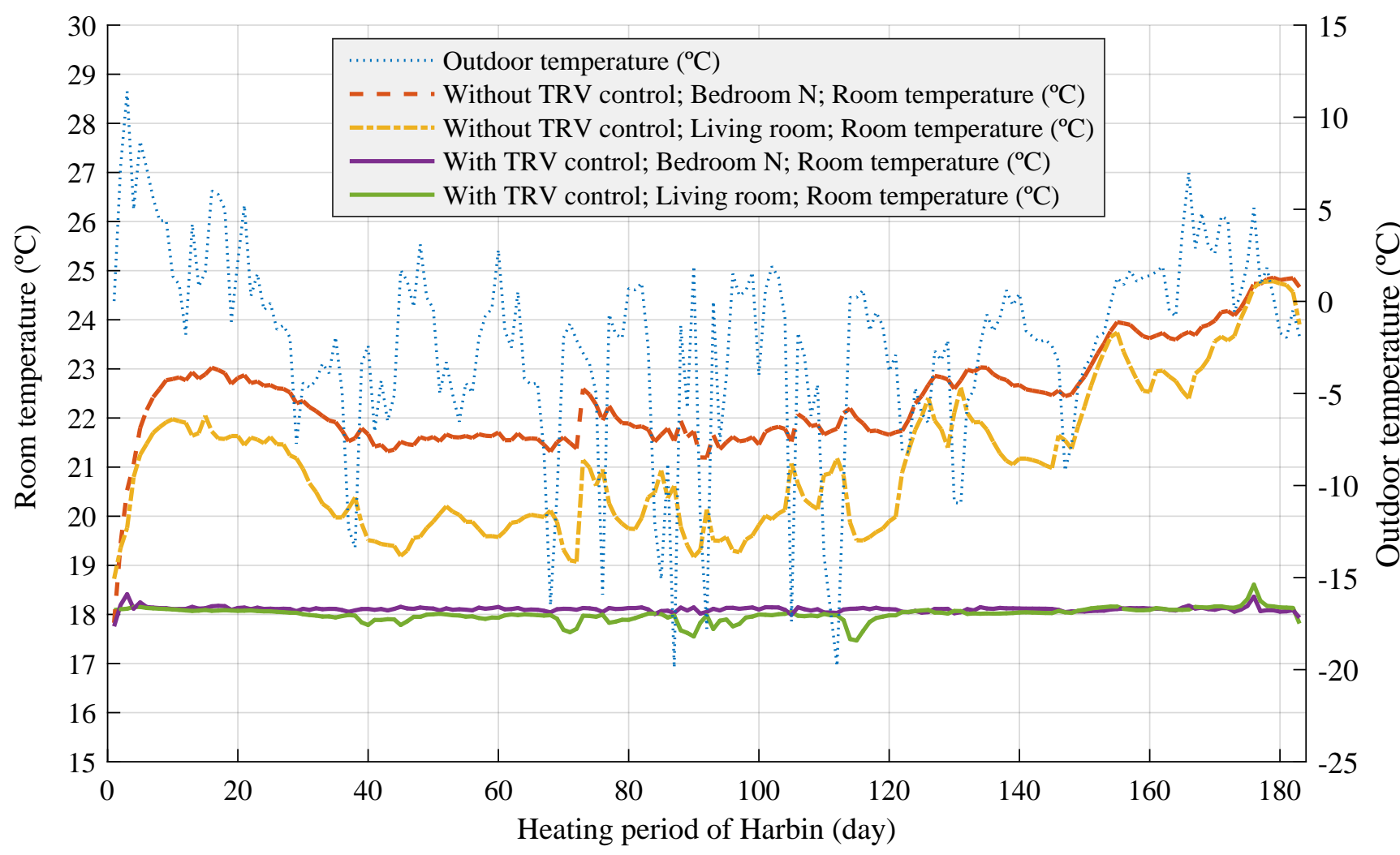




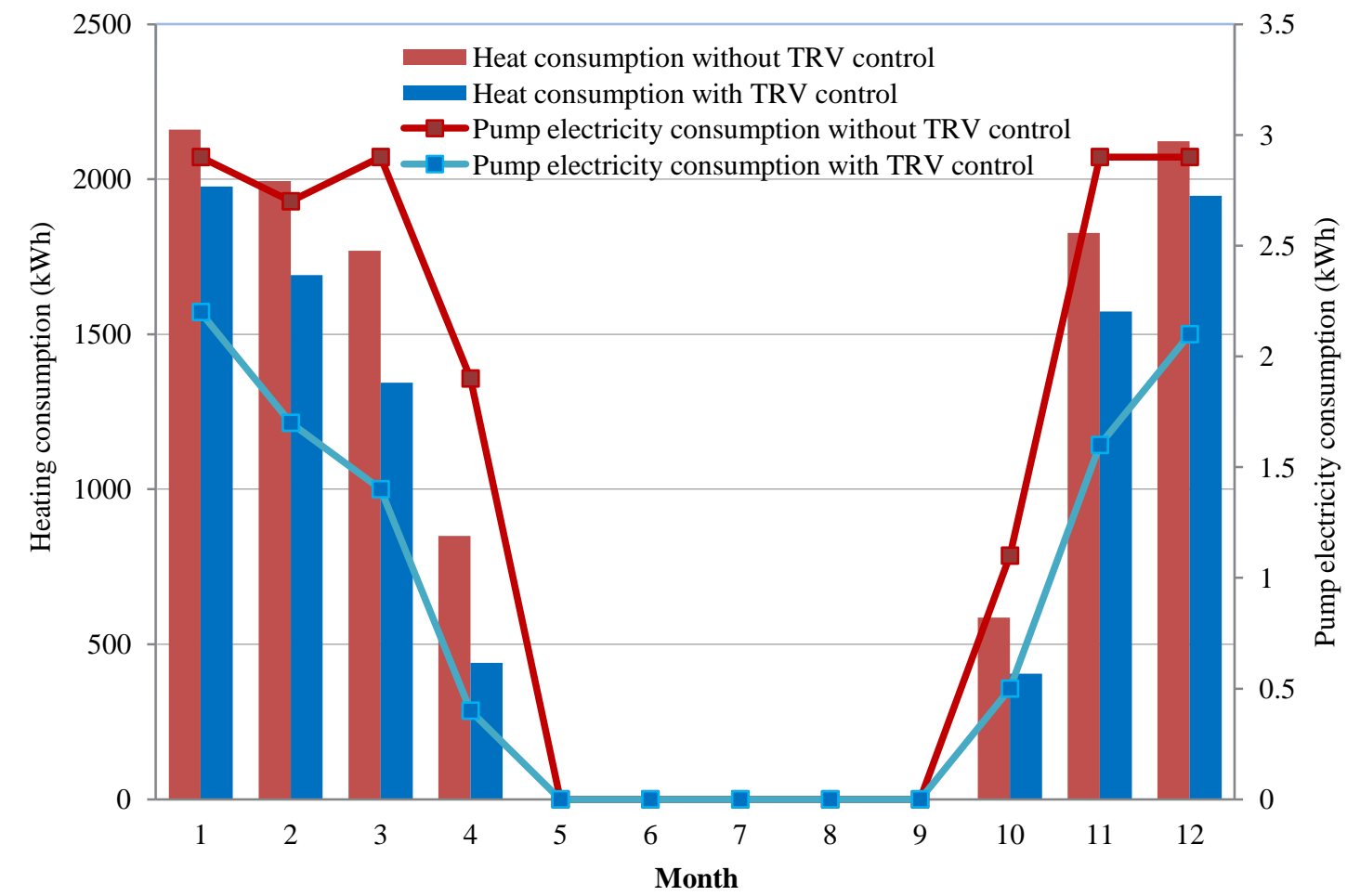

Figure 12. Heat consumption comparison between the scenarios with and without TRV control 


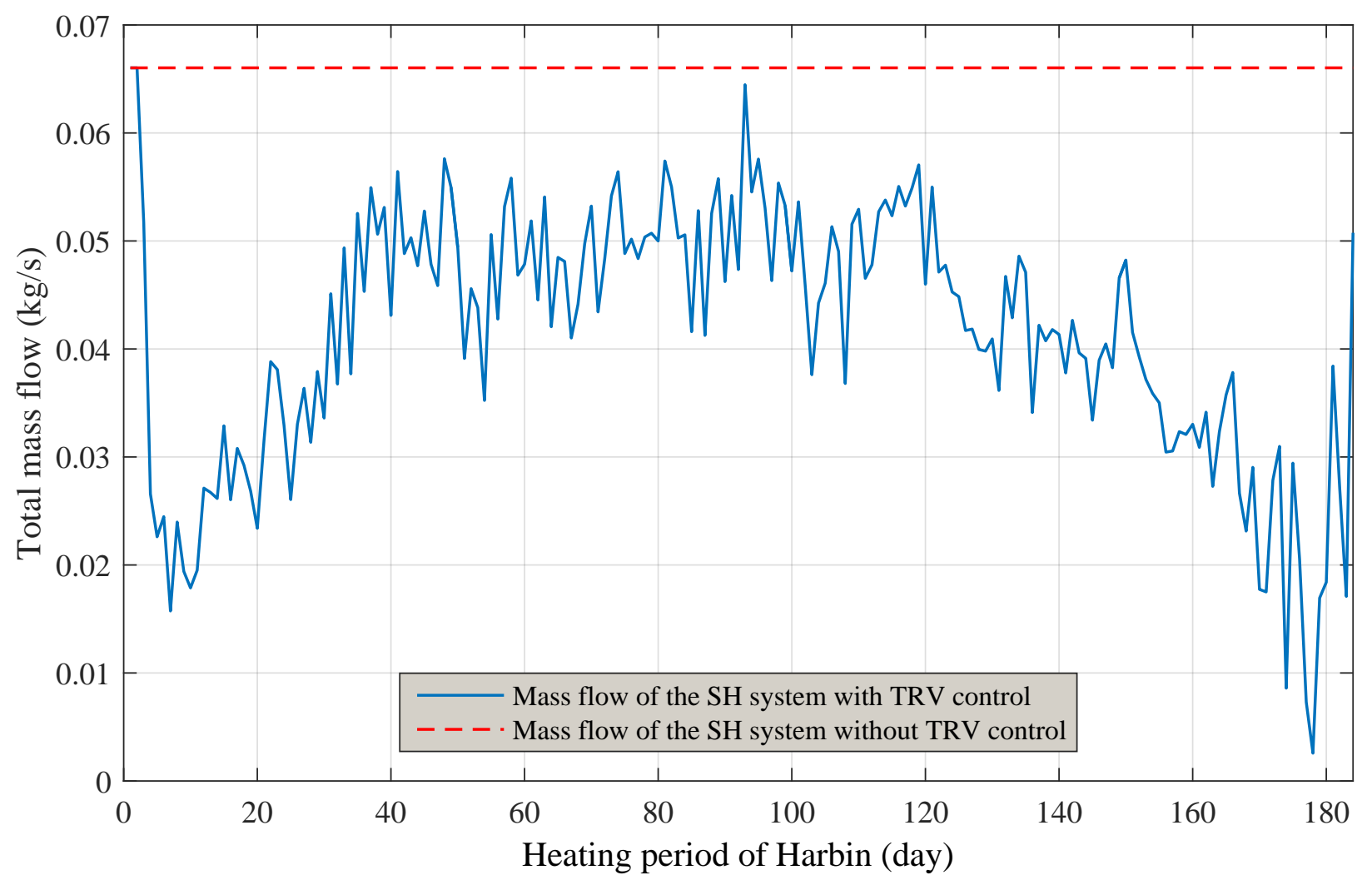


Table 1. Details of the relevant devices installed in tested apartment

\begin{tabular}{llll}
\hline \multicolumn{2}{c}{ Device name } & \multicolumn{1}{c}{ Type } & Dimension \\
\hline Radiator valve & & RA-N[21] & DN15 (mm) \\
Auto balancing & DP controller & ASV-PV[23] & DN20 (mm) \\
valves & Partner valve & ASV-M[23] & DN20 (mm) \\
Ultrasonic energy meter & SONOMETER 1100[24] & DN20 (mm) \\
\hline
\end{tabular}


Table 2. Basic information about the apartment tested

\begin{tabular}{llllll}
\hline Room name & $\begin{array}{l}\text { Floor area } \\
\left(\mathrm{m}^{2}\right)\end{array}$ & Heat load $(\mathrm{W})$ & $\begin{array}{l}\text { Desired operating } \\
\text { temperature } \\
\text { difference }\left({ }^{\circ} \mathrm{C}\right)\end{array}$ & $\begin{array}{l}\text { Desired flow } \\
(\mathrm{l} / \mathrm{h})\end{array}$ & Pre-set values \\
\hline Living Room & 18 & 810 & 15 & 46.4 & 3 \\
Bedroom A & 14.5 & 654 & 15 & 37.5 & 2.5 \\
Bedroom B & 8.7 & 391 & 15 & 22.5 & 1.5 \\
Bathroom & 3.4 & 168 & 15 & 9.6 & 1 \\
Kitchen & 4 & 180 & 15 & 10.3 & 1 \\
Total & 48.6 & 2203 & & 126 & \\
\hline
\end{tabular}


Table 3. Temperature measurement comparison between with and without pre-setting in Test II

\begin{tabular}{lll}
\hline Parameter of tested apartment loop & No pre-setting & Pre-setting \\
\hline Total flow of apartment loop $(\mathrm{l} / \mathrm{h})$ & 557 & 181 \\
Supply temperature $\left({ }^{\circ} \mathrm{C}\right)$ & 62.6 & 62 \\
Return temperature $\left({ }^{\circ} \mathrm{C}\right)$ & 53.6 & 44.7 \\
Delta T $\left({ }^{\circ} \mathrm{C}\right)$ & 9 & 17.3 \\
Average indoor temperature $\left({ }^{\circ} \mathrm{C}\right)$ & 22.6 & 22 \\
Outdoor temperature $\left({ }^{\circ} \mathrm{C}\right)$ & -4 & -4 \\
\hline
\end{tabular}

